\title{
Implications of Primary Cilia and Associated Lysophosphatidic Acid Signaling in Glioblastoma Biology and Therapy
}

Yuriy V. Loskutov

Follow this and additional works at: https://researchrepository.wvu.edu/etd

\section{Recommended Citation}

Loskutov, Yuriy V., "Implications of Primary Cilia and Associated Lysophosphatidic Acid Signaling in Glioblastoma Biology and Therapy" (2017). Graduate Theses, Dissertations, and Problem Reports. 6113. https://researchrepository.wvu.edu/etd/6113

This Dissertation is protected by copyright and/or related rights. It has been brought to you by the The Research Repository @ WVU with permission from the rights-holder(s). You are free to use this Dissertation in any way that is permitted by the copyright and related rights legislation that applies to your use. For other uses you must obtain permission from the rights-holder(s) directly, unless additional rights are indicated by a Creative Commons license in the record and/ or on the work itself. This Dissertation has been accepted for inclusion in WVU Graduate Theses, Dissertations, and Problem Reports collection by an authorized administrator of The Research Repository @ WVU.

For more information, please contact researchrepository@mail.wvu.edu. 
Implications of primary cilia and associated lysophosphatidic acid signaling in glioblastoma biology and therapy.

Yuriy V. Loskutov

Dissertation Submitted

to the School of Medicine

at West Virginia University

In Partial Fulfillment of the Requirements for the Degree of

Doctor of Philosophy in Cancer Cell Biology

\author{
Michael Schaller, Ph.D., Chair \\ Michael Ruppert, Ph.D. \\ Karen Martin, Ph.D. \\ Maxim Sokolov, Ph.D. \\ Peter Stoilov, Ph.D. \\ Elena Pugacheva, Ph.D., Mentor
}

Cancer Cell Biology Program

Morgantown, West Virginia

2017

Keywords: LPA, primary cilia, LPAR1, GBM

Copyright 2017 Yuriy Loskutov 


\title{
Abstract \\ Implications of primary cilia and associated lysophosphatidic acid signaling in glioblastoma biology and therapy.
}

\author{
Yuriy Loskutov
}

The primary cilium is a ubiquitous organelle presented on most human cells. It serves as a crucial signaling hub for multiple pathways including growth factor and G-protein coupled receptors. Loss of primary cilia was observed in various cancers, however, the implications of this event are unclear. Several studies show that loss of cilia promotes cell proliferation, suggesting that alteration of ciliary-dependent signaling can drive the hyperproliferative phenotype of cancer cells, therefore re-establishing primary cilia or targeting altered signaling pathways could be a beneficial strategy as an anti-cancer therapy.

Glioblastoma (GBM) is one of the deadliest cancers with a median survival of 14 months. Such rapid progression of the disease is usually due to the very high growth rate of the tumor and rapid recurrence after surgical resection. Current standard of care for GBM patients includes aggressive radiation and chemotherapy, thus there is a high demand for more targeted approaches. Primary cilia formation is drastically decreased in GBM, however, the role of cilia in glioblastoma proliferation has not been explored. The overall aim of this work was to elucidate the mechanisms of increases in proliferation driven by the loss of cilia, and utilize it to target GBM. The cellular origins of GBM are currently under debate. One of the potential candidates are astrocytes, a highly abundant type of cell in the brain. Loss of primary cilia in human astrocytes stimulates proliferation in the presence of serum. Lysophosphatidic acid (LPA) was found to be a serum component responsible for this phenotype. Lysophosphatidic acid receptor 1 (LPAR1), a G-protein coupled receptor, was found to be accumulated in primary cilium in both astrocytes and GBM cells when cilium was present, while previously reported interactors of LPAR1, $\mathrm{Ga}_{12}$ and $\mathrm{Ga} a_{\mathrm{q}}$, were excluded from cilium. LPAR1 signaling through $\mathrm{Ga}_{12} / \mathrm{Ga}_{\mathrm{q}}$ was previously reported to be responsible for cancer cell proliferation. Such compartmentalization in ciliated cells creates a barrier against unlimited proliferation, which is one of the hallmarks of cancer.

Inhibition of LPA signaling with the small molecule compound Ki16425 in deciliated, highly proliferative astrocytes or GBM cells/xenografts drastically suppresses their growth both in vitro and in vivo. Moreover, Ki16425 brain delivery via PEG-PLGA nanoparticles inhibited tumor progression in an intracranial glioblastoma patient-derived xenograft (PDX) model. Overall, in the current studies, a novel mechanism by which primary cilium restricts proliferation was established. Loss of primary cilia is sufficient to increase mitogenic signaling, and is important for the maintenance of a highly proliferative cancer phenotype. Clinical application of LPA inhibitors may prove beneficial to restrict glioblastoma proliferation and ensure local control of the disease. 


\section{Acknowledgements}

I would like to thank my advisor Dr. Elena Pugacheva for being patient and understanding, for pushing me to achieve more, and for supporting me through all the perils of research.

I would also like to acknowledge my graduate committee for their guidance and constant support, and Dr. Andrey Bobko and Dr. Werner Geldenhuys for invaluable methodological support.

I would like to acknowledge all of the current and past lab members of the Pugacheva lab for their objective opinions and critiques, very special thanks go to Brandon Jones for his perfect editorial skills.

Finally, I would like to thank Maria Voronkova for putting up with me for so long and being a faithful companion and friend. 


\section{Table of Contents}

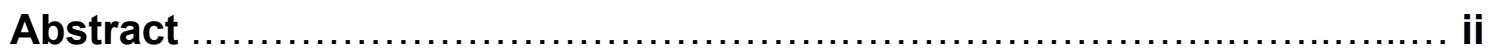

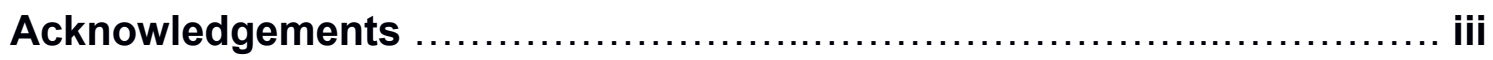

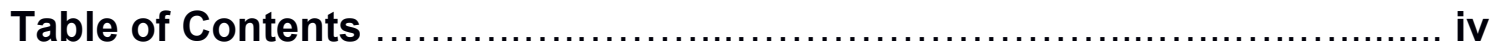

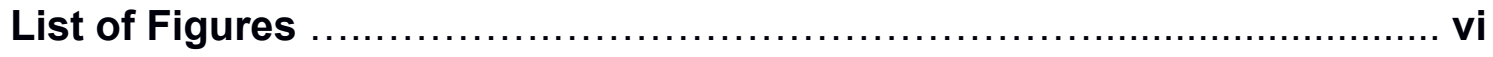

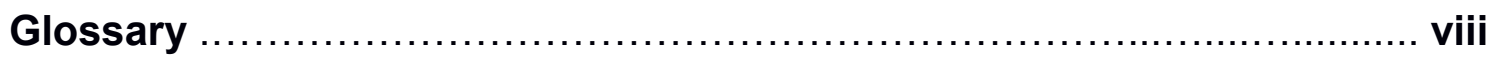

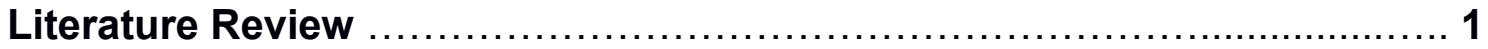

1. Primary cilia: signaling hub/organelle/molecular machine $\ldots \ldots \ldots \ldots \ldots \ldots 1$

1.1Primary cilia structure, maintenance, and function

1.2 Mechanisms of assembly/disassembly of primary cilia

1.3Primary cilia and signal transduction in mammalian cells

1.4 Primary cilia loss/dysfunction-associated diseases-ciliopathies

2. Primary cilia: potential target for anti-cancer therapy $\ldots \ldots \ldots \ldots \ldots \ldots \ldots 6$

2.1 Primary cilia and cancer

2.2 Glioblastoma and primary cilia

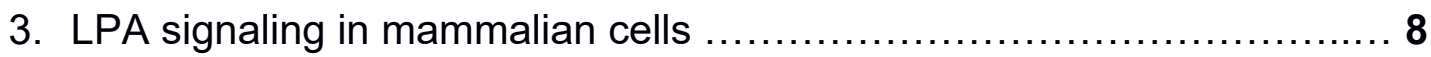

3.1 LPA production and signaling

3.2 LPA receptors: expression function and regulation

3.3 LPA/LPAR signaling in cancer

4. Kinesin 13 family motors and their role in cancer

4.1 Kinesin motor superfamily in regulation of microtubule dynamics

4.2 Cellular function of Kinesin-13 family members

4.3 Kinesin-13 family members in cancer

5. Aurora kinase A: master regulator of cilium

5.1 AURKA structure and function

5.2 Role of AURKA in regulation of the ciliary dynamics

5.3LPA/LPAR signaling in cancer

References 
Study 1: LPA signaling is regulated through the primary cilium: a novel target in

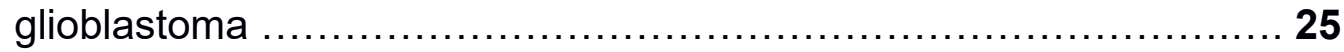

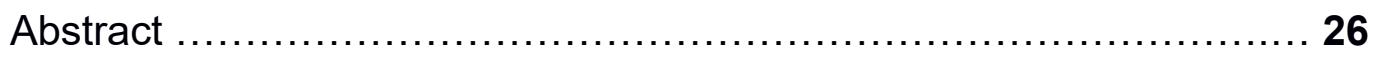

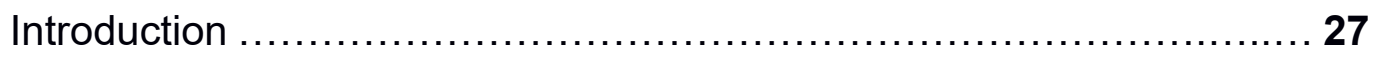

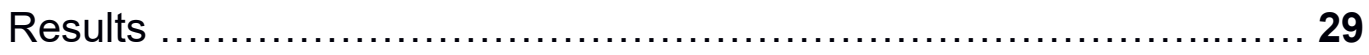

Discussion .......................................................... 34

Materials and Methods ................................................. 37

References ....................................................... 43

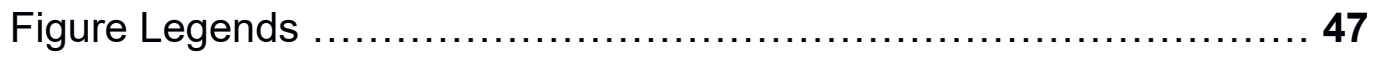

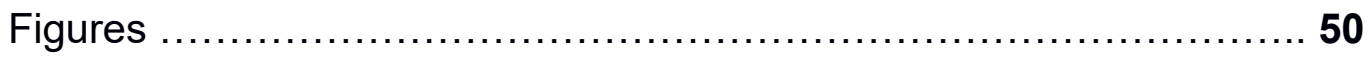

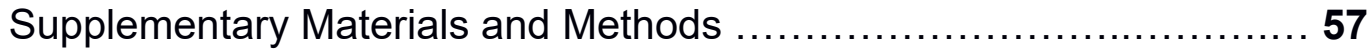

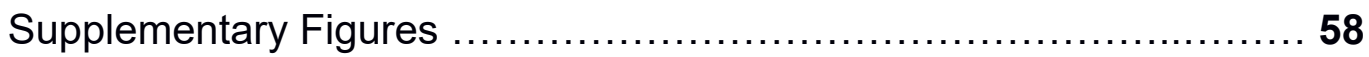

Supplementary Tables .............................................. 67

Study 2: The role of KIF2C/AURKA signaling in cilia loss and progression of glioblastoma ................................................................ 70

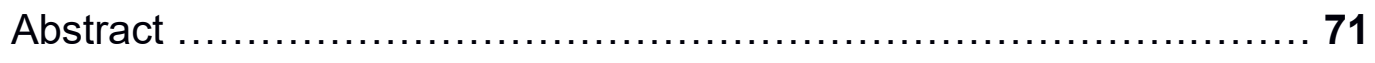

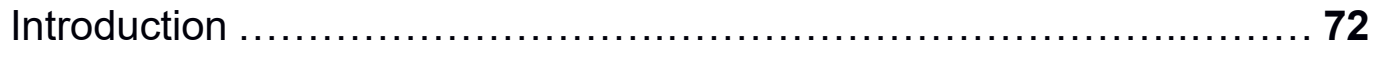

Materials and Methods ............................................... 74

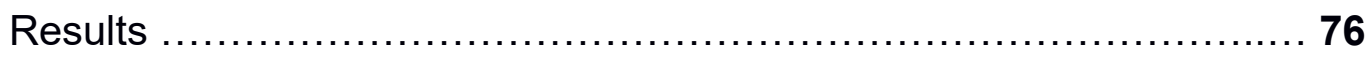

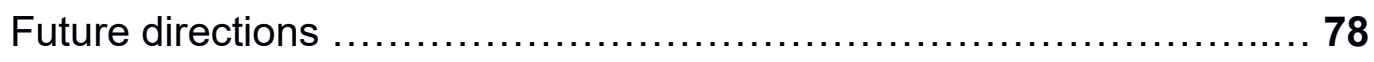

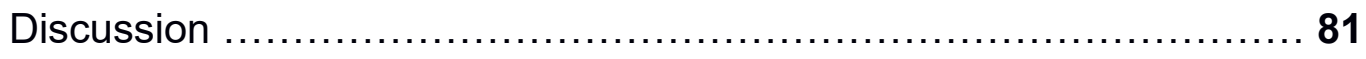

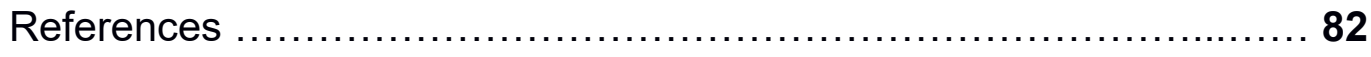

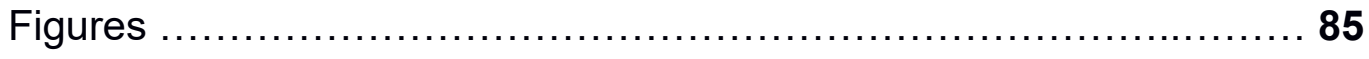

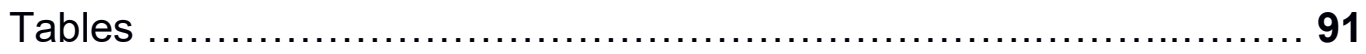

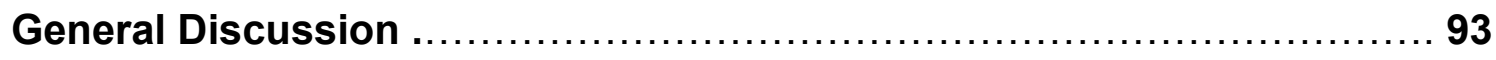

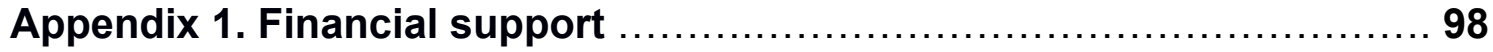

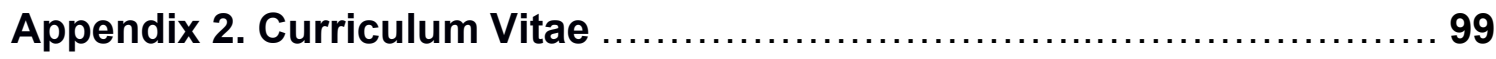




\section{List of Figures}

\section{Introduction}

1. Principal components and organization of the primary cilium.

2. Schematic of LPAR signaling.

3. Schematic of regulation of human KIF2C through phosphorylation.

\section{Study 1}

4. Loss of primary cilia promotes astrocyte proliferation in a growth factor-dependent manner.

5. Loss of cilium promotes increased ERK1/2 phosphorylation in response to serum stimulation.

6. Loss of cilium promotes decreased AKT phosphorylation in response to serum stimulation.

7. Lysophosphatidic acid promotes proliferation in deciliated astrocytes.

8. Intracellular localization of LPA signaling cascade components.

9. Inhibition of LPA signaling suppresses proliferation of GBM PDXs in vivo.

10. Targeted brain delivery of Ki16425 suppresses GBM PDX growth in an intracranial model.

\section{Supplementary figures:}

S1. Primary cilia formation in human astrocytes and astrocytes immortalized with large $T$ antigen.

S2. Proliferation and ERK1/2 and AKT phosphorylation in response to single growth factor stimulation of HA-LTA.

S3. Proliferation and ERK1/2 and AKT phosphorylation in response to single growth factor stimulation of HA-LTA.

S4. LPAR1, 3 and 6 subcellular localization in cells with assembled primary cilium.

S5. LPAR1, 3 and 6 subcellular localization in cells with disassembled primary cilium.

S6. LPAR1 antibodies validation for immunofluorescent staining.

S7. Endogenous LPAR1 localization in cells with and without primary cilium. 
S8. GBM6 and GBM12 have decreased ciliation and utilize LPA as a growth factor.

S9. Administration of Ki16425 has no effect on intracranial tumor growth.

\section{Study 2}

1. KIF2C overexpression drives cilia disassembly in an AURKA-dependent manner.

2. Stem-cell/differentiation marker status of ciliated cells is different from cells without primary cilia.

3. Effects of KIF2C depletion and inhibition of AURKA on GBM cells proliferation and ciliation. 


\section{Glossary}

GBM glioblastoma multiforme

LPA lysophosphatidic acid

LPAR lysophosphatidic acid receptor

PDX patient derived xenograft

PEG-PLGA poly(ethylene glycol)- poly(lactide-co-glycolide)

ERK1/2

extracellular signal-regulated kinase $1 / 2$

AKT

protein kinase $B$

PAKT

phosphorylated protein kinase B

HA

human astrocytes

HA-LTA human astrocytes immortalized with SV40 large T antigen

SV40

Simian vacuolating virus $\mathbf{4 0}$

IFT

intraflagellar transport

BBS

Bardet-Biedl syndrome

BBSome

complex of BBS proteins

KAP

kinesin accessory protein

AURKA

aurora kinase A

AURKB

aurora kinase $B$

AURKC

aurora kinase $\mathrm{C}$

NEDD9

neural precursor cell expressed developmentally down-regulated

protein 9

HDAC6

histone deacetylase 6

Plk1

polo-like kinase 1

CCRK

cell cycle related kinase

ICK

intestinal cell kinase

MAK

male germ cell-associated kinase

Shh

Sonic Hedgehog

Ptch1

patched 1

Smo

smoothened

PKA

protein kinase $A$ 
RTK

PDGFR

PDGF

IGF1R

EGFR

FGFR

GPCR

AC

JBTS

ATX

LPC

Arf

ADP

GAP

GTP

AGAP1

EB1/3

TPX2

PP2a

Cdk1

Pifo

Nek2

SFM

SSM

cSSM

EGF

bFGF receptor tyrosine kinase

platelets derived growth factor receptor

platelets derived growth factor

insulin-like growth factor 1 receptor

epidermal growth factor receptor

fibroblast growth factor receptor

G-protein coupled receptor

adenylyl cyclase

Joubert Syndrome

autotoxin

Lysophosphatidylcholine

ADP ribosylation factor

adenosine diphosphate

GTPase-activating proteins

Guanosine triphosphate

ArfGAP with GTPase Domain, Ankyrin Repeat And PH Domain 1 end binding protein $1 / 3$

differentially expressed in cancerous and non-cancerous lung cells 2

serine/threonine protein phosphatase $2 \mathrm{~A}$

cyclin-dependent kinase 1

protein pitchfork

NIMA related kinase 2

serum free media

serum supplemented media

charcoal stripped serum supplemented media

epidermal growth factor

basic fibroblast growth factor 
HGF hepatocyte growth factor

CRISPR-Cas9 clustered regularly interspaced short palindromic repeats associated protein Cas 9

MRI magnetic resonance imaging

PTEN phosphatase and tensin homolog

DMEM/F12 Dulbecco's modified Eagle medium/nutrient mixture F-12 50/50 mixture

FBS fetal bovine serum

MTA material transfer agreement

BSA bovine serum albumin

NIH National Institutes of Health

HRP horseradish peroxidase

F-IHC fluorescent immunohistochemistry

TBS tris-buffered saline

HMEC human mammary epithelial cells

NSG NOD.Cg-Prkdc $\quad$ scid $\| 2$ rg $^{\text {tm1 } 1 w_{j} / / S z J}$ (NSG) immunodeficient mice

DPBS Dulbecco's phosphate-buffered saline

PBS phosphate-buffered saline

DMSO dimethyl sulfoxide

WVU IACUC West Virginia University Institutional Animal Care and Use Committee

DTPA diethylenetriaminepentaacetic acid

RPE1 hTert retinal pigmented epithelial cells immortalized with human telomerase

ATCC American Type Culture Collection

PCR polymerase chain reaction

ANOVA analysis of variance

AcTub acetylated $\alpha$-tubulin 


$\begin{array}{ll}\text { YTub } & \text { Y-tubulin } \\ \text { ShRNA } & \text { short hairpin RNA } \\ \text { RNA } & \text { ribonucleic acid } \\ \text { GAPDH } & \text { glyceraldehyde 3-phosphate dehydrogenase } \\ \text { MCS } & \text { multiple cloning site } \\ \text { Sox2 } & \text { sex determining region Y-box } 2 \\ \text { CD44 } & \text { hyaluronate receptor } \\ \text { Dox } & \text { doxycycline } \\ \text { DAPI } & 4 \text { ',6-Diamidino-2-Phenylindole, Dihydrochloride }\end{array}$




\section{Literature Review}

\section{Primary cilia: signaling hub/organelle/molecular machine}

\subsection{Primary cilia structure, maintenance, and function}

Primary cilium is a non-motile, microtubule-based organelle. It is formed as a protrusion of a mature centriole in $\mathrm{G} 1 / \mathrm{G} 0$, consists of nine doublets of microtubules known as an axoneme, and is covered with the plasma membrane (1) (Fig.1). Ciliary microtubules are built from tubulin $\alpha$ and $\beta$ dimers with the "+"end located at the tip of the cilium. The axoneme includes a transition zone linking the cilium to the centriole/basal body, a doublet zone including both microtubule doublet $A$ (full microtubule) and B (hemitube), and a singlet zone where only A tubes are present (2). The base of the primary cilium usually emerges from an invagination in the cell plasma membrane known as the ciliary pocket (3).

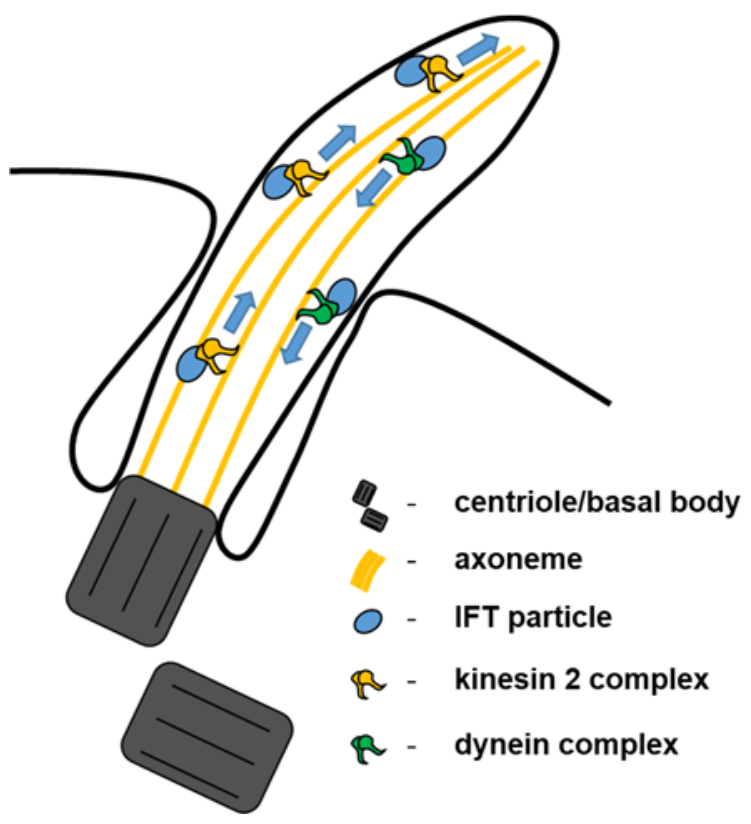

Figure 1. Principal components and organization of the primary cilium.

Cilia accumulate multiple receptors and signal transduction components, thus tight regulation of ciliary trafficking is required. Indeed, an elaborate system of intraflagellar transport machinery exists, and the core components of this system are intraflagellar 
transport (IFT) particles (Fig.1). IFT particles consist of motor proteins, IFT-A, IFT-B, and BBSome complexes (4). Motor proteins include heterodimeric kinesin II complex (KIF3A, KIF3B and KAP), homodimeric kinesin II complex (KIF17), and IFT dynein complex. Heterodimeric kinesin II is required for cilium assembly (5) and movement of the IFT particles along the doublet zone (6). Homodimeric kinesin II seems to be dispensable for cilium assembly (7) and is required for movement along the singlet zone of the axoneme (6). IFT-dynein propels the IFT particles from the tip of the cilium back to the cell body (8).Loss of IFT-dynein results in abnormal, bulging cilia with accumulation of the IFT particles at the tip $(9,10)$. IFT-A and IFT-B complexes form the core of IFT particles, however, the exact function and relation of their components are not clear (11). Several components, such as IFT88, were reported to be essential for cilium assembly (12). The BBSome complex derives its name from Bardet-Biedl syndrome, since mutations in its components cause this disease (13). The BBSome interacts with IFT-A and IFT-B complexes and is believed to participate in trafficking of the transmembrane proteins along the cilium (14).

\subsection{Mechanisms of assembly/disassembly of primary cilia}

Assembly of the primary cilium begins in $\mathrm{G} 1$ with a docking of the small cytoplasmic vesicles to the mother centriole, this is Cep164 and Talpid3-dependent event (15). The fusion of the small vesicles, which requires EDH1 and EDH3, generates a large ciliary vesicle encapsulating the growing axoneme (16). After the assembly of the large ciliary vesicle, Rabin 8 activates Rab8, which promotes cilium elongation (16). Elongation of the axoneme deforms the ciliary vesicle by creating two membrane surfaces: the sheath (outer membrane) and the shaft (membrane surrounding axoneme). After the docking of the mother centriole to the plasma membrane, the ciliary vesicle fuses with it, exposing the growing cilium to the extracellular environment (17).

Disassembly of the primary cilium is a crucial event for cell cycle progression. As the cilium is a protrusion of the basal body, it anchors the centriole in the perimembrane area, thereby preventing it from participation in mitotic spindle formation (18). During the cell cycle, the cilium is assembled in the $\mathrm{G} 1 / \mathrm{G} 0$ phase, fluctuates through $\mathrm{S}$ and $\mathrm{G} 2$, and gets disassembled during G2/M transition (19). It is not entirely clear what is the mechanism 
of cilium disassembly, however, there are several lines of evidence suggesting complex regulation of this process. Activation of the mitotic kinase Aurora A (AURKA) is a key player in cilium disassembly, and inhibition or transient depletion of AURKA abolishes serum-initiated cilia disassembly. The scaffold protein NEDD9, also known as neural precursor cell expressed developmentally down-regulated protein 9 , has been implicated in the activation of AURKA (20) and is required for cilium disassembly. Histone deacetylase 6 (HDAC6), an enzyme that deacetylates tubulin (21), is a known phosphorylation target of AURKA, which increases its deacetylase activity and destabilizes axonemal microtubules (19). Interestingly, the role of HDAC6 seems to be dispensable for cilia development, arguing that cilium can be disassembled without HDAC6 involvement (22). The microtubule-destabilizing kinesins KIF2A and KIF2C are potential candidates for direct disassembly of axonemal microtubules. Overexpression of both kinesins triggers cilium disassembly, and KIF2A activity towards cilia is regulated by polo-like kinase 1 (Plk1) (23). Plk1 is a well-known target of AURKA (24), and moreover, both KIF2A and KIF2C are known to be regulated by AURKA during mitosis $(25,26)$, which puts them in the same AURKA-driven pathway for cilium disassembly. Cell cycle related kinase (CCRK) and its substrates intestinal cell kinase (ICK) and male germ cellassociated kinase (MAK) were reported to participate in cilium disassembly (27). Furthermore, CCRK has been implicated in Sonic Hedgehog (Shh) signaling and cilium length and morphology regulation (28).

\subsection{Primary cilia and signal transduction}

The complexity and evolutionary stability of the primary cilium suggest that it has some important functionality. For a long time, primary cilia was known for its role in Hedgehog signaling, making it indispensable for proper development. In mammalian cells, Shh receptor patched 1 (Ptch1) localizes to the primary cilium in absence of the ligand, and excludes the intermediate signaling molecule smoothened $(\mathrm{Smo})$ from it. Protein kinase A (PKA) promotes proteolytic processing of Gli2/3 into a repressor form, thereby inhibiting Shh-driven gene expression. In the presence of Shh, Ptch1 translocates to the plasma membrane, and Smo moves into the cilium. This abrogates PKA activation, promoting Gli2/3 accumulation in the ciliary tip and activating Gli transcription factor formation (2931). 
Recently, several of the receptor tyrosine kinases (RTK) were reported to localize to the primary cilium, and signal in a cilium-dependent manner. Platelet-derived growth factor receptor (PDGFR) a was found to specifically accumulate in the primary cilium of fibroblasts, while PDGFR $\beta$ was excluded from the cilium. Engineered loss of the cilium induces rapid degradation of PDGFRa, and loss of its signaling ligand, PDGF-AA, while preserving signal transduction of PDGF-BB, a PDGFRß-specific ligand (32). Insulin-like growth factor 1 receptor (IGF1R) is not exclusive to primary cilium, however, ciliary localization tends to sensitize it, as activation of the receptor upon stimulation was first detected in the cilium, and then spread further to the plasma membrane. Similarly to PDGFRa, loss of cilia drastically decreases ligand-induced activation of IGF1R and downstream phosphorylation of protein kinase B (AKT) (33). Other RTKs were also reported to localize to primary cilia, such as epidermal growth factor receptor (EGFR), which was found in cilia in kidney epithelial cells (34), astrocytes, and neuroblasts (35). Fibroblast growth factor receptor (FGFR) was reported to localize to motile cilia in the airways of rhesus monkeys (36), as well as to the basal body of primary cilia in mouse neural progenitor cells (37). Angiopoietin receptors Tie1/2 localize to primary cilia on the surface epithelium of the murine ovary, bursa, and extra-ovarian rete ducts (38). Unfortunately, the significance and role of cilia in these RTK signaling cascades are still unknown.

Finally, a long list of receptors from the superfamily of G-protein coupled receptors (GPCR) was found to accumulate in the primary cilium of various cell types $(39,40)$. Several cilium-targeting sequences were identified within different types of GPCRs (41, 42). Still, the importance of the cilium for GPCR signaling is very poorly understood. There is evidence suggesting that the cilium serves as a compartment to scaffold GPCR signaling components including adenylyl cyclases (AC) 3/5/6 and phosphodiesterase 4C, thus limiting the spread of downstream signaling (43). In addition to this, it has become evident that cilia can serve as a platform for GPCR signaling crosstalk through GPCR hetero-oligomerization (44) and downstream signaling modulation by co-localized receptors (45). In addition to these, a growing body of evidence indicates that the downstream effectors of GPCRs, heterotrimeric G-proteins, can also be accumulated or excluded from primary cilium. For example, $\mathrm{Ga}_{\mathrm{s}}$ is accumulated in cilia (46), as well as 
$\mathrm{Ga}_{\mathrm{i} 2}$ and $\mathrm{i}_{3}$, while $\mathrm{G}_{\mathrm{i} 1}$ is excluded from it (47). Since GPCRs can usually interact with several types of $\mathrm{Ga}$ subunits, such compartmentalization creates a possibility for the cilium to act as a switch in GPCR signaling.

\subsection{Primary cilia loss/dysfunction associated diseases}

Mutations in cilium-associated genes can cause a plethora of diseases, collectively referred to as ciliopathies. Ciliopathies are systemic diseases with a wide variety of symptoms, usually including the development of abnormalities (polydactyly, situs inversus), vision loss, cyst formation in multiple organs, obesity, and neurological disorders (48). A classic example of a ciliopathy is Joubert syndrome (JBTS; MIM\#213300). It is characterized by hypotonia, ataxia, psychomotor delay, an irregular breathing pattern, and distinctive cerebellar and brain stem malformations. Additional clinical features include retinal degeneration, cystic kidney disease, ocular colobomas, occipital encephalocele, hepatic fibrosis, polydactyly, and endocrine abnormalities (49). Another classic example is Bardet-Biedl syndrome (BBS, MIM\#209900), which includes rod-cone dystrophy, polydactyly, obesity, learning disabilities, hypogonadism, and renal anomalies. Secondary features include speech delay or disorder, developmental delay, behavioral abnormalities, brachydactyly/syndactyly, ataxia/poor coordination/imbalance, mild hypertonia, anosmia, diabetes, fibrocystic liver disease, Hirschsprung's disease, as well as dental and cardiovascular anomalies (50). Symptoms and clinical representations of ciliopathies are largely overlapping, and can be separated by developmental abnormalities such as polydactyly and situs inversus, which are usually associated with impaired Shh signaling, or by degenerative processes, such as retinal degeneration, and different manifestations of dysplasia. The latter is of particular interest, as it occurs through the whole life of the patient and manifests as cyst formation in the kidney (51) and liver (52). Interestingly, modeling loss of cilia usually produces a hyperproliferative phenotype in normal cells $(53,54)$, thus one may expect to see increased incidence of cancer in patients with ciliopathies. Unfortunately, no such data is currently available, however Birt-Hogg-Dubé syndrome, which is associated with an increased incidence of renal cancer, was recently recognized as a ciliopathy (55). 


\section{Primary cilia: potential target for anti-cancer therapy}

\subsection{Primary cilia and cancer}

In multiple cancer types, cilia tend to be lost, however, the role of this event is not clear. Recent publications suggest that loss of cilia in cancer is a relatively early event in disease progression. For instance, a drastic decrease in ciliation can be observed in breast cancer at the stage of non-invasive ductal carcinoma in situ (56). The same observation holds true in prostate cancer. In preinvasive stage of prostatic intraepithelial neoplasia, the number of cilia is significantly decreased (57). In a mouse model of pancreatic cancer, loss of cilia was noted even earlier in pre-cancer lesions. In this model, pancreatic intraepithelial neoplasia of varying grades can be detected prior to tumor development, and in these lesions, cilia were already absent (58). On the other hand, a few reports claim that cilia may be needed for cancer progression in some cases. Since Shh signaling requires the primary cilium, cancer development in models driven by the activation of Smo was strongly inhibited by loss of the cilia, but if the driver was the activated form of Gli, then the cilia loss enhanced tumorigenesis $(59,60)$. So far, such observations have only been specific for Shh-driven tumors, which puts them on a list of peculiar exceptions from the general trend.

So far, cilia loss seems to correlate with tumor progression and also perhaps, malignant transformation, but is it a driving force for the latter, or is it just a consequence of transformation? Modeling the loss of cilia in normal cells suggests that it promotes hyperproliferation in Shh-independent cells. Engineered loss of primary cilia promotes proliferation in the mouse dermis in vivo (54). In cell culture settings, deciliation of normal cholangiocytes was sufficient to increase the proliferation rate, and moreover, loss of cilia promoted attachment-independent growth (53). In the case of Shh-dependent cell populations such as neural stem cells, ablation of primary cilia seems to inhibit their proliferation and lead to hypocellularity $(61,62)$. This observation goes along with tumor models driven by Smo activation, where cilia are required for tumor initiation $(59,60)$.

Several approaches have been made to restore primary cilia in cancer cells. In cholangiacarcinoma cells, depletion or inhibition of the protein HDAC6, which is 
implicated in cilia disassembly (19), was found to robustly restore primary cilia and suppress proliferation (53). In glioblastoma cells, depletion of CCRK, which is also implicated in cilium disassembly, was found to significantly inhibit proliferation and restore ciliation. Interestingly, the number of ciliated cells increased up to $10 \%$ in this study, but depletion of protein KIF3A, which is required for cilia assembly, abrogated all effects of CCRK depletion on both ciliation and proliferation (27).

Overall, in the majority of cancers, loss of cilia seems to be an early event associated with an increase in proliferation, and restoration of the cilia, even in small cell populations, drastically decreases the proliferative capacity of cancer cells.

\subsection{Glioblastoma and primary cilia}

GBM is one of the most fast progressing cancers, which has a median patient survival of 13-16 months (63). Currently, treatment options for GBM are very limited, with the standard of care including aggressive surgical resection, radiation therapy, and chemotherapy (64). Unfortunately, due to its high invasiveness and fast tumor growth rate, the majority of GBM patients present signs of recurrent disease within 32-36 weeks (65). There is therefore a very critical need for the discovery of new targets and the design of new therapeutic approaches to treat GBM.

Recently, GBM was reported to have a drastically decreased ciliation rate. Only about $10 \%$ of GBM cells can assemble cilia. Moreover, electron microscopy analysis of GBM biopsies showed that the few cilia that they do form possess multiple structural abnormalities (66-68). Further inhibition of primary cilia assembly in patient-derived GBM primary cell culture through the introduction of a dominant-negative variant of KIF3A seems to have a minimal and non-coherent effect on both cell proliferation in vitro and tumor growth in a mouse intracranial model (69). On the other hand, even minimal restoration of primary cilia seems to have a tremendous effect on cell proliferation (27). This clearly suggests that loss of cilia in GBM is a non-random event and may be associated with the high proliferative capacity of tumor cells. Understanding the mechanisms of cilia loss in GBM and which pathways lead to increased proliferation upon loss of the cilia will allow to devise new strategies to battle GBM. 


\section{LPA signaling in mammalian cells}

\subsection{LPA production and function}

LPA (lysophosphatidic acid) is a water-soluble lipid metabolite with a wide variety of cellular functions. LPA promotes proliferation in fibroblasts (70), astrocytes (71), and multiple other cell types (72-77). In addition to proliferation, LPA promotes cell migration $(76,77)$, platelet aggregation (78), smooth muscle contraction (79), and neurite retraction (80), making it a versatile signal molecule. LPA is present in large amounts in serum (81), saliva (82), brain (83), and tumor ascites (84).For a long time, the biosynthesis of LPA was a mystery, but it is now known that there are two main pathways to produce LPA: 1) autotaxin (ATX), a secreted lysophospholipase $D$ enzyme, converts lysophosphatidylcholine (LPC) into LPA (85), and 2) phospholipase A can produce LPA from phosphatidic acid (86). During development, LPA signaling participates in wound healing (87), blood and lymphatic vessel formation (88), and brain development (89).

\subsection{LPA receptors: expression and function}

LPA signals through a family of GPCRs known as lysophosphatidic acid receptors 16 (LPAR1-6) (Fig.2). LPARs have distinctive expression patterns and functions. LPAR1 is expressed in the heart, brain, placenta, skeletal muscle, kidney, pancreas, spleen, prostate, testis, ovary, small intestine, and colon (90). LPAR1 can interact with the heterotrimeric G-protein family members $\mathrm{Ga}_{\mathrm{i} / \mathrm{o}}, \mathrm{Ga}_{12 / 13}$, and $\mathrm{Ga}_{\mathrm{q} / 11}(91)$, and promote cell proliferation, migration, survival, and cytoskeleton rearrangements. LPAR1 knockout in mice can cause a reduction in body weight, minor craniofacial deformities, and increased neonatal lethality due to decreased suckling behavior (92). LPAR2 is expressed in the embryonic brain, testis, leukocytes, prostate, spleen, thymus, and pancreas (93). Predicted interactors of LPAR2 include $\mathrm{Ga}_{\mathrm{i} / 0}, \mathrm{Ga}_{12 / 13}$, and $\mathrm{Ga}_{\mathrm{q} / 11} \mathrm{G}$-protein family members. Surprisingly, LPAR2 knockout in mice did not reveal any gross abnormalities (94). LPAR3 is broadly expressed, interacts with $\mathrm{Ga}_{\mathrm{i} / \mathrm{o}}$ and $\mathrm{Ga}_{\mathrm{q} / 11} \mathrm{G}$-protein family members, and its knockout in mice does not cause any severe gross abnormalities, however, multiple reproductive defects were observed in LPAR3 -/- females (95). LPAR4 is distinct from LPAR1-3, being structurally close to P2Y purinergic receptors, and interacts with all four major classes of Ga proteins (91). Knockout of LPAR4 in mice 
produces embryonic lethality caused by impaired vascular development (88). LPAR5 is also structurally similar to $\mathrm{P} 2 \mathrm{Y}$ receptors, and interacts with $\mathrm{Ga}_{12 / 13}$ and $\mathrm{Ga}_{\mathrm{q} / 11} \mathrm{G}$-proteins. LPAR5-knockout mice display decreased nociception and behavioral abnormalities such as decreased anxiety, motivational changes, and reduced social exploration (96). LPAR6 is the most recently discovered R2Y type of LPA receptor, which interacts with $\mathrm{Ga}_{12 / 13}$ (97). Knockout of LPAR6 does not seem to cause any alterations in mice behavior or development, however, it does completely abrogate liver regeneration (98). So far, nothing is known about the regulation or subcellular localization of LPARs.

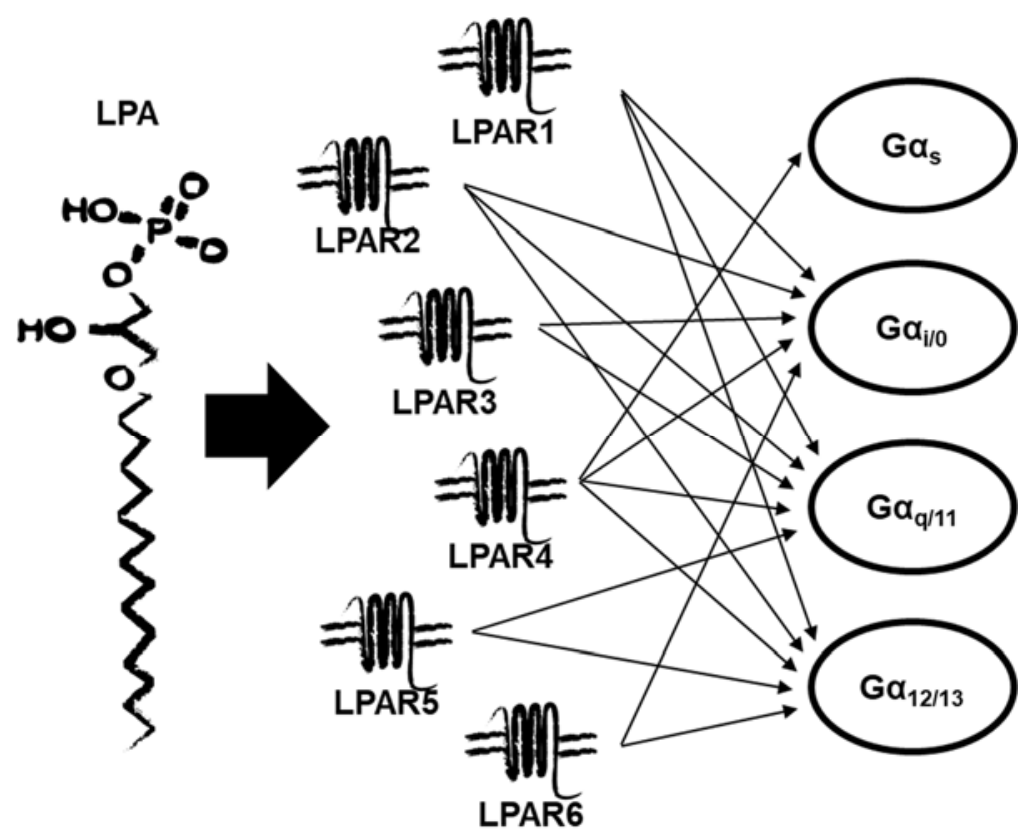

Figure 2. Schematic of LPAR signaling.

\subsection{LPA/LPAR signaling in cancer}

Recently, it became evident that LPA signaling is involved in cancer development and progression. ATX, the major enzyme involved in LPA production, is highly expressed in multiple cancer types including neuroblastoma, hepatocellular carcinoma, breast cancer, renal cancer, and GBM (99). LPA promotes migration in a variety of cancers including pancreatic (84), prostate (100), breast (101), and GBM (102), as well as promotes proliferation (75). Mechanistically, LPA can activate multiple pathways inducing proliferation, potentially in cell type specific manner. In head and neck squamous cell carcinoma, LPA stimulation causes transactivation of EGFR (74), while in colorectal 
cancer LPA promotes $\beta$-catenin pathway activation (75). In ovarian cancer, LPAR1 requires $\mathrm{Ga}_{12}$ to sustain LPA-driven proliferation (72), and $\mathrm{Ga}_{\mathrm{q}}$ is required for normal intestinal epithelium proliferation (103). Depletion of LPAR2 significantly decreases colitis-associated colon cancer development, while LPA promotes it (104). In addition, the level of LPA can be used as a prognostic marker in ovarian and gastric cancers (105, 106). Surprisingly, inhibition of LPA signaling is still poorly investigated as a therapeutic strategy against cancer, however, several works indicate that inhibition of LPAR1 with Ki16425 is sufficient to abrogate metastasis formation in breast cancer $(107,108)$ and inhibition of ATX increases radiosensitivity in GBM (109).

\section{Kinesin-13 family motors and their role in cancer}

\subsection{Kinesin motor superfamily in regulation of microtubule dynamics}

The kinesin superfamily is a superfamily of motor proteins capable of moving along microtubules. Most kinesins target to the growing "+" end of microtubules, but there are several exceptions. The primary role of kinesins is believed to be the transport of different cargoes within the cell. The kinesin superfamily includes 16 families of proteins: kinesin1-12 possess a conserved N-terminal motor domain and move towards the "+" end of the microtubules (110-112), kinesin-13 family members have a motor domain in the middle and tend to disassemble microtubule lattice (113), and kinesin-14 family members have a C-terminal motor domain and move toward the "-" end of microtubules (114). The kinesin-1, 2, and 3 families are involved in the trafficking of membrane-bound vesicles and organelles, while the kinesin-4, 5, 6, and 14 families function during mitosis and participate in spindle microtubule organization and chromosome tethering (115). The kinesin- 8 and 13 families regulate microtubule dynamics by either inhibiting microtubule elongation or initiating disassembly. Kinesin-8 family members have increased processivity, promoting accumulation of the motors at the "+" end of long microtubules (116). At the "+" end, kinesin-8 family members can prevent the addition of new tubulin dimers to the lattice or can directly remove tubulin from microtubules; however, reports on the ability of kinesin-8 to directly disassemble microtubules are controversial (117). Kinesin-13 family members are directly implicated in microtubule disassembly. Their motor domain localizes in the middle of the protein, and by itself can destabilize 
microtubules $(118,119)$, but their disassembly rate is significantly enhanced by the addition of the neck region, which directly precedes the motor domain (120-122). Mechanistically, kinesin-13 family members disassemble microtubules by bending tubulin protofilaments at the end of microtubules, locking them in an unstable conformation, and thus, initiating microtubule catastrophe $(123,124)$.

\subsection{Cellular function of kinesin-13 family members}

Kinesin-13 family members include KIF2A, KIF2B, KIF2C and KIF24 proteins (117). $\mathrm{KIF} 2 \mathrm{~A}$ is involved in mitosis and is required for bipolar spindle formation (125). It is also well known to be involved in brain development through suppression of axon branching and to be required for axon pruning $(126,127)$. It seems to be involved in the regulation of cytoskeleton remodeling during cell movement through interaction with Arf GAP using GTP-binding protein-like, ankyrin repeats and PH Domains1 (AGAP1), but the implications of this are still vague (128). KIF2B is poorly studied, but it is known to have a distinct function during mitosis (125). KIF2C is well known for its mitotic functions (125), and was shown to interact with EB1 and EB3 and target growing microtubules, suggesting potential participation in rapid tubulin cytoskeleton rearrangements (129). KIF24 participates in the remodeling of centriole microtubules (130) and suppresses cilium assembly during mitosis (131). KIF2A and KIF2C were recently shown to be able to induce cilia disassembly (23). Surprisingly, both studies involved KIF24 and KIF2A/C and did not distinguish between the effects of the kinesin-13 family members on pre-formed cilia versus de-novo ciliogenesis.

\subsection{Kinesin-13 family members in cancer}

Recently, the potential involvement of kinesin-13 family members in cancer was highlighted in multiple publications. For instance, all of the kinesin-13 family members are associated with progression and poor prognosis of hepatocellular carcinoma (132). High expression of KIF2A can predict poor prognosis for diffuse large B-cell lymphoma (133) and gastric cancer (134), and it is associated with high-grade glioma (135). KIF2C was found to have strong prognostic value in renal clear cell carcinoma (136) and glioma (137), and was recognized as a potential anti-cancer drug target (138). The reason for such a strong association with poor prognosis of kinesin-13 family motors, particularly 
KIF2A and KIF2C, is still elusive. However, several lines of evidence indicate that KIF2A expression is required for maintaining a highly proliferative phenotype and supporting migration in cancer cells $(135,139)$. The same observations were made for KIF2C (140, 141). Moreover, depletion of KIF2A or KIF2C is sufficient to induce apoptosis in cancer cells (142) or to promote senescence (143). Interestingly, both KIF2A and KIF2C induce primary cilia disassembly (23), and even partial restoration of the primary cilia drastically inhibits cancer cell proliferation $(27,53)$. Thus it is tempting to speculate that KIF2A and $\mathrm{KIF} 2 \mathrm{C}$ drive the loss of primary cilia in cancer cells.

\section{Aurora kinase A: master regulator of cilium}

\subsection{AURKA structure and function}

AURKA is a mitotic serine/threonine kinase. The Aurora family of proteins consists of three known members: AURKA, AURKB, and AURKC. The N-terminal domain (1-128aa) of AURKA targets it to the basal body/centrosomes and allows it to interact with microtubules during mitosis (144). The $\mathrm{N}$-terminal domain also inhibits the catalytic activity of AURKA when it is not bound to activating proteins (145) such as NEDD9 and TPX2. Activation of AURKA results in autophosphorylation of threonine 288 (activational phosphorylation) $(19,146-148)$ and serine 51 (protecting from degradation) (149). Inactivation of AURKA is regulated by protein phosphatase type 2a (PP2a) (150). Active AURKA is targeted to the centrosome through microtubule binding where it can function as a mitotic kinase. During mitosis, AURKA regulates the formation of Cdk1/CyclinB1complex through phosphorylation and activation of cdc25b phosphatase, which removes inhibitory phosphorylation from Cdk1 (151).Accumulation of AURKA is required for centrosome maturation and segregation (152). After nuclear envelope breakdown, AURKA is targeted to the mitotic spindle in complex with the microtubulebinding protein TPX2 (146). Depletion of AURKA in normal cells results in G2/M arrest or the formation of a monopolar spindle, causing an inability to separate DNA and subsequent cell death (153).

\subsection{Role of AURKA in regulation of the ciliary dynamics}

Most AURKA studies focus on its role in mitosis and G2/M AURKA activation. Recently, a non-mitotic role of AURKA as a master-regulator of cilia disassembly became 
evident. Serum stimulation of G1/G0-synchronized cells yielded activation of AURKA that was spatially restricted to the centrioles, and also cilia disassembly. In these settings, disassembly of the cilia occurs in two waves: first, within 1-2 hours after serum stimulation, and second, after 18-24 hours. The latter represents G2/M transition, but the first wave occurs during G1. Inhibition or depletion of AURKA completely abrogates the disassembly of cilia, while injection of the cells with pre-activated AURKA induces rapid deciliation (19). The exact mechanism of AURKA activation during the initiation of cilium disassembly has yet to be elucidated. However, several proteins participating in this event have already been established. Loss of NEDD9, a phosphorylation-independent AURKA activator, severely blunted cilia disassembly in response to serum (19). Calmodulin was shown to directly activate AURKA in a $\mathrm{Ca}^{2+}$-dependent manner, and binding to calmodulin is a prerequisite for serum treatment-induced cilia disassembly (154). Pitchfork (Pifo) also interacts directly with AURKA and promotes AURKA activation during cilia disassembly (155).

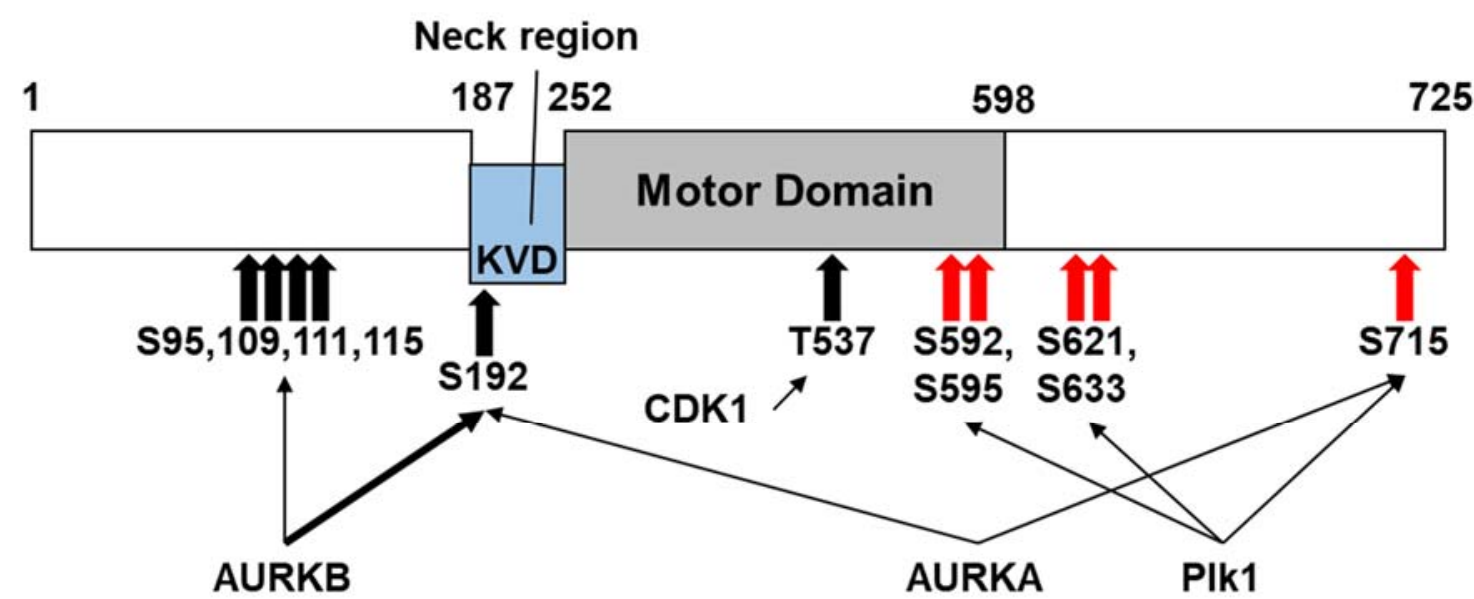

- activational phosphorylation

- inhibitory phosphorylation

Figure 3. Schematic of regulation of human KIF2C through phosphorylation.

\subsection{AURKA and KIF2C interface in mitosis and cilia}

KIF2A and KIF2C, microtubule-destabilizing kinesins, are potential candidates for direct disassembly of the cilia (23). During mitosis, AURKA regulates spindle targeting of both KIF2A and KIF2C, and interestingly, AURKA phosphorylation of KIF2A suppresses 
its microtubule depolymerizing activity and suppresses spindle microtubules binding (25). KIF2C phosphorylation of serine 192 by AURKA can also suppress its depolymerization activity, however, the main effect of AURKA seems to be due to the phosphorylation of serine 719 (xenopus)/ 715 (human), leading to the redistribution of KIF2C to bipolar spindle microtubules (26). Plk1, a direct target of AURKA, can also phosphorylate serine 715 and enhance depolymerization activity of KIF2C (156). In non-mitotic ciliated cells, overexpression of KIF2A or KIF2C initiates disassembly of cilia, but KIF2A was more potent (23). The observations were made in a serum-free media synchronized cell population, where AURKA is mostly inactive. Taking previously discussed data into account, activation of AURKA may drastically change the picture, since it will tend to inhibit KIF2A and activate KIF2C (Fig.3). 


\section{References}

1. Wheatley DN. Primary cilia in normal and pathological tissues. Pathobiology : journal of immunopathology, molecular and cellular biology. 1995;63(4):222-38.

2. Fisch C, Dupuis-Williams $P$. Ultrastructure of cilia and flagellaback to the future! Biology of the cell. 2011;103(6):249-70.

3. Benmerah A. The ciliary pocket. Current opinion in cell biology. 2013;25(1):78-84. 4. Jensen VL, Leroux MR. Gates for soluble and membrane proteins, and two trafficking systems (IFT and LIFT), establish a dynamic ciliary signaling compartment. Current opinion in cell biology. 2017;47:83-91.

5. Brown JM, Marsala C, Kosoy R, Gaertig J. Kinesin-II is preferentially targeted to assembling cilia and is required for ciliogenesis and normal cytokinesis in Tetrahymena. Molecular biology of the cell. 1999;10(10):3081-96.

6. Prevo B, Mangeol P, Oswald F, Scholey JM, Peterman EJ. Functional differentiation of cooperating kinesin-2 motors orchestrates cargo import and transport in C. elegans cilia. Nature cell biology. 2015;17(12):1536-45.

7. Jiang L, Tam BM, Ying G, Wu S, Hauswirth WW, Frederick JM, et al. Kinesin family 17 (osmotic avoidance abnormal-3) is dispensable for photoreceptor morphology and function. FASEB journal : official publication of the Federation of American Societies for Experimental Biology. 2015;29(12):4866-80.

8. Mijalkovic J, Prevo B, Oswald F, Mangeol P, Peterman EJ. Ensemble and singlemolecule dynamics of IFT dynein in Caenorhabditis elegans cilia. Nature communications. 2017;8:14591.

9. Pazour GJ, Dickert BL, Witman GB. The DHC1b (DHC2) isoform of cytoplasmic dynein is required for flagellar assembly. The Journal of cell biology. 1999;144(3):473-81. 10. Porter ME, Bower R, Knott JA, Byrd P, Dentler W. Cytoplasmic dynein heavy chain $1 \mathrm{~b}$ is required for flagellar assembly in Chlamydomonas. Molecular biology of the cell. 1999;10(3):693-712.

11. Rosenbaum JL, Witman GB. Intraflagellar transport. Nature reviews Molecular cell biology. 2002;3(11):813-25.

12. Pazour GJ, Baker SA, Deane JA, Cole DG, Dickert BL, Rosenbaum JL, et al. The intraflagellar transport protein, IFT88, is essential for vertebrate photoreceptor assembly and maintenance. The Journal of cell biology. 2002;157(1):103-13.

13. Forsythe E, Beales PL. Bardet-Biedl syndrome. European journal of human genetics : EJHG. 2013;21(1):8-13.

14. Jin H, White SR, Shida T, Schulz S, Aguiar M, Gygi SP, et al. The conserved Bardet-Biedl syndrome proteins assemble a coat that traffics membrane proteins to cilia. Cell. 2010;141(7):1208-19.

15. Schmidt KN, Kuhns S, Neuner A, Hub B, Zentgraf H, Pereira G. Cep164 mediates vesicular docking to the mother centriole during early steps of ciliogenesis. The Journal of cell biology. 2012;199(7):1083-101.

16. Lu Q, Insinna C, Ott C, Stauffer J, Pintado PA, Rahajeng J, et al. Early steps in primary cilium assembly require EHD1/EHD3-dependent ciliary vesicle formation. Nature cell biology. 2015;17(3):228-40.

17. Rohatgi R, Snell WJ. The ciliary membrane. Current opinion in cell biology. 2010;22(4):541-6. 
18. Plotnikova OV, Pugacheva EN, Golemis EA. Primary cilia and the cell cycle. Methods in cell biology. 2009;94:137-60.

19. Pugacheva EN, Jablonski SA, Hartman TR, Henske EP, Golemis EA. HEF1dependent Aurora A activation induces disassembly of the primary cilium. Cell. 2007;129(7):1351-63.

20. Pugacheva EN, Golemis EA. The focal adhesion scaffolding protein HEF1 regulates activation of the Aurora-A and Nek2 kinases at the centrosome. Nature cell biology. 2005;7(10):937-46.

21. Hubbert C, Guardiola A, Shao R, Kawaguchi Y, Ito A, Nixon A, et al. HDAC6 is a microtubule-associated deacetylase. Nature. 2002;417(6887):455-8.

22. Zhang Y, Kwon S, Yamaguchi T, Cubizolles F, Rousseaux S, Kneissel M, et al. Mice lacking histone deacetylase 6 have hyperacetylated tubulin but are viable and develop normally. Molecular and cellular biology. 2008;28(5):1688-701.

23. Miyamoto T, Hosoba K, Ochiai H, Royba E, Izumi H, Sakuma T, et al. The Microtubule-Depolymerizing Activity of a Mitotic Kinesin Protein KIF2A Drives Primary Cilia Disassembly Coupled with Cell Proliferation. Cell reports. 2015.

24. Macurek L, Lindqvist A, Lim D, Lampson MA, Klompmaker R, Freire R, et al. Pololike kinase-1 is activated by aurora $A$ to promote checkpoint recovery. Nature. 2008;455(7209):119-23.

25. Jang CY, Coppinger JA, Seki A, Yates JR, 3rd, Fang G. Plk1 and Aurora A regulate the depolymerase activity and the cellular localization of Kif2a. Journal of cell science. 2009;122(Pt 9):1334-41.

26. Zhang X, Ems-McClung SC, Walczak CE. Aurora A phosphorylates MCAK to control ran-dependent spindle bipolarity. Molecular biology of the cell. 2008;19(7):275265.

27. Yang Y, Roine N, Makela TP. CCRK depletion inhibits glioblastoma cell proliferation in a cilium-dependent manner. EMBO reports. 2013;14(8):741-7.

28. Snouffer A, Brown D, Lee H, Walsh J, Lupu F, Norman R, et al. Cell Cycle-Related Kinase (CCRK) regulates ciliogenesis and Hedgehog signaling in mice. PLoS genetics. 2017;13(8):e1006912.

29. Corbit KC, Aanstad P, Singla V, Norman AR, Stainier DY, Reiter JF. Vertebrate Smoothened functions at the primary cilium. Nature. 2005;437(7061):1018-21.

30. Rohatgi R, Milenkovic L, Scott MP. Patched1 regulates hedgehog signaling at the primary cilium. Science. 2007;317(5836):372-6.

31. Tuson M, He M, Anderson KV. Protein kinase A acts at the basal body of the primary cilium to prevent Gli2 activation and ventralization of the mouse neural tube. Development. 2011;138(22):4921-30.

32. Schneider L, Clement CA, Teilmann SC, Pazour GJ, Hoffmann EK, Satir P, et al. PDGFRalphaalpha signaling is regulated through the primary cilium in fibroblasts. Current biology : CB. 2005;15(20):1861-6.

33. Zhu D, Shi S, Wang H, Liao K. Growth arrest induces primary-cilium formation and sensitizes IGF-1-receptor signaling during differentiation induction of 3T3-L1 preadipocytes. Journal of cell science. 2009;122(Pt 15):2760-8.

34. Ma R, Li WP, Rundle D, Kong J, Akbarali HI, Tsiokas L. PKD2 functions as an epidermal growth factor-activated plasma membrane channel. Molecular and cellular biology. 2005;25(18):8285-98. 
35. Danilov AI, Gomes-Leal W, Ahlenius H, Kokaia Z, Carlemalm E, Lindvall O. Ultrastructural and antigenic properties of neural stem cells and their progeny in adult rat subventricular zone. Glia. 2009;57(2):136-52.

36. Evans MJ, Fanucchi MV, Van Winkle LS, Baker GL, Murphy AE, Nishio SJ, et al. Fibroblast growth factor-2 during postnatal development of the tracheal basement membrane zone. American journal of physiology Lung cellular and molecular physiology. 2002;283(6):L1263-70.

37. Garcia-Gonzalez D, Murcia-Belmonte V, Esteban PF, Ortega F, Diaz D, SanchezVera I, et al. Anosmin-1 over-expression increases adult neurogenesis in the subventricular zone and neuroblast migration to the olfactory bulb. Brain structure \& function. 2016;221(1):239-60.

38. Teilmann SC, Christensen ST. Localization of the angiopoietin receptors Tie-1 and Tie-2 on the primary cilia in the female reproductive organs. Cell biology international. 2005;29(5):340-6.

39. Mykytyn K, Askwith C. G-Protein-Coupled Receptor Signaling in Cilia. Cold Spring Harbor perspectives in biology. 2017;9(9).

40. Omori Y, Chaya T, Yoshida S, Irie S, Tsuji T, Furukawa T. Identification of G Protein-Coupled Receptors (GPCRs) in Primary Cilia and Their Possible Involvement in Body Weight Control. PloS one. 2015;10(6):e0128422.

41. Berbari NF, Johnson AD, Lewis JS, Askwith CC, Mykytyn K. Identification of ciliary localization sequences within the third intracellular loop of $G$ protein-coupled receptors. Molecular biology of the cell. 2008;19(4):1540-7.

42. Schou KB, Pedersen LB, Christensen ST. Ins and outs of GPCR signaling in primary cilia. EMBO reports. 2015;16(9):1099-113.

43. Choi YH, Suzuki A, Hajarnis S, Ma Z, Chapin HC, Caplan MJ, et al. Polycystin-2 and phosphodiesterase $4 \mathrm{C}$ are components of a ciliary A-kinase anchoring protein complex that is disrupted in cystic kidney diseases. Proceedings of the National Academy of Sciences of the United States of America. 2011;108(26):10679-84.

44. Green JA, Gu C, Mykytyn K. Heteromerization of ciliary G protein-coupled receptors in the mouse brain. PloS one. 2012;7(9):e46304.

45. Marley A, Choy RW, von Zastrow M. GPR88 reveals a discrete function of primary cilia as selective insulators of GPCR cross-talk. PloS one. 2013;8(8):e70857.

46. He X, Zhang L, Chen Y, Remke M, Shih D, Lu F, et al. The G protein alpha subunit Galphas is a tumor suppressor in Sonic hedgehog-driven medulloblastoma. Nature medicine. 2014;20(9):1035-42.

47. Barzi M, Kostrz D, Menendez A, Pons S. Sonic Hedgehog-induced proliferation requires specific Galpha inhibitory proteins. The Journal of biological chemistry. 2011;286(10):8067-74.

48. Waters AM, Beales PL. Ciliopathies: an expanding disease spectrum. Pediatric nephrology. 2011;26(7):1039-56.

49. Valente EM, Marsh SE, Castori M, Dixon-Salazar T, Bertini E, Al-Gazali L, et al. Distinguishing the four genetic causes of Jouberts syndrome-related disorders. Annals of neurology. 2005;57(4):513-9.

50. Beales PL, Elcioglu N, Woolf AS, Parker D, Flinter FA. New criteria for improved diagnosis of Bardet-Biedl syndrome: results of a population survey. Journal of medical genetics. 1999;36(6):437-46. 
51. Lancaster MA, Gleeson JG. The primary cilium as a cellular signaling center: lessons from disease. Current opinion in genetics \& development. 2009;19(3):220-9.

52. Gunay-Aygun M. Liver and kidney disease in ciliopathies. American journal of medical genetics Part C, Seminars in medical genetics. 2009;151C(4):296-306.

53. Gradilone SA, Radtke BN, Bogert PS, Huang BQ, Gajdos GB, LaRusso NF. HDAC6 inhibition restores ciliary expression and decreases tumor growth. Cancer research. 2013;73(7):2259-70.

54. Croyle MJ, Lehman JM, O'Connor AK, Wong SY, Malarkey EB, Iribarne D, et al. Role of epidermal primary cilia in the homeostasis of skin and hair follicles. Development. 2011;138(9):1675-85.

55. Luijten MN, Basten SG, Claessens T, Vernooij M, Scott CL, Janssen R, et al. BirtHogg-Dube syndrome is a novel ciliopathy. Human molecular genetics. 2013;22(21):4383-97.

56. Menzl I, Lebeau L, Pandey R, Hassounah NB, Li FW, Nagle R, et al. Loss of primary cilia occurs early in breast cancer development. Cilia. 2014;3:7.

57. Hassounah NB, Nagle R, Saboda K, Roe DJ, Dalkin BL, McDermott KM. Primary cilia are lost in preinvasive and invasive prostate cancer. PloS one. 2013;8(7):e68521.

58. Seeley ES, Carriere C, Goetze T, Longnecker DS, Korc M. Pancreatic cancer and precursor pancreatic intraepithelial neoplasia lesions are devoid of primary cilia. Cancer research. 2009;69(2):422-30.

59. Han YG, Kim HJ, Dlugosz AA, Ellison DW, Gilbertson RJ, Alvarez-Buylla A. Dual and opposing roles of primary cilia in medulloblastoma development. Nature medicine. 2009;15(9):1062-5.

60. Wong SY, Seol AD, So PL, Ermilov AN, Bichakjian CK, Epstein EH, Jr., et al. Primary cilia can both mediate and suppress Hedgehog pathway-dependent tumorigenesis. Nature medicine. 2009;15(9):1055-61.

61. Han YG, Spassky N, Romaguera-Ros M, Garcia-Verdugo JM, Aguilar A, Schneider-Maunoury S, et al. Hedgehog signaling and primary cilia are required for the formation of adult neural stem cells. Nature neuroscience. 2008;11(3):277-84.

62. Tong CK, Han YG, Shah JK, Obernier K, Guinto CD, Alvarez-Buylla A. Primary cilia are required in a unique subpopulation of neural progenitors. Proceedings of the National Academy of Sciences of the United States of America. 2014;111(34):12438-43. 63. Ries LAG. Cancer survival among adults : U.S. SEER program, 1988-2001, patient and tumor characteristics. Bethesda, MD: U.S. Department of Health and Human Services, National Institutes of Health, National Cancer Institute; 2007. 276 p. p.

64. Adult Central Nervous System Tumors Treatment (PDQ(R)): Health Professional Version. PDQ Cancer Information Summaries. Bethesda (MD)2002.

65. Birk HS, Han SJ, Butowski NA. Treatment options for recurrent high-grade gliomas. CNS oncology. 2017;6(1):61-70.

66. Moser JJ, Fritzler MJ, Rattner JB. Ultrastructural characterization of primary cilia in pathologically characterized human glioblastoma multiforme (GBM) tumors. BMC clinical pathology. 2014;14:40.

67. Sarkisian MR, Siebzehnrubl D, Hoang-Minh L, Deleyrolle L, Silver DJ, Siebzehnrubl FA, et al. Detection of primary cilia in human glioblastoma. Journal of neurooncology. 2014;117(1):15-24. 
68. Moser JJ, Fritzler MJ, Rattner JB. Primary ciliogenesis defects are associated with human astrocytoma/glioblastoma cells. BMC cancer. 2009;9:448.

69. Hoang-Minh LB, Deleyrolle LP, Siebzehnrubl D, Ugartemendia G, Futch H, Griffith $\mathrm{B}$, et al. Disruption of KIF3A in patient-derived glioblastoma cells: effects on ciliogenesis, hedgehog sensitivity, and tumorigenesis. Oncotarget. 2016;7(6):7029-43.

70. van Corven EJ, Groenink A, Jalink K, Eichholtz T, Moolenaar WH. Lysophosphatidate-induced cell proliferation: identification and dissection of signaling pathways mediated by $\mathrm{G}$ proteins. Cell. 1989;59(1):45-54.

71. Shano S, Moriyama R, Chun J, Fukushima N. Lysophosphatidic acid stimulates astrocyte proliferation through LPA1. Neurochemistry international. 2008;52(1-2):216-20. 72. Goldsmith ZG, Ha JH, Jayaraman M, Dhanasekaran DN. Lysophosphatidic Acid Stimulates the Proliferation of Ovarian Cancer Cells via the gep Proto-Oncogene Galpha(12). Genes \& cancer. 2011;2(5):563-75.

73. Ferry G, Tellier E, Try A, Gres S, Naime I, Simon MF, et al. Autotaxin is released from adipocytes, catalyzes lysophosphatidic acid synthesis, and activates preadipocyte proliferation. Up-regulated expression with adipocyte differentiation and obesity. The Journal of biological chemistry. 2003;278(20):18162-9.

74. Gschwind A, Prenzel N, Ullrich A. Lysophosphatidic acid-induced squamous cell carcinoma cell proliferation and motility involves epidermal growth factor receptor signal transactivation. Cancer research. 2002;62(21):6329-36.

75. Yang M, Zhong WW, Srivastava N, Slavin A, Yang J, Hoey T, et al. G proteincoupled lysophosphatidic acid receptors stimulate proliferation of colon cancer cells through the \{beta\}-catenin pathway. Proceedings of the National Academy of Sciences of the United States of America. 2005;102(17):6027-32.

76. Hayashi M, Okabe K, Kato K, Okumura M, Fukui R, Fukushima N, et al. Differential function of lysophosphatidic acid receptors in cell proliferation and migration of neuroblastoma cells. Cancer letters. 2012;316(1):91-6.

77. Kim J, Keys JR, Eckhart AD. Vascular smooth muscle migration and proliferation in response to lysophosphatidic acid (LPA) is mediated by LPA receptors coupling to Gq. Cellular signalling. 2006;18(10):1695-701.

78. Benton AM, Gerrard JM, Michiel T, Kindom SE. Are lysophosphatidic acids or phosphatidic acids involved in stimulus activation coupling in platelets? Blood. 1982;60(3):642-9.

79. Toews ML, Ustinova EE, Schultz HD. Lysophosphatidic acid enhances contractility of isolated airway smooth muscle. Journal of applied physiology. 1997;83(4):1216-22.

80. Sayas CL, Moreno-Flores MT, Avila J, Wandosell F. The neurite retraction induced by lysophosphatidic acid increases Alzheimer's disease-like Tau phosphorylation. The Journal of biological chemistry. 1999;274(52):37046-52.

81. Cho WH, Park T, Park YY, Huh JW, Lim CM, Koh Y, et al. Clinical significance of enzymatic lysophosphatidylcholine (LPC) assay data in patients with sepsis. European journal of clinical microbiology \& infectious diseases : official publication of the European Society of Clinical Microbiology. 2012;31(8):1805-10.

82. Sugiura T, Nakane S, Kishimoto S, Waku K, Yoshioka Y, Tokumura A. Lysophosphatidic acid, a growth factor-like lipid, in the saliva. Journal of lipid research. 2002;43(12):2049-55. 
83. Nakane S, Oka S, Arai S, Waku K, Ishima Y, Tokumura A, et al. 2-Arachidonoylsn-glycero-3-phosphate, an arachidonic acid-containing lysophosphatidic acid: occurrence and rapid enzymatic conversion to 2-arachidonoyl-sn-glycerol, a cannabinoid receptor ligand, in rat brain. Archives of biochemistry and biophysics. 2002;402(1):51-8. 84. Yamada T, Sato K, Komachi M, Malchinkhuu E, Tobo M, Kimura T, et al. Lysophosphatidic acid (LPA) in malignant ascites stimulates motility of human pancreatic cancer cells through LPA1. The Journal of biological chemistry. 2004;279(8):6595-605.

85. Perrakis A, Moolenaar WH. Autotaxin: structure-function and signaling. Journal of lipid research. 2014;55(6):1010-8.

86. Eder AM, Sasagawa T, Mao M, Aoki J, Mills GB. Constitutive and lysophosphatidic acid (LPA)-induced LPA production: role of phospholipase D and phospholipase A2. Clinical cancer research : an official journal of the American Association for Cancer Research. 2000;6(6):2482-91.

87. Xu KP, Yin J, Yu FS. Lysophosphatidic acid promoting corneal epithelial wound healing by transactivation of epidermal growth factor receptor. Investigative ophthalmology \& visual science. 2007;48(2):636-43.

88. Sumida H, Noguchi K, Kihara Y, Abe M, Yanagida K, Hamano F, et al. LPA4 regulates blood and lymphatic vessel formation during mouse embryogenesis. Blood. 2010;116(23):5060-70.

89. Fukushima N, Shano S, Moriyama R, Chun J. Lysophosphatidic acid stimulates neuronal differentiation of cortical neuroblasts through the LPA1-G(i/o) pathway. Neurochemistry international. 2007;50(2):302-7.

90. Yung YC, Stoddard NC, Chun J. LPA receptor signaling: pharmacology, physiology, and pathophysiology. Journal of lipid research. 2014;55(7):1192-214.

91. Gonzalez-Gil I, Zian D, Vazquez-Villa H, Ortega-Gutierrez S, Lopez-Rodriguez ML. The status of the lysophosphatidic acid receptor type 1 (LPA(1)R). Medchemcomm. 2015;6(1):13-23.

92. Contos JJ, Fukushima N, Weiner JA, Kaushal D, Chun J. Requirement for the IpA1 lysophosphatidic acid receptor gene in normal suckling behavior. Proceedings of the National Academy of Sciences of the United States of America. 2000;97(24):13384-9.

93. Choi JW, Herr DR, Noguchi K, Yung YC, Lee CW, Mutoh T, et al. LPA receptors: subtypes and biological actions. Annual review of pharmacology and toxicology. 2010;50:157-86.

94. Contos JJ, Ishii I, Fukushima N, Kingsbury MA, Ye X, Kawamura S, et al. Characterization of Ipa(2) (Edg4) and Ipa(1)//pa(2) (Edg2/Edg4) lysophosphatidic acid receptor knockout mice: signaling deficits without obvious phenotypic abnormality attributable to Ipa(2). Molecular and cellular biology. 2002;22(19):6921-9.

95. Ye X, Hama K, Contos JJ, Anliker B, Inoue A, Skinner MK, et al. LPA3-mediated lysophosphatidic acid signalling in embryo implantation and spacing. Nature. 2005;435(7038):104-8.

96. Callaerts-Vegh Z, Leo S, Vermaercke B, Meert T, D'Hooge R. LPA5 receptor plays a role in pain sensitivity, emotional exploration and reversal learning. Genes, brain, and behavior. 2012;11(8):1009-19.

97. Ishii S, Noguchi K, Yanagida K. Non-Edg family lysophosphatidic acid (LPA) receptors. Prostaglandins \& other lipid mediators. 2009;89(3-4):57-65. 
98. Zuckerman V, Kirks R, Siddiqui I, Swet J, Jacobs W, Vrochides D, et al. Lysophosphatidic acid receptor 6 inhibits hepatocyte function following repopulation after partial hepatectomy2017. S53 p.

99. Houben AJ, Moolenaar WH. Autotaxin and LPA receptor signaling in cancer. Cancer metastasis reviews. 2011;30(3-4):557-65.

100. Hao F, Tan M, Xu X, Han J, Miller DD, Tigyi G, et al. Lysophosphatidic acid induces prostate cancer PC3 cell migration via activation of LPA(1), p42 and p38alpha. Biochimica et biophysica acta. 2007;1771(7):883-92.

101. Zhang H, Xu X, Gajewiak J, Tsukahara R, Fujiwara Y, Liu J, et al. Dual activity lysophosphatidic acid receptor pan-antagonist/autotaxin inhibitor reduces breast cancer cell migration in vitro and causes tumor regression in vivo. Cancer research. 2009;69(13):5441-9.

102. Kishi Y, Okudaira S, Tanaka M, Hama K, Shida D, Kitayama J, et al. Autotaxin is overexpressed in glioblastoma multiforme and contributes to cell motility of glioblastoma by converting lysophosphatidylcholine to lysophosphatidic acid. The Journal of biological chemistry. 2006;281(25):17492-500.

103. Lee SJ, Leoni G, Neumann PA, Chun J, Nusrat A, Yun CC. Distinct phospholipase C-beta isozymes mediate lysophosphatidic acid receptor 1 effects on intestinal epithelial homeostasis and wound closure. Molecular and cellular biology. 2013;33(10):2016-28.

104. Lin S, Wang D, lyer S, Ghaleb AM, Shim H, Yang VW, et al. The absence of LPA2 attenuates tumor formation in an experimental model of colitis-associated cancer. Gastroenterology. 2009;136(5):1711-20.

105. Sutphen R, Xu Y, Wilbanks GD, Fiorica J, Grendys EC, Jr., LaPolla JP, et al. Lysophospholipids are potential biomarkers of ovarian cancer. Cancer epidemiology, biomarkers \& prevention : a publication of the American Association for Cancer Research, cosponsored by the American Society of Preventive Oncology. 2004;13(7):1185-91.

106. Zeng R, Li B, Huang J, Zhong M, Li L, Duan C, et al. Lysophosphatidic Acid is a Biomarker for Peritoneal Carcinomatosis of Gastric Cancer and Correlates with Poor Prognosis. Genetic testing and molecular biomarkers. 2017.

107. Boucharaba A, Serre CM, Guglielmi J, Bordet JC, Clezardin P, Peyruchaud O. The type 1 lysophosphatidic acid receptor is a target for therapy in bone metastases. Proceedings of the National Academy of Sciences of the United States of America. 2006;103(25):9643-8.

108. David M, Ribeiro J, Descotes F, Serre CM, Barbier M, Murone M, et al. Targeting lysophosphatidic acid receptor type 1 with Debio 0719 inhibits spontaneous metastasis dissemination of breast cancer cells independently of cell proliferation and angiogenesis. International journal of oncology. 2012;40(4):1133-41.

109. Bhave SR, Dadey DY, Karvas RM, Ferraro DJ, Kotipatruni RP, Jaboin JJ, et al. Autotaxin Inhibition with PF-8380 Enhances the Radiosensitivity of Human and Murine Glioblastoma Cell Lines. Frontiers in oncology. 2013;3:236.

110. Hirokawa N, Noda Y, Tanaka Y, Niwa S. Kinesin superfamily motor proteins and intracellular transport. Nature reviews Molecular cell biology. 2009;10(10):682-96.

111. Lawrence CJ, Dawe RK, Christie KR, Cleveland DW, Dawson SC, Endow SA, et al. A standardized kinesin nomenclature. The Journal of cell biology. 2004;167(1):19-22. 112. Miki H, Okada $\mathrm{Y}$, Hirokawa N. Analysis of the kinesin superfamily: insights into structure and function. Trends in cell biology. 2005;15(9):467-76. 
113. Moores CA, Milligan RA. Lucky 13-microtubule depolymerisation by kinesin-13 motors. Journal of cell science. 2006;119(Pt 19):3905-13.

114. Endow SA. Determinants of molecular motor directionality. Nature cell biology. 1999;1(6):E163-7.

115. Moore JD, Endow SA. Kinesin proteins: a phylum of motors for microtubule-based motility. BioEssays : news and reviews in molecular, cellular and developmental biology. 1996;18(3):207-19.

116. Varga V, Helenius J, Tanaka K, Hyman AA, Tanaka TU, Howard J. Yeast kinesin8 depolymerizes microtubules in a length-dependent manner. Nature cell biology. 2006;8(9):957-62.

117. Walczak CE, Gayek S, Ohi R. Microtubule-depolymerizing kinesins. Annual review of cell and developmental biology. 2013;29:417-41.

118. Moores CA, Yu M, Guo J, Beraud C, Sakowicz R, Milligan RA. A mechanism for microtubule depolymerization by Kinl kinesins. Molecular cell. 2002;9(4):903-9.

119. Ovechkina $\mathrm{Y}$, Wagenbach $\mathrm{M}$, Wordeman L. K-loop insertion restores microtubule depolymerizing activity of a "neckless" MCAK mutant. The Journal of cell biology. 2002;159(4):557-62.

120. Hertzer KM, Ems-McClung SC, Kline-Smith SL, Lipkin TG, Gilbert SP, Walczak CE. Full-length dimeric MCAK is a more efficient microtubule depolymerase than minimal domain monomeric MCAK. Molecular biology of the cell. 2006;17(2):700-10.

121. Maney T, Wagenbach M, Wordeman L. Molecular dissection of the microtubule depolymerizing activity of mitotic centromere-associated kinesin. The Journal of biological chemistry. 2001;276(37):34753-8.

122. Ogawa T, Nitta R, Okada Y, Hirokawa N. A common mechanism for microtubule destabilizers-M type kinesins stabilize curling of the protofilament using the class-specific neck and loops. Cell. 2004;116(4):591-602.

123. Wang W, Cantos-Fernandes S, Lv Y, Kuerban H, Ahmad S, Wang C, et al. Insight into microtubule disassembly by kinesin-13s from the structure of Kif2C bound to tubulin. Nature communications. 2017;8(1):70.

124. Gardner MK, Zanic M, Gell C, Bormuth V, Howard J. Depolymerizing kinesins Kip3 and MCAK shape cellular microtubule architecture by differential control of catastrophe. Cell. 2011;147(5):1092-103.

125. Manning AL, Ganem NJ, Bakhoum SF, Wagenbach M, Wordeman L, Compton DA. The kinesin-13 proteins Kif2a, Kif2b, and Kif2c/MCAK have distinct roles during mitosis in human cells. Molecular biology of the cell. 2007;18(8):2970-9.

126. Maor-Nof M, Homma N, Raanan C, Nof A, Hirokawa N, Yaron A. Axonal pruning is actively regulated by the microtubule-destabilizing protein kinesin superfamily protein 2A. Cell reports. 2013;3(4):971-7.

127. Noda $\mathrm{Y}$, Niwa S, Homma N, Fukuda H, Imajo-Ohmi S, Hirokawa N. Phosphatidylinositol 4-phosphate 5-kinase alpha (PIPKalpha) regulates neuronal microtubule depolymerase kinesin, KIF2A and suppresses elongation of axon branches. Proceedings of the National Academy of Sciences of the United States of America. 2012;109(5):1725-30.

128. Luo R, Chen PW, Wagenbach M, Jian X, Jenkins L, Wordeman L, et al. Direct Functional Interaction of the Kinesin-13 Family Membrane Kinesin-like Protein 2A (Kif2A) 
and Arf GAP with GTP-binding Protein-like, Ankyrin Repeats and PH Domains1 (AGAP1). The Journal of biological chemistry. 2016;291(41):21350-62.

129. Lee T, Langford KJ, Askham JM, Bruning-Richardson A, Morrison EE. MCAK associates with EB1. Oncogene. 2008;27(17):2494-500.

130. Kobayashi T, Tsang WY, Li J, Lane W, Dynlacht BD. Centriolar kinesin Kif24 interacts with CP110 to remodel microtubules and regulate ciliogenesis. Cell. 2011;145(6):914-25.

131. Kim S, Lee K, Choi JH, Ringstad N, Dynlacht BD. Nek2 activation of Kif24 ensures cilium disassembly during the cell cycle. Nature communications. 2015;6:8087.

132. Chen J, Li S, Zhou S, Cao S, Lou Y, Shen H, et al. Kinesin superfamily protein expression and its association with progression and prognosis in hepatocellular carcinoma. Journal of cancer research and therapeutics. 2017;13(4):651-9.

133. Zhang $Y$, You X, Liu H, Xu M, Dang Q, Yang L, et al. High KIF2A expression predicts unfavorable prognosis in diffuse large $B$ cell lymphoma. Annals of hematology. 2017;96(9):1485-91.

134. Zhang S, Huang F, Wang Y, Song Q, Yang X, Wu H. KIF2A Overexpression and Its Association with Clinicopathologic Characteristics and Poor Prognoses in Patients with Gastric Cancer. Disease markers. 2016;2016:7484516.

135. Zhang X, Ma C, Wang Q, Liu J, Tian M, Yuan Y, et al. Role of KIF2A in the progression and metastasis of human glioma. Molecular medicine reports. 2016;13(2):1781-7.

136. Gu Y, Lu L, Wu L, Chen H, Zhu W, He Y. Identification of prognostic genes in kidney renal clear cell carcinoma by RNAseq data analysis. Molecular medicine reports. 2017;15(4):1661-7.

137. Bie L, Zhao G, Wang YP, Zhang B. Kinesin family member $2 \mathrm{C}$ (KIF2C/MCAK) is a novel marker for prognosis in human gliomas. Clinical neurology and neurosurgery. 2012;114(4):356-60.

138. Sanhaji M, Friel CT, Wordeman L, Louwen F, Yuan J. Mitotic centromereassociated kinesin (MCAK): a potential cancer drug target. Oncotarget. 2011;2(12):93547.

139. Wang J, Ma S, Ma R, Qu X, Liu W, Lv C, et al. KIF2A silencing inhibits the proliferation and migration of breast cancer cells and correlates with unfavorable prognosis in breast cancer. BMC cancer. 2014;14:461.

140. Nakamura Y, Tanaka F, Haraguchi N, Mimori K, Matsumoto T, Inoue H, et al. Clinicopathological and biological significance of mitotic centromere-associated kinesin overexpression in human gastric cancer. British journal of cancer. 2007;97(4):543-9.

141. Shimo A, Tanikawa C, Nishidate T, Lin ML, Matsuda K, Park JH, et al. Involvement of kinesin family member $2 \mathrm{C} /$ mitotic centromere-associated kinesin overexpression in mammary carcinogenesis. Cancer science. 2008;99(1):62-70.

142. Wang K, Lin C, Wang C, Shao Q, Gao W, Song B, et al. Silencing Kif2a induces apoptosis in squamous cell carcinoma of the oral tongue through inhibition of the PI3K/Akt signaling pathway. Molecular medicine reports. 2014;9(1):273-8.

143. Gwon MR, Cho JH, Kim JR. Mitotic centromere-associated kinase (MCAK/Kif2C) regulates cellular senescence in human primary cells through a p53-dependent pathway. FEBS letters. 2012;586(23):4148-56. 
144. Giet R, Prigent $C$. The non-catalytic domain of the Xenopus laevis auroraA kinase localises the protein to the centrosome. Journal of cell science. 2001;114(Pt 11):2095104.

145. Zhang Y, Ni J, Huang Q, Ren W, Yu L, Zhao S. Identification of the auto-inhibitory domains of Aurora-A kinase. Biochemical and biophysical research communications. 2007;357(2):347-52.

146. Kufer TA, Sillje HH, Korner R, Gruss OJ, Meraldi P, Nigg EA. Human TPX2 is required for targeting Aurora-A kinase to the spindle. The Journal of cell biology. 2002;158(4):617-23.

147. Ohashi S, Sakashita G, Ban R, Nagasawa M, Matsuzaki H, Murata $Y$, et al. Phospho-regulation of human protein kinase Aurora-A: analysis using anti-phosphoThr288 monoclonal antibodies. Oncogene. 2006;25(59):7691-702.

148. Walter AO, Seghezzi W, Korver W, Sheung J, Lees E. The mitotic serine/threonine kinase Aurora2/AIK is regulated by phosphorylation and degradation. Oncogene. 2000;19(42):4906-16.

149. Littlepage LE, Ruderman JV. Identification of a new APC/C recognition domain, the $A$ box, which is required for the Cdh1-dependent destruction of the kinase Aurora-A during mitotic exit. Genes \& development. 2002;16(17):2274-85.

150. Katayama H, Zhou H, Li Q, Tatsuka M, Sen S. Interaction and feedback regulation between STK15/BTAK/Aurora-A kinase and protein phosphatase 1 through mitotic cell division cycle. The Journal of biological chemistry. 2001;276(49):46219-24.

151. Horn V, Thelu J, Garcia A, Albiges-Rizo C, Block MR, Viallet J. Functional interaction of Aurora-A and PP2A during mitosis. Molecular biology of the cell. 2007;18(4):1233-41.

152. Wang LH, Xiang J, Yan M, Zhang Y, Zhao Y, Yue CF, et al. The mitotic kinase Aurora-A induces mammary cell migration and breast cancer metastasis by activating the Cofilin-F-actin pathway. Cancer research. 2010;70(22):9118-28.

153. Glover DM, Leibowitz MH, McLean DA, Parry $\mathrm{H}$. Mutations in aurora prevent centrosome separation leading to the formation of monopolar spindles. Cell. 1995;81(1):95-105.

154. Plotnikova OV, Nikonova AS, Loskutov YV, Kozyulina PY, Pugacheva EN, Golemis EA. Calmodulin activation of Aurora-A kinase (AURKA) is required during ciliary disassembly and in mitosis. Molecular biology of the cell. 2012;23(14):2658-70.

155. Kinzel D, Boldt K, Davis EE, Burtscher I, Trumbach D, Diplas B, et al. Pitchfork regulates primary cilia disassembly and left-right asymmetry. Developmental cell. 2010;19(1):66-77.

156. Zhang L, Shao H, Huang Y, Yan F, Chu Y, Hou H, et al. PLK1 phosphorylates mitotic centromere-associated kinesin and promotes its depolymerase activity. The Journal of biological chemistry. 2011;286(4):3033-46. 


\title{
Study1: LPA signaling is regulated through the primary cilium: a novel target in glioblastoma.
}

\author{
Yuriy V. Loskutov ${ }^{1}$, Caryn L. Griffin ${ }^{1}$, Kristina M. Marinak ${ }^{1}$, Andrey Bobko ${ }^{2}$, Naira V. \\ Margaryan $^{2}$, Werner J. Geldenhuys ${ }^{3}$, Jann N. Sarkaria ${ }^{5}$ and Elena N. Pugacheva ${ }^{1,2,4}$ \\ ${ }^{1}$ WVU Cancer Institute, ${ }^{2}$ Department of Biochemistry, ${ }^{3}$ Department of Pharmaceutical \\ Sciences, Department of Radiation Oncology ${ }^{4}$ West Virginia University School of \\ Medicine, Morgantown, WV, USA 26506. ${ }^{5}$ Mayo Clinic, Rochester, MN, USA 55905
}

Accepted for publication in Oncogene on September 25 2017.

Corresponding author:

Elena N. Pugacheva,

Department of Biochemistry, PO Box 9142, 1 Medical Center Drive, West Virginia University School of Medicine, Morgantown, WV 26506.

Phone: 304-293-5295

Fax: 304-293-4667

E-mail: epugacheva@hsc.wvu.edu 


\begin{abstract}
The primary cilium is a ubiquitous organelle presented on most human cells. It is a crucial signaling hub for multiple pathways including growth factor and G-protein coupled receptors. Loss of primary cilia, observed in various cancers, has been shown to affect cell proliferation. Primary cilia formation is drastically decreased in glioblastoma (GBM), however, the role of cilia in normal astrocyte or glioblastoma proliferation has not been explored. Here we report that loss of primary cilia in human astrocytes stimulates growth rate in a lysophosphatidic acid (LPA)-dependent manner. We show that lysophosphatidic acid receptor 1 (LPAR1) is accumulated in primary cilia. LPAR1 signaling through $\mathrm{Ga}_{12} / \mathrm{Ga}_{\mathrm{q}}$ was previously reported to be responsible for cancer cell proliferation. We found that in ciliated cells, $\mathrm{Ga}_{12}$ and $\mathrm{Ga}_{q}$ are excluded from the cilium, creating a barrier against unlimited proliferation, one of the hallmarks of cancer. Upon loss of primary cilia, LPAR1 redistributes to the plasma membrane with a concomitant increase in LPAR1 association with $\mathrm{Ga}_{12}$ and $\mathrm{Ga}_{\mathrm{q}}$. Inhibition of LPA signaling with the small molecule compound Ki16425 in deciliated highly proliferative astrocytes or glioblastoma patient-derived cells/xenografts drastically suppresses their growth both in vitro and in vivo. Moreover, Ki16425 brain delivery via PEG-PLGA nanoparticles inhibited tumor progression in an intracranial glioblastoma PDX model. Overall, our findings establish a novel mechanism by which primary cilium restricts proliferation and indicate that loss of primary cilia is sufficient to increase mitogenic signaling, and is important for the maintenance of a highly proliferative phenotype. Clinical application of LPA inhibitors may prove beneficial to restrict glioblastoma growth and ensure local control of disease.
\end{abstract}




\section{Introduction}

The primary cilium is a ubiquitous, microtubule-based organelle which is built on top of a membrane-anchored basal body. Primary cilium is an important negative regulator of proliferation and a key sensory organelle. It serves as a hub for multiple signaling cascades including receptor tyrosine kinase (1), Sonic hedgehog (Shh) (2), and G-protein coupled receptors (GPCRs) (3). Disassembly of primary cilium leads to release of the basal body, also called the mother centriole, which is required for mitotic spindle formation and mitosis. Multiple mitotic kinases initiate cilium disassembly including AURKA, Plk1, and Nek2 (4-6). Centrosome sequestration is considered one of the primary mechanisms of negative regulation of proliferation by primary cilium. Nevertheless, cilium shortening and disassembly is often observed immediately after growth factor stimulation in interphase (4). The role of this short-term disassembly in cell proliferation is currently unknown. Recent publications suggest that in different types of cancer including breast, prostate, renal, and glioblastoma (GBM), cilia tend to be lost (7-10). However, the importance of this event on tumor maintenance and progression or treatment is not well understood.

Several studies report that loss of primary cilia in normal cells increases proliferation and supports attachment-independent growth $(11,12)$, which are common hallmarks of cancer. Attempts to restore primary cilia in cancer cells yield a significant inhibition on proliferation $(12,13)$. These observations suggest that cilia loss can promote/sustain a highly proliferative phenotype. However, in a subset of Sonic hedgehog (Shh)-dependent medulloblastomas, presence of cilium is mandatory (14) for cancer maintenance, therefore studies on specific cancer subtypes are warranted to establish cilia's role in tumor biology and potential therapeutic applications.

Astrocytoma is the most commonly diagnosed adult brain cancer (15), which often progresses to GBM. The majority of GBM patients succumb to the disease within 13-16 months (15). GBM is a highly proliferative disease with limited treatment options (16). Lysophosphatidic acid (LPA) is an abundant mitogen in brain tissue (17). LPA acts through binding of heterotrimeric G-protein coupled receptors (LPAR1-6). It was previously reported that LPAR1 can signal through $\mathrm{Ga}_{i}, \mathrm{Ga}_{12}$, and $\mathrm{Ga}_{\mathrm{q}}$ family members $(18,19)$. LPA stimulates cell proliferation in astrocytes (20) and cancer cells (21). 
Astrocytes are abundant glial cells and well known for their ability to proliferate, especially in the activated state (22), and were previously reported as the potential cells of origin for GBM (23).

In our current work, we establish that loss of primary cilia promotes proliferation of primary non-transformed human astrocytes, providing permissive conditions for transformation in an LPA-dependent manner. GBM primary cells, with a decreased occurrence of primary cilia, were also sensitive to LPA and LPAR1/3 inhibition. Mechanistically, we found that LPA-LPAR1-driven mitogenic signaling was restricted in cells with primary cilium due to compartmentalization of LPAR1 and its downstream effectors, $\mathrm{Ga}_{12}$ and $\mathrm{G} \alpha_{\mathrm{q}}$, in cilia and in cytoplasm, respectively. LPAR1 was redistributed to the plasma membrane upon loss of primary cilium, thus enabling its binding to $\mathrm{Ga}_{12}$ and $\mathrm{Ga}_{\mathrm{q}}$, and therefore suggesting that redistribution of LPAR1 is a key mechanism driving proliferation in a cilia-dependent manner.

Inhibition of LPAR1/3 with the small molecule inhibitor Ki16425 significantly reduces cell growth rate only in deciliated astrocytes. Likewise, patient-derived GBM proliferation was stimulated by LPA and abrogated by Ki16425 in a dose-dependent manner. Importantly, the growth of GBM patient-derived xenografts in vivo was drastically decreased upon Ki16425 administration as a monotherapy without significant side effects.

Taken together, our findings indicate that loss of primary cilia eliminates spatial barriers curbing proliferation, thus unlocking the potential for unlimited proliferation. LPA is one of the key mitogenic factors driving highly proliferative GBM with no or very low basal ciliation, therefore clinical interventions based on inhibiting LPA signaling may significantly improve GBM patient survival and local disease control. 


\section{Results}

\section{Loss of primary cilium promotes proliferation of astrocytes.}

Human astrocytes (HA) can form primary cilia. Incubation in serum-free media (SFM) promotes ciliation resulting in nearly $80 \%$ of cells having cilia (Fig.1A-B). This ciliation rate is similar to that observed in vivo (24). To allow for long term experiments, the primary human astrocytes (HA) were immortalized using SV40 large T antigen (HA-LTA) (25). Immortalization by LTA did not affect ciliation, which was similar to the parental astrocytes (Fig.S1A). To test how loss of primary cilia affects proliferation of primary (HA) or immortalized (HA-LTA) astrocytes, we utilized shRNA-driven knockdown of IFT88 or KIF3B, which are well characterized components of cilium assembly machinery $(26,27)$. Two shRNAs were used to target IFT88 or KIF3B resulting in up to a $90 \%$ knockdown (Fig1.C). Depletion of either IFT88 or KIF3B was sufficient to decrease ciliation to $5-15 \%$ (Fig.1D-E). These ciliation rates are similar to tissue biopsies from GBM patients (28).

The loss of primary cilia resulted in a significant increase in growth rate of both immortalized and primary astrocytes (Fig1.F-G). Interestingly, this difference in growth rate was observed between ciliated (shCon) and deciliated (shKIF3B or shIFT88) cells only upon addition of serum-supplemented media (SSM), but not in SFM. Addition of SSM caused resorption of primary cilia in control cells in a biphasic wave pattern (Fig.S1B), which has been described previously for other cell types (4). These findings indicate that loss of primary cilia by itself does not promote proliferation, but rather increases the response to some mitogenic stimuli present in serum.

\section{Loss of primary cilia changes spatio-temporal response to mitogen stimulation.}

To elucidate the potential mechanism underlying cilia-dependent changes in cell growth rate, a time course analysis of synchronized (SFM starved) astrocytes was performed. Phosphorylation of ERK1/2 (Thr202/Tyr204) and AKT (Ser473), common readouts for a variety of mitogen and pro-survival stimuli, was used to follow the seruminduced response. In agreement with previous reports, addition of $10 \%$ serum triggers a rapid (5-60min) increase in ERK1/2 and AKT phosphorylation followed by a gradual decrease (60-240min) in phosphorylation in all cell lines independent of ciliation status (Fig.2, Fig.3). Interestingly, the amount of phosphorylated ERK1/2 was twofold higher in 
deciliated cells (shKIF3B or shIFT88) than in control (shCon) based on immunofluorescent and western blot assays (Fig.2A-F). Contrary to ERK1/2, phosphorylation of AKT was twofold lower in deciliated cells than in control (Fig.3A-F), indicating that changes in the pattern and intensity of the signal initiation/propagation act in a cilia-dependent manner.

Lysophosphatidic acid signaling is critical for increased proliferation in deciliated astrocytes.

To define the mitogene/s potentially responsible for the hyperproliferative phenotype of deciliated astrocytes, charcoal-stripped serum was used. Charcoal stripping is an efficient way to deplete bioactive lipids, as well as hormones and some vitamins (29), but preserve protein-based growth factors. Surprisingly, charcoal-treatment of serum (cSSM) was sufficient to completely abrogate the increase in growth rate observed in deciliated astrocytes (Fig.4A). One of the most abundant lipid-based mitogens found in serum is lysophosphatidic acid (LPA), which binds to LPA receptors (LPARs) to elicit a response. To test if LPA is involved in deciliation-dependent stimulation of proliferation, a small molecule inhibitor of LPAR1-3, Ki16425 (30), was used. Similar to cSSM, addition of Ki16425 to SSM was sufficient to abrogate the deciliation-dependent increase in growth rates, without any effect on growth of ciliated astrocytes (SSM vs. SSM+Ki16425) (Fig.4B). Moreover, addition of LPA alone to the serum-free medium (SFM) was sufficient to stimulate proliferation of astrocytes, and partially recapitulate the difference observed between ciliated and deciliated cells in the presence of serum (Fig.4B). As expected, LPA addition resulted in a pattern of ERK1/2 and AKT phosphorylation similar to the one observed during serum stimulation (Fig.4C-E). Surprisingly, treatment with EGF, bFGF, PDGF-A/B, or HGF as single agents was neither sufficient to induce proliferation (Fig.S2A) nor able to recapitulate the difference in phosphorylation of both ERK1/2 and AKT (Fig.S2B-C, Fig.S3A-B) previously observed between ciliated and deciliated cells (Fig.2E, Fig.3E). Interestingly, addition of a cocktail of protein growth factors (GFs) including EGF, bFGF, and B27 supplement along with LPA was sufficient to fully recapitulate the phenotype observed with addition of serum (Fig.4F). These findings indicate that LPA signaling is responsible for the highly proliferative phenotype observed 
in astrocytes with disrupted ciliogenesis, but it requires additional growth factors to amplify its effect.

\section{LPAR1 localizes to primary cilia.}

To understand the mechanisms underlying cilia-dependent action of LPA, the subcellular localization of LPARs and Ga subunits participating in downstream signal transduction pathways was analyzed. A panel of LPARs fused with 3xFLAG-tag was exogenously expressed in astrocytes followed by immunofluorescent analysis using antiFLAG antibodies. LPAR1 and LPAR3, but not LPAR6, were consistently localized in primary cilium (Fig.5A, S4A-B). Interestingly, in deciliated cells, both LPAR1 and LPAR3 were targeted to the plasma membrane (Fig.S5A-B). To exclude the possibility of overexpression-driven cilium targeting of LPAR1, we validated several anti-LPAR1 antibodies for immunofluorescent staining, using CRISPR-Cas9 driven LPAR1 depleted astrocytes as a control (Fig.S6). Utilizing validated antibodies we were able to confirm that endogenous LPAR1 localizes to primary cilium when it is present (Fig.S7).

Analysis of the cellular localization of multiple $\mathrm{Ga}$ subunits shows that only $\mathrm{Ga}_{\mathrm{s}}$ consistently targeted to primary cilia, similar to previous reports (31). However, whether other $\mathrm{G} \alpha$ subunits enter primary cilia is currently unknown. We found that $\mathrm{Ga}_{\mathrm{i} i}, \mathrm{G} \alpha_{\mathrm{q}}$, and $\mathrm{Ga}_{12}$ did not display ciliary localization, but rather diffuse cytoplasmic and plasma membrane staining (Fig.5C). Such a pattern of compartmentalization suggests that LPARs may engage in interactions with different $\mathrm{Ga}$ subunits depending upon presence or absence of primary cilia.

\section{LPAR1 directly binds to $\mathbf{G a}_{12}$ and $\mathrm{Ga}_{\mathrm{q}}$ subunits in deciliated cells.}

To test this hypothesis, immunoprecipitation analysis was performed in shCon, shIFT88, and shKIF3B astrocytes transiently overexpressing 3xFLAG-LPAR1. Based on sequence similarity, LPAR1 is predicted to interact with $\mathrm{Ga}_{\mathrm{i}}, \mathrm{Ga}_{\mathrm{q}}$, and $\mathrm{Ga}_{12}$ (19). No

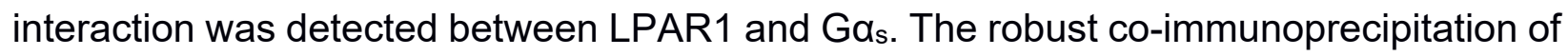
$\mathrm{Ga}_{12}$ and $\mathrm{Ga}_{\mathrm{q}}$ with LPAR1 was noted, being 2-3 times higher in deciliated astrocytes (Fig.5D). Previously, LPAR1 was reported to promote cancer cell proliferation specifically through $\mathrm{Ga}_{12}$ (18). $\mathrm{Ga}_{q}$ was also reported to transmit pro-proliferative signals in cancer 
(32). We concluded that LPAR1 is sequestered in primary cilia, which prevents its interaction with cytoplasmic $\mathrm{Ga}_{12}$ and $\mathrm{Ga}_{\mathrm{q}}$, restricting its proliferative signaling. Loss of cilia promotes LPAR1 interaction with $\mathrm{Ga}_{12}$ and $\mathrm{Ga}_{\mathrm{q}}$, thus promoting the proliferative response to LPA (Fig.5D).

\section{LPA signaling drives GBM proliferation both in vitro and in vivo.}

To evaluate our findings in disease-relevant settings, previously characterized GBM patient-derived cells and xenografts $(33,34)$ of two molecular subtypes (classical-GBM6 and mesenchymal-GBM12) were used. In agreement with previous reports (28), only 5$10 \%$ of GBM cells in vivo (GBM xenografts in mice, Fig.S8A-B) or in vitro (primary cells short term cultures, Fig.S8C-D) possess primary cilia. LPAR1 staining in GBM6 and 12 cells shows similar pattern to primary astrocytes (Fig.S8E). LPA was previously implicated in GBM progression and invasiveness (35), hence its effects on GBM cell proliferation was evaluated. Upon addition of LPA in serum-free GF-supplemented media, a significant increase of primary GBM cell growth rate in vitro was observed (Fig.S8F), while addition of the LPA inhibitor, Ki16425, to SSM decreases GBM cell growth rate in a dose-dependent manner (Fig.S8G).

Similar to in vitro studies, daily intraperitoneal administration of $30 \mathrm{mg} / \mathrm{kg} \mathrm{Ki} 16425$ as a monotherapy over 4-5 weeks significantly decreased the growth of subcutaneously transplanted GBM xenografts in immunodeficient mice (Fig 6A-E). In agreement with in vitro PDX cell line proliferation data (Fig.S8G), the number of mitotic figures in Ki16425treated tumors (Fig 6D, E) was twofold lower. Overall, these findings indicate that LPA is an important mitogen in GBM and inhibition of LPA signaling is a viable option to improve anti-GBM therapy.

\section{PEG-PLGA Ki16425 loaded nanoparticles slow down GBM growth in brain.}

To assess the feasibility of targeting GBM with Ki16425 in patients, its effect on GBM growth was evaluated in an intracranial mouse model. Preliminary studies indicated that the regimen used for the subcutaneous GBM PDX experiment was not efficient in the intracranial model (Fig.S9A-B), suggesting that Ki16425 is not capable of crossing the blood brain barrier. To overcome this issue, we used a PEG-PLGA nanoparticle-based 
delivery system (36) to allow for robust Ki16425 brain entry. Fluorescently labeled nanoparticles rapidly entered the brain upon IP injection and were gradually excreted/degraded over the next $12 \mathrm{~h}$ period (Fig.S9C-D).To account for this decay, the regimen was modified to $30 \mathrm{mg} / \mathrm{kg}$ Ki16425 loaded into nanoparticles and delivered every $12 \mathrm{~h}$. Mice were intracranially injected with $5 \times 10^{5}$ GBM12 cells and tumor growth was monitored weekly via MRI. Upon tumors reaching $5 \mathrm{~mm}^{3}$, mice were randomly assigned to Ki16425 or a vehicle loaded nanoparticles control group. Over 2 weeks of treatment, the Ki16425 nanoparticle-treated group showed a twofold decrease in tumor progression, compared to control (Fig.7A-B). In agreement with our previous experiments, the number of mitotic cells was decreased twofold (Fig.7C-D). These findings show that Ki16425 with a proper delivery method can significantly suppress GBM progression, and potentially, in combination with the current standard of care, improve local disease control and GBM patient survival. 


\section{Discussion}

Primary cilium is well known for its role in multiple signaling cascades $(1,2,11)$. Primary cilia length and the number of cells with cilium is significantly reduced or lost in multiple cancer types including GBM (7-10). Moreover, several studies have noted an increase in cell proliferation upon loss of primary cilia $(11,12)$. The proposed mechanism of cilia-driven proliferation control involves the sequestration of basal body (mother centriole) and the inability to form the mitotic spindle (37). Previously, it was shown that primary cilium disassembly is biphasic: a first wave of fast, transient disassembly within 1-2h after exposure to mitogenic stimuli (4), followed by a second wave of disassembly at $18-24 \mathrm{~h}$, which coincides with mitotic entry. The role of the first wave of cilium disassembly in mitogenic signaling is currently unknown, as is the mechanism/s underlying the increase in proliferation upon loss of primary cilia.

Several pro-proliferative signaling cascades are reported to require primary cilium for proper signal transduction. For instance, PDGF-AA signaling through PDGFRad is lost in deciliated fibroblasts, therefore stimulation with PDGF-AA does not cause ERK1/2 or AKT activation (38); however, the overall proliferation effect of cilia loss was not evaluated in this work. SHH signaling is well-studied in conjunction with primary cilium. Loss of cilia ablates SHH signaling and Shh-driven proliferation (39), and correspondingly, Shh-driven cancers have a tendency to maintain high ciliation rates $(14,40)$. On the other hand, ciliary localization of IGF1R (41) and Notch (11) signaling is needed for differentiation and restriction of cell proliferation. Importantly, cilium can selectively sequester signaling components like GPR88 (42) and LPAR1/3 (Fig.5, S4) from their interaction with ciliaexcluded co-factors, thus conferring selectivity on signal propagation/amplification through the lateral segregation of receptors. This strongly argues that the effect of primary cilia on proliferation is context-dependent, with pro-proliferative effects during development through Shh signaling and anti-proliferative effects in more differentiated cells.

In GBM, the complete inhibition of ciliogenesis seems to have minimal and noncoherent effects on overall proliferation and tumor progression (43). Nevertheless, ciliation compared to normal brain cells is drastically decreased (9), supporting an antimitogenic function of primary cilium in GBM. Our current findings suggest that the 
engineered loss of primary cilia in normal human astrocytes phenotypically closely mimics transient cilium disassembly (Fig.S1B), and also resembles cilia loss in GBM cells (Fig.S8B, D). The increase in growth rate observed in deciliated cells (Fig.1F, G) suggests that transient cilia disassembly may be a key event augmenting mitogenic signaling. Mechanistically, we found that loss of primary cilia in human non-transformed astrocytes results in the amplification of ERK1/2 phosphorylation and promotes proliferation in an LPA-dependent manner (Fig.2, Fig.4). Interestingly, phosphorylation of AKT in response to LPA or serum stimulation was decreased in deciliated astrocytes (Fig.3). This can be attributed to inactivation of PDGFRaa (38) and IGF1R (41) driven signaling, and adds to the understanding of increased stress sensitivity in deciliated astrocytes (44). These findings support the idea that loss of primary cilia changes the pattern of the cellular response to mitogen stimulation, resulting in higher, more sustainable ERK1/2 activation thus explaining the increase in proliferation, but revealing the potential vulnerability of deciliated cells to stress via a decrease in pro-survival signaling (pAKT). Since GBMs usually have high pAKT levels (45) and we did not observe the transformation of deciliated astrocytes, we conclude that additional hit/s such as those well-known for GBM including RTK amplification/PTEN inactivation/PI3K activation, are required for overcoming the decrease in AKT activation.

Previously, LPA was implicated in the regulation of cell migration and proliferation (21, $35)$, however, the role of primary cilia in these signaling pathways was not explored. The LPA receptors (LPAR1/3) are specifically localized to primary cilium, but the LPAR downstream effectors, $\mathrm{Ga}_{12}$ and $\mathrm{Ga}_{\mathrm{q}}$, are excluded from it (Fig.5, S4). Both $\mathrm{Ga}_{12}$ and $\mathrm{Ga}_{\mathrm{q}}$ activation is known to be implicated in cancer cell proliferation and cancer progression $(46,47)$. For $\mathrm{Ga}_{12}$, activation through LPAR1 specifically was reported in ovarian cancer cells (18). Our findings support the notion that in the absence of primary cilia, LPAR1 localizes to the plasma membrane and interacts with $\mathrm{Ga}_{12}$ and $\mathrm{Ga}_{\mathrm{q}}$ (Fig.5D, S5, S7). However, further research is required to pinpoint the intracellular compartment for $\mathrm{Ga}_{12}$ and $G_{q}$ and endogenous LPAR1 interaction. Hence, loss of primary cilia could be responsible for increased proliferation in a subset of cancers, and thus cilia restoration or the manipulation of cilia-dependent signaling such as LPA could be used to develop new therapeutic approaches to fight cancer. 
GBM cells seem to be highly dependent on LPA as a mitogen, since inhibition of LPA signaling with Ki16425 abrogates their growth in vitro, and in both subcutaneous and intracranial GBM models (Fig.S8, Fig.6, Fig.7). Interestingly, the magnitude of the Ki16425 effect was the same between two in vivo models (Fig.6, Fig.7), suggesting that LPA signaling is equally engaged in both of them. LPA is known to be highly abundant in brain (3.7-35 pmol/mg) and serum concentration of LPA was reported to be close to this range $(4-15.5 \mu \mathrm{M})(17)$. In addition, GBMs were reported to increase LPA production by secreting autotaxin (48). However, further studies are required for comprising the LPA levels in GBM PDXs grown in subcutaneous versus brain settings.

GBM6 and GBM12 used in the current study are of classical and mesenchymal molecular subtypes respectively, and are highly aggressive in mouse models $(33,34)$. Both of these subtypes are associated with rapid disease progression and poor prognosis. Our in vivo experiments clearly show that targeting LPA signaling yields a twofold reduction of tumor growth, specifically through a decrease in the proliferation rate of tumor cells (Fig.6, Fig.7). Moreover, utilizing a PEG-PLGA nanoparticles delivery system confirmed the effectiveness of targeting LPA signaling in intracranial settings. The median survival of GBM patients with the current standard of care including aggressive surgery, radiation, and chemotherapy (49) is about 12 months (15), with the majority of patients experiencing recurrence within 32-36 weeks (16). Targeting LPA signaling can prove to be highly beneficial in addition to standard care, since LPA is implicated in proliferation and migration/invasion $(21,35)$. Further studies are required, but based on our findings, we expect a substantial increase in recurrence-free survival upon inhibition of LPA signaling.

Overall, our data supports the role of LPA signaling in cancer cell proliferation, and for the first time, highlights primary cilia as a switch for the interpretation of LPA as a mitogen. 


\section{Materials and Methods}

\section{Cell lines and reagents}

Human astrocytes isolated from human cortex (1800) were obtained from ScienCell Research Labs and maintained in DMEM/F12, supplemented with $10 \%$ heat-inactivated FBS, Antibiotic-Antimycotic (ThermoFisher) and $10 \mu \mathrm{g} / \mathrm{ml}$ of gentamycin (MP Biomedicals). Cells were propagated and cryopreserved at passage 2 , for all studies cells were not passaged more than 10 times or 8 weeks, no authentication or mycoplasma testing were performed. For immortalization, primary astrocytes at passage 5 or 6 were cultured until $50-75 \%$ confluency and transfected with SV40 large T-antigen construct (25), followed by selection with $500 \mu \mathrm{g} / \mathrm{ml}$ G418 (Sigma) until resistant colonies were formed. GBM6 and 12 PDXs (33) were kindly provided by Dr. Jann Sarkaria (Mayo Clinic, Rochester, MN) through a shared MTA agreement, no authentication or mycoplasma testing were performed. PDXs were maintained and used for intracranial injections or primary cell culture isolation as previously described (34). A list of antibodies and their used applications is outlined in Table S1. shRNA constructs were obtained from Dharmacon and are outlined in Table S2. All primers were purchased from IDT Technologies or Invitrogen, the sequences of which are reported in Table S3. The following reagents were used: Lysophosphatidic acid (LPA, Cayman Chemical), EGF and PDGF-AB (Sigma), HGF (R\&D Technologies), bFGF (Peprotech), B27 supplement (ThermoFisher), Ki16425 (ApexBio). For lysophosphatidic acid stimulation experiments, bovine serum albumin (BSA; BP1600, Fisher Scientific) was used as a carrier and was added to all cells to a final concentration of $0.1 \%$.

\section{Western blotting}

Western blotting was performed using standard procedures (50). Primary antibodies used are outlined in Table S1. Secondary anti-mouse and anti-rabbit HRP-conjugated antibodies (Jackson ImmunoResearch Labs) were diluted 1:10,000 followed by chemiluminescence-based detection with HyGLO ${ }^{\text {TM }}$ (Denville Scientific). Bands were quantified using the digital electrophoresis documentation and image analysis software GeneTools (Syngene Corp.), with signal intensity normalized to either a-tubulin or GAPDH. 


\section{Immunofluorescent cell analysis}

Cells were processed as previously described (4). Primary antibodies used are outlined in Table S1. Secondary antibodies included AlexaFluor 488, 555, and 647 (ThermoFisher). Images were captured using a standard setting by an LSM510 confocal microscope (Zeiss) (50). All images represent whole-cell 3D reconstructed projections with $0.4 \mu \mathrm{m}$ steps. All quantifications were done using ImageJ $(\mathrm{NIH})$.

\section{Cell growth/proliferation analysis}

Cell growth rate was determined using semi-automated cell counting in ImageJ $(\mathrm{NIH})$. Cells were plated at $1 \times 10^{4}$ cells per well and grown in the specified conditions for five days, fixed with methanol, and stained with Hoechst33342. Four random 10x fields per well were analyzed with at least three replicates per independent experiment; each graph represents at least three independent experiments.

\section{Fluorescent immunohistochemistry (F-IHC)}

Deparaffinization and rehydration of $4-5 \mu \mathrm{m}$ thin sections was performed as following: 1) three times for 3 min in xylene, 2) three times for 2 min in 100\% ethanol, 3) 2 min in $95 \%$ ethanol, 4) $2 \mathrm{~min}$ in 80\% ethanol, 5) $2 \mathrm{~min}$ in $70 \%$ ethanol, and 6) $5 \mathrm{~min}$ in 1XTBS. Antigen retrieval was done using $98^{\circ} \mathrm{C}$ citrate buffer, $\mathrm{pH} 6.0$ for 20 minutes. Sections were blocked for 60 min with 5\% BSA, 1XTBS solution and stained with the indicated primary antibodies. Secondary antibodies included AlexaFluor-488, 555, and 647 (ThermoFisher) and sections were mounted with ProLong Gold DAPI-containing media (ThermoFisher). Images were captured using LSM510 confocal microscope as previously described (50) (Zeiss). All images represent whole-cell 3D reconstructed projections with $0.4 \mu \mathrm{m}$ steps. All quantifications were done using Image $(\mathrm{NIH})$.

\section{LPAR cloning}

For robust expression and detection of LPARs, pcDNA3.1 vector was modified as previously described (51). Briefly, the insert containing the cleavable ER-targeting sequence followed by a 3xFLAG-tag and multiple cloning site (Table S3) was synthesized 
through String ${ }^{\mathrm{TM}}$ service (ThermoFisher) and cloned into pcDNA3.1 between HindIII and Sall restriction sites. LPAR1, 3, 6 cDNA was amplified from a Human Mammary Epithelial Cells (HMECs) cDNA library kindly provided by Dr. Alexey Ivanov (West Virginia University, Morgantown, WV); primers are shown in Table S3. The generated inserts were cloned into pcDNA3.1 ER-3xFLAG between BamHI and Xhol restriction sites. All constructs were validated by sequencing.

\section{Immunoprecipitation}

For LPAR1 immunoprecipitation, 3xFLAG-LPAR1 was transiently overexpressed in cells pre-incubated for $24 \mathrm{~h}$ in serum-free media. Cells were lysed as previously described (52). 3xFLAG-LPAR1 was precipitated with anti-FLAG M2 affinity gel (Sigma) and used for subsequent Western blot analysis.

\section{Animal experiments}

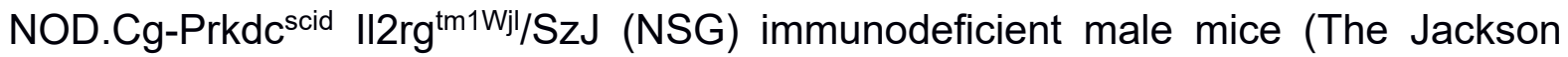
Laboratory) were housed in the West Virginia University Animal Facility under pathogenfree conditions with an approved Institutional Animal Care and Use Committee protocol. For subcutaneous injections, $100 \mu \mathrm{l}$ of GBM6 or GBM12 tumor mash mixed 1:1 with Matrigel (Corning) was injected into the mice flanks. For intracranial injections, transient primary cell cultures were established as previously described (34), and $5 \times 10^{5}$ cells in $5 \mu l$ of Ca/Mg-free Dulbecco modified Phosphate Buffer Saline (DPBS) were administrated into the mouse cortex via stereotactic device-guided injection (34). Subcutaneous tumor growth was assessed weekly via caliper measurements; treatment was initiated upon tumor volume reaching $100 \mathrm{~mm}^{3}$. Intracranial tumor volume was assessed weekly via contrast enhanced MRI (53) or twice a week via bioluminescence imaging (54); treatment was initiated upon tumor volume exceeding $5 \mathrm{~mm}^{3}$. Animals were randomly assigned to the treatment group by simple randomization, investigator was single blinded during group allocation. Mice bearing subcutaneous tumors were intraperitoneally injected with $30 \mathrm{mg} / \mathrm{kg} \mathrm{Ki} 16425$ in $95 \%$ corn oil/5\% DMSO or vehicle alone daily. For the intracranial model, mice were administered 30mg/kg Ki16425 loaded into PEG-PLGA nano-particles in PBS or given nano-particles alone twice daily. All animals were euthanized upon 
reaching a moribund condition, according to the WVU IACUC Tumor Development and Tumor Scoring in Rodents policy.

\section{Contrast enhanced Magnetic Resonance Imaging (MRI)}

To visualize the intracranial tumors, mice were intraperitoneally injected with gadolinium-DTPA (contrast reagent, BioPAL) to a final concentration of $2 \mathrm{mmol} / \mathrm{kg} \mathrm{(55)}$, and imaged with a compact MRI system (ICON, Bruker). Images were taken with T1 weighted RARE sequence (echo time: $26.23 \mathrm{~ms}$; repetition time $1984.158 \mathrm{~ms}$; averages: 8; rare factor: 6 ). Overall time of scan was $25 \mathrm{~min}$ and final resolution was $0.125 \mathrm{~mm}$ for all axes. Stack images were reconstructed and analyzed using ImageJ $(\mathrm{NIH})$.

\section{Animal bioluminescence imaging}

Mice were imaged twice a week for quantitative evaluation of tumor growth as previously described (56). Images were obtained using the IVIS Lumina-II Imaging System and Living Image-4.0 software (PerkinElmer).

\section{PEG-PLGA nano-particles}

Nano-particles were prepared as previously described (36). Briefly, PEG-PLGA and Ki16425 were dissolved in acetone and added dropwise into water. The nano-particles were stirred for $2 \mathrm{~h}$ at $40^{\circ} \mathrm{C}$ before being collected by centrifugation ( $4000 \mathrm{~g}$ for $90 \mathrm{~min}$ ). After discarding the supernatant, the nanoparticles were resuspended in PhosphateBuffered Saline (PBS).

\section{Statistical analysis}

Statistical comparisons were made using two-tailed Student's t-test. When more than two groups were analyzed, one-way or two-way analysis of variance (ANOVA) was used. $\mathrm{P}<0.05$ was considered to be significant $\left({ }^{*}\right)$ as indicated in figure legends. All treatment groups were compared to vehicle/control unless mentioned otherwise. Experimental values were reported as the means with +/-S.E.M (standard error of mean). All calculations of statistical significance were made using GraphPad software. Sampe sizes 
and statistical analysis chosen were based on our previous experience and recommendations of biostatistician $(4,50,56)$. 


\section{Conflicts of interest.}

The authors declare no conflicts of interest.

\section{Acknowledgments.}

The authors thank Dr. Alexey Ivanov for sharing of the HMLE cDNA library and Brandon Jones for invaluable help with manuscript preparation. 


\section{References}

1. Christensen ST, Clement CA, Satir P, Pedersen LB. Primary cilia and coordination of receptor tyrosine kinase (RTK) signalling. The Journal of pathology. 2012;226(2):17284.

2. Robbins DJ, Fei DL, Riobo NA. The Hedgehog signal transduction network. Science signaling. 2012;5(246):re6.

3. Schou KB, Pedersen LB, Christensen ST. Ins and outs of GPCR signaling in primary cilia. EMBO reports. 2015;16(9):1099-113.

4. Pugacheva EN, Jablonski SA, Hartman TR, Henske EP, Golemis EA. HEF1dependent Aurora A activation induces disassembly of the primary cilium. Cell. 2007;129(7):1351-63.

5. Kim S, Lee K, Choi JH, Ringstad N, Dynlacht BD. Nek2 activation of Kif24 ensures cilium disassembly during the cell cycle. Nature communications. 2015;6:8087.

6. Wang G, Chen Q, Zhang X, Zhang B, Zhuo X, Liu J, et al. PCM1 recruits Plk1 to the pericentriolar matrix to promote primary cilia disassembly before mitotic entry. Journal of cell science. 2013;126(Pt 6):1355-65.

7. Basten SG, Willekers S, Vermaat JS, Slaats GG, Voest EE, van Diest PJ, et al. Reduced cilia frequencies in human renal cell carcinomas versus neighboring parenchymal tissue. Cilia. 2013;2(1):2.

8. Hassounah NB, Nagle R, Saboda K, Roe DJ, Dalkin BL, McDermott KM. Primary cilia are lost in preinvasive and invasive prostate cancer. PloS one. 2013;8(7):e68521.

9. Moser JJ, Fritzler MJ, Rattner JB. Primary ciliogenesis defects are associated with human astrocytoma/glioblastoma cells. BMC cancer. 2009;9:448.

10. Yuan K, Frolova N, Xie Y, Wang D, Cook L, Kwon YJ, et al. Primary cilia are decreased in breast cancer: analysis of a collection of human breast cancer cell lines and tissues. The journal of histochemistry and cytochemistry : official journal of the Histochemistry Society. 2010;58(10):857-70.

11. Ezratty EJ, Stokes N, Chai S, Shah AS, Williams SE, Fuchs E. A role for the primary cilium in Notch signaling and epidermal differentiation during skin development. Cell. 2011;145(7):1129-41.

12. Gradilone SA, Radtke BN, Bogert PS, Huang BQ, Gajdos GB, LaRusso NF. HDAC6 inhibition restores ciliary expression and decreases tumor growth. Cancer research. 2013;73(7):2259-70.

13. Yang Y, Roine N, Makela TP. CCRK depletion inhibits glioblastoma cell proliferation in a cilium-dependent manner. EMBO reports. 2013;14(8):741-7.

14. Han YG, Kim HJ, Dlugosz AA, Ellison DW, Gilbertson RJ, Alvarez-Buylla A. Dual and opposing roles of primary cilia in medulloblastoma development. Nature medicine. 2009;15(9):1062-5.

15. Ries LAG, SEER Program (National Cancer Institute (U.S.)). Cancer survival among adults U.S. SEER program, 1988-2001 : patient and tumor characteristics. Bethesda, MD: U.S. Dept. of Health and Human Services, National Institutes of Health, National Cancer Institute ; 2007. Available from: http://seer.cancer.gov/publications/survival/seer survival mono highres.pdf http://purl.fdlp.gov/GPO/gpo808 http://seer.cancer.gov/publications/survival/Freely available online. 
16. Birk HS, Han SJ, Butowski NA. Treatment options for recurrent high-grade gliomas. CNS oncology. 2016.

17. Yung YC, Stoddard NC, Chun J. LPA receptor signaling: pharmacology, physiology, and pathophysiology. Journal of lipid research. 2014;55(7):1192-214.

18. Goldsmith ZG, Ha JH, Jayaraman M, Dhanasekaran DN. Lysophosphatidic Acid Stimulates the Proliferation of Ovarian Cancer Cells via the gep Proto-Oncogene Galpha(12). Genes \& cancer. 2011;2(5):563-75.

19. Gonzalez-Gil I, Zian D, Vazquez-Villa H, Ortega-Gutierrez S, Lopez-Rodriguez ML. The status of the lysophosphatidic acid receptor type 1 (LPA(1)R). Medchemcomm. 2015;6(1):13-23.

20. Shano S, Moriyama R, Chun J, Fukushima N. Lysophosphatidic acid stimulates astrocyte proliferation through LPA1. Neurochemistry international. 2008;52(1-2):216-20. 21. Gschwind A, Prenzel N, Ullrich A. Lysophosphatidic acid-induced squamous cell carcinoma cell proliferation and motility involves epidermal growth factor receptor signal transactivation. Cancer research. 2002;62(21):6329-36.

22. Sofroniew MV, Vinters HV. Astrocytes: biology and pathology. Actaneuropathologica. 2010;119(1):7-35.

23. Friedmann-Morvinski D, Bushong EA, Ke E, Soda Y, Marumoto T, Singer O, et al. Dedifferentiation of neurons and astrocytes by oncogenes can induce gliomas in mice. Science. 2012;338(6110):1080-4.

24. Kasahara K, Miyoshi K, Murakami S, Miyazaki I, Asanuma M. Visualization of astrocytic primary cilia in the mouse brain by immunofluorescent analysis using the cilia marker Arl13b. Actamedica Okayama. 2014;68(6):317-22.

25. Schuermann M. An expression vector system for stable expression of oncogenes. Nucleic acids research. 1990;18(16):4945-6.

26. Nonaka S, Tanaka Y, Okada Y, Takeda S, Harada A, Kanai Y, et al. Randomization of left-right asymmetry due to loss of nodal cilia generating leftward flow of extraembryonic fluid in mice lacking KIF3B motor protein. Cell. 1998;95(6):829-37.

27. Pazour GJ, Dickert BL, Vucica Y, Seeley ES, Rosenbaum JL, Witman GB, et al. Chlamydomonas IFT88 and its mouse homologue, polycystic kidney disease gene tg737, are required for assembly of cilia and flagella. The Journal of cell biology. 2000;151(3):709-18.

28. Sarkisian MR, Siebzehnrubl D, Hoang-Minh L, Deleyrolle L, Silver DJ, Siebzehnrubl FA, et al. Detection of primary cilia in human glioblastoma. Journal of neurooncology. 2014;117(1):15-24.

29. Cao Z, West C, Norton-Wenzel CS, Rej R, Davis FB, Davis PJ, et al. Effects of resin or charcoal treatment on fetal bovine serum and bovine calf serum. Endocrine research. 2009;34(4):101-8.

30. Ohta H, Sato K, Murata N, Damirin A, Malchinkhuu E, Kon J, et al. Ki16425, a subtype-selective antagonist for EDG-family lysophosphatidic acid receptors. Molecular pharmacology. 2003;64(4):994-1005.

31. Barzi M, Kostrz D, Menendez A, Pons S. Sonic Hedgehog-induced proliferation requires specific Galpha inhibitory proteins. The Journal of biological chemistry. 2011;286(10):8067-74. 
32. Patel BR, Tall GG. Ric-8A gene deletion or phorbol ester suppresses tumorigenesis in a mouse model of GNAQ(Q209L)-driven melanoma. Oncogenesis. 2016;5(6):e236.

33. Carlson BL, Grogan PT, Mladek AC, Schroeder MA, Kitange GJ, Decker PA, et al. Radiosensitizing effects of temozolomide observed in vivo only in a subset of O6methylguanine-DNA methyltransferase methylated glioblastoma multiforme xenografts. International journal of radiation oncology, biology, physics. 2009;75(1):212-9.

34. Carlson BL, Pokorny JL, Schroeder MA, Sarkaria JN. Establishment, maintenance and in vitro and in vivo applications of primary human glioblastoma multiforme (GBM) xenograft models for translational biology studies and drug discovery. Current protocols in pharmacology / editorial board, SJ Enna. 2011;Chapter 14:Unit 146.

35. Manning TJ, Jr., Parker JC, Sontheimer H. Role of lysophosphatidic acid and rho in glioma cell motility. Cell motility and the cytoskeleton. 2000;45(3):185-99.

36. Geldenhuys W, Wehrung D, Groshev A, Hirani A, Sutariya V. Brain-targeted delivery of doxorubicin using glutathione-coated nanoparticles for brain cancers. Pharmaceutical development and technology. 2015;20(4):497-506.

37. Basten SG, Giles RH. Functional aspects of primary cilia in signaling, cell cycle and tumorigenesis. Cilia. 2013;2(1):6.

38. Schneider L, Clement CA, Teilmann SC, Pazour GJ, Hoffmann EK, Satir P, et al. PDGFRalphaalpha signaling is regulated through the primary cilium in fibroblasts. Current biology : CB. 2005;15(20):1861-6.

39. Barzi M, Berenguer J, Menendez A, Alvarez-Rodriguez R, Pons S. Sonichedgehog-mediated proliferation requires the localization of PKA to the cilium base. Journal of cell science. 2010;123(Pt 1):62-9.

40. Li L, Grausam KB, Wang J, Lun MP, Ohli J, Lidov HG, et al. Sonic Hedgehog promotes proliferation of Notch-dependent monociliated choroid plexus tumour cells. Nature cell biology. 2016;18(4):418-30.

41. Zhu D, Shi S, Wang H, Liao K. Growth arrest induces primary-cilium formation and sensitizes IGF-1-receptor signaling during differentiation induction of 3T3-L1 preadipocytes. Journal of cell science. 2009;122(Pt 15):2760-8.

42. Marley A, Choy RW, von Zastrow M. GPR88 reveals a discrete function of primary cilia as selective insulators of GPCR cross-talk. PloS one. 2013;8(8):e70857.

43. Hoang-Minh LB, Deleyrolle LP, Siebzehnrubl D, Ugartemendia G, Futch H, Griffith $\mathrm{B}$, et al. Disruption of KIF3A in patient-derived glioblastoma cells: effects on ciliogenesis, hedgehog sensitivity, and tumorigenesis. Oncotarget. 2016;7(6):7029-43.

44. Yoshimura K, Kawate T, Takeda S. Signaling through the primary cilium affects glial cell survival under a stressed environment. Glia. 2011;59(2):333-44.

45. McDowell KA, Riggins GJ, Gallia GL. Targeting the AKT pathway in glioblastoma. Current pharmaceutical design. 2011;17(23):2411-20.

46. Kalinec G, Nazarali AJ, Hermouet S, Xu N, Gutkind JS. Mutated alpha subunit of the $\mathrm{Gq}$ protein induces malignant transformation in NIH 3T3 cells. Molecular and cellular biology. 1992;12(10):4687-93.

47. Gan CP, Patel V, Mikelis CM, Zain RB, Molinolo AA, Abraham MT, et al. Heterotrimeric G-protein alpha-12 (Galpha12) subunit promotes oral cancer metastasis. Oncotarget. 2014;5(20):9626-40. 
48. Hoelzinger DB, Nakada M, Demuth T, Rosensteel T, Reavie LB, Berens ME. Autotaxin: a secreted autocrine/paracrine factor that promotes glioma invasion. Journal of neuro-oncology. 2008;86(3):297-309.

49. Adult Central Nervous System Tumors Treatment (PDQ $(R))$ : Health Professional Version. PDQ Cancer Information Summaries. Bethesda (MD)2002.

50. Kozyreva VK, Kiseleva AA, Ice RJ, Jones BC, Loskutov YV, Matalkah F, et al. Combination of Eribulin and Aurora A Inhibitor MLN8237 Prevents Metastatic Colonization and Induces Cytotoxic Autophagy in Breast Cancer. Molecular cancer therapeutics. 2016;15(8):1809-22.

51. Guan XM, Kobilka TS, Kobilka BK. Enhancement of membrane insertion and function in a type Illb membrane protein following introduction of a cleavable signal peptide. The Journal of biological chemistry. 1992;267(31):21995-8.

52. Pal K, Badgandi H, Mukhopadhyay S. Studying G protein-coupled receptors: immunoblotting, immunoprecipitation, phosphorylation, surface labeling, and crosslinking protocols. Methods in cell biology. 2015;127:303-22.

53. Koutcher JA, Hu X, Xu S, Gade TP, Leeds N, Zhou XJ, et al. MRI of mouse models for gliomas shows similarities to humans and can be used to identify mice for preclinical trials. Neoplasia. 2002;4(6):480-5.

54. Sarkaria JN, Yang L, Grogan PT, Kitange GJ, Carlson BL, Schroeder MA, et al. Identification of molecular characteristics correlated with glioblastoma sensitivity to EGFR kinase inhibition through use of an intracranial xenograft test panel. Molecular cancer therapeutics. 2007;6(3):1167-74.

55. Portnoy S, Bishop J, Dazai J, Spring S, Henkelman R. Characterization of signal enhancement following the intraperitoneal injection of Gadolinium based contrast agents. 56. Loskutov YV, Kozyulina PY, Kozyreva VK, Ice RJ, Jones BC, Roston TJ, et al. NEDD9/Arf6-dependent endocytic trafficking of matrix metalloproteinase 14: a novel mechanism for blocking mesenchymal cell invasion and metastasis of breast cancer. Oncogene. 2015;34(28):3662-75. 


\section{Figure Legends}

Fig. 1. Loss of primary cilia promotes astrocyte proliferation in a growth factordependent manner.

(A) Representative image of the cilium formed by primary human astrocyte (HA), stained for acetylated $\alpha$-tubulin (AcTub, cilium marker) and $y$-tubulin (YTub, basal body marker); scale bar $-10 \mu \mathrm{m}$. (B) Quantification of primary astrocytes forming cilium, as in (A), in regular serum-supplemented media (SSM) or upon $48 \mathrm{~h}$ of serum starvation (SFM); 300 cells, 100 cells in each of 3 independent experiments; Student's t-test, $p<0.05$. (C) Western blot of IFT88 and KIF3B in primary and immortalized astrocytes (HA-LTA) stably expressing non-targeting shRNA (Con) or shRNA against IFT88 or KIF3B. (D, E) Quantification of primary astrocytes (D) and immortalized astrocytes $(E)$ forming primary cilium, as in (B) upon depletion of IFT88 or KIF3B, as in (C); 300 cells, 100 cells in each of 3 independent experiments; one-way ANOVA with Dunnett's post hoc test, $p<0.05$. ( $F$, G) Growth rates of primary astrocytes $(F)$ and immortalized astrocytes $(G)$ upon depletion of IFT88 or KIF3B in full media or in serum-free conditions (SFM); 3 independent experiments; one-way ANOVA with Dunnett's post hoc test, $p<0.05$.

Fig. 2. Loss of cilium promotes increased ERK1/2 phosphorylation in response to serum stimulation.

(A) Experiment schematics (top) and representative images of cells stably expressing non-targeting shRNA (Con) or shRNA against IFT88 or KIF3B, stained for acetylated $\alpha$ tubulin (AcTub, cilium marker), $\gamma$-tubulin ( $\gamma$ Tub, basal body marker), and ERK1/2

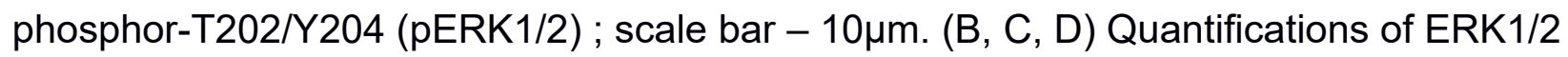
phosphor-T202/Y204 intensities in whole cells (B), nuclei (C) and cytoplasm (D) as in (A); 100 cells in 3 independent experiments; two-way ANOVA with Dunnett's post hoc test, $p<0.05$. (E) Representative western blot analysis of cells as in $(A)$, stained for ERK $1 / 2$ phosphor-T202/Y204, total ERK1/2, and GAPDH. (F) Quantifications of ERK1/2 phosphor-T202/Y204 bands intensities, as in (E).

Fig. 3. Loss of cilium promotes decreased AKT phosphorylation in response to serum stimulation. 
(A) Experiment schematics (top) and representative images of cells stably expressing non-targeting shRNA (Con) or shRNA against IFT88 or KIF3B, stained for acetylated $\alpha$ -

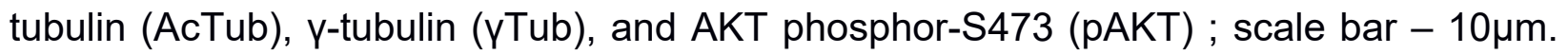
(B, C, D) Quantifications of AKT phosphor-S473 intensities in whole cells (B), nuclei (C) and cytoplasm (D) as in (A); 100 cells in 3 independent experiments; two-way ANOVA with Dunnett's post hoc test, $p<0.05$. (E) Representative western blot analysis of cells as in (A), stained for AKT phosphor-S473, total AKT, and GAPDH. (F) Quantifications of AKT phosphor-S473 bands intensities, as in (E).

Fig. 4. Lysophosphatidic acid promotes proliferation in deciliated astrocytes.

(A) Growth rates of immortalized astrocytes stably expressing non-targeting shRNA (Con) or shRNA against IFT88 or KIF3B in serum-supplemented media (SSM), media supplemented with charcoal-stripped serum (CSSM), or in serum-free conditions (SFM); 3 independent experiments; one-way ANOVA with Dunnett's post hoc test, $p<0.05$. (B) Growth rates of cells as in (A) in serum-supplemented media (SSM), serumsupplemented media supplemented with $10 \mu \mathrm{mol} / \mathrm{L} \mathrm{Ki} 16425$, serum-free media supplemented with $1 \mu \mathrm{mol} / \mathrm{L}$ LPA (SFM LPA), or in serum-free conditions (SFM); 3 independent experiments; one-way ANOVA with Dunnett's post hoc test, $p<0.05$. (C) Experiment schematics (top) and representative western blot analysis of cells as in (A) stained for ERK1/2 phosphor-T202/Y204, total ERK1/2, AKT phosphor-S473, total AKT, and $\alpha$-tubulin. (D) Quantifications of ERK1/2 phosphor-T202/Y204 bands intensities, as in (C). (E) Quantifications of AKT phosphor-S473 bands intensities, as in (C). (F) Growth rates of cells as in (A) SSM, SFM supplemented with $20 \mathrm{ng} / \mathrm{ml} \mathrm{EGF,} \mathrm{20ng/ml} \mathrm{bFGF,} \mathrm{and}$ B27 supplement (SFM-GF), SFM supplemented with 20ng/ml EGF, 20ng/ml bFGF, B27 supplement and $1 \mu \mathrm{mol} / \mathrm{L}$ LPA (SFM-GF LPA), or in serum-free conditions (SFM); 3 independent experiments; one-way ANOVA with Dunnett's post hoc test, $p<0.05$.

Fig. 5. Intracellular localization of LPA signaling cascade components.

(A) Representative images of immortalized astrocytes expressing exogenous 3xFLAG-LPAR1/LPAR3/LPAR6, stained for acetylated a-tubulin (AcTub, cilium marker), y-tubulin (YTub, basal body marker) and FLAG-tag, arrowheads indicate primary cilium; 
scale bar $-10 \mu \mathrm{m}$ (B) Representative images of immortalized astrocytes stained for acetylated a-tubulin (AcTub), $\gamma$-tubulin ( $\left(\gamma T u b\right.$ ), $G a_{s}, G_{q}, G_{12}$ and $G_{\alpha_{i 1}}$, arrowheads indicate primary cilium; scale bar $-10 \mu \mathrm{m}$. (C) Immunoprecipitation of 3xFLAG tagged LPAR1 expressed in immortalized astrocytes stably expressing non-targeting shRNA (Con) or shRNA against IFT88 or KIF3B in serum-free conditions. (D) Schematic of potential mechanism of primary cilium restrictive action on the proliferative component of LPA signaling.

Fig. 6. Inhibition of LPA signaling suppresses proliferation of GBM PDXs in vivo.

(A) Representative images of mice subcutaneously injected with GBM6 (left panel) and GBM12 (right panel) and administered with vehicle or 30 mg/kg/day Ki16425. (B, C) Analysis of tumor growth as in (A) for GBM6 (B) and GBM12 (C); 5 mice per group; twoway ANOVA with Sidak's post hoc test, p<0.05. (D, E) Analysis of GBM6 (D) and GBM12 (E) terminal tumor weight; 5 tumors per group; Student's t-test, $p<0.05$. $(F, G)$ Representative images of GBM6 (F) and GBM12 (G), stained with DAPI; arrowheads

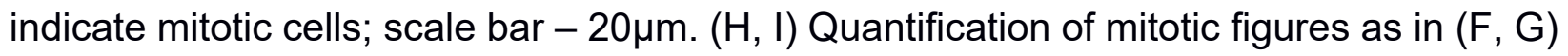
for GBM6 (H) and GBM12 (I); at least 1000 cells within 10 random fields per group; Student's t-test, $p<0.05$.

Fig. 7. Targeted brain delivery of Ki16425 suppresses GBM PDX growth in an intracranial model.

(A) Representative MRI images of mice bearing intracranially grafted GBM12 throughout the treatment with PEG-PLGA nanoparticles loaded with Ki16425 (30mg/kg twice a day); scale bar $-5 \mathrm{~mm}$. (B) Analysis of tumor growth as in (A); 5 mice per group; two-way ANOVA with Sidak's post hoc test, $p<0.05$. (C) Quantification of mitotic figures as in (D); at least 1000 cells within 10 random fields per group; Student's t-test, $p<0.05$. (D) Representative images of tumors from (A), stained with DAPI; arrowheads indicate mitotic cells; scale bar $-20 \mu \mathrm{m}$. 

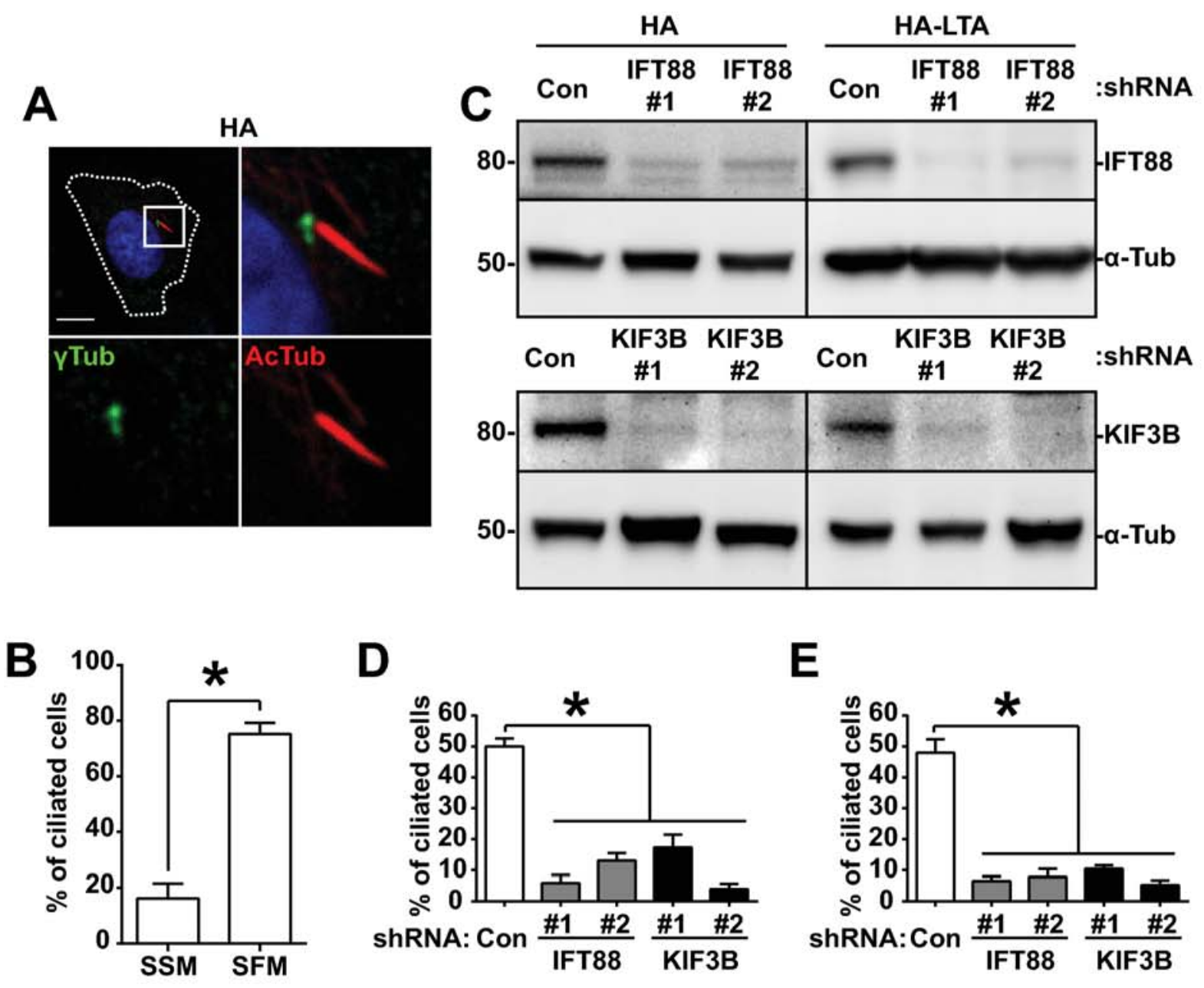

D

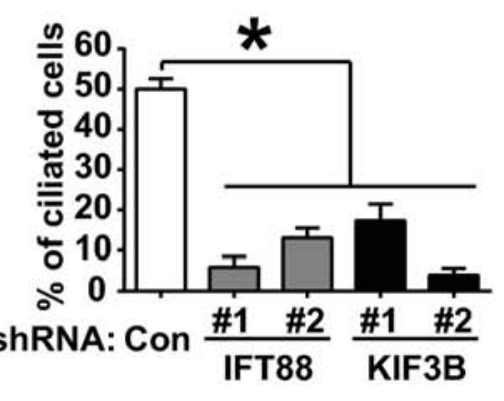

E
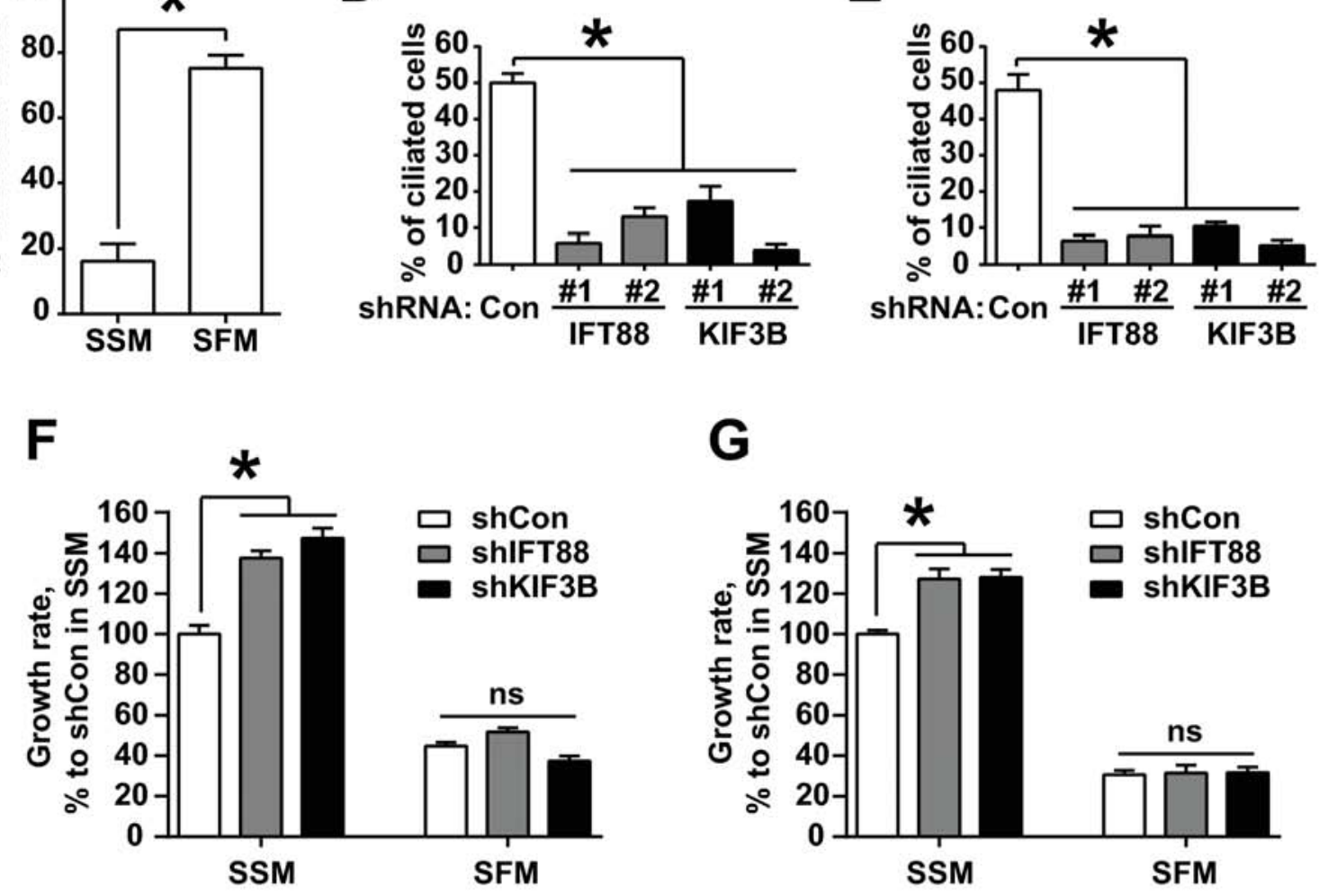

Figure 1. Loskutov 

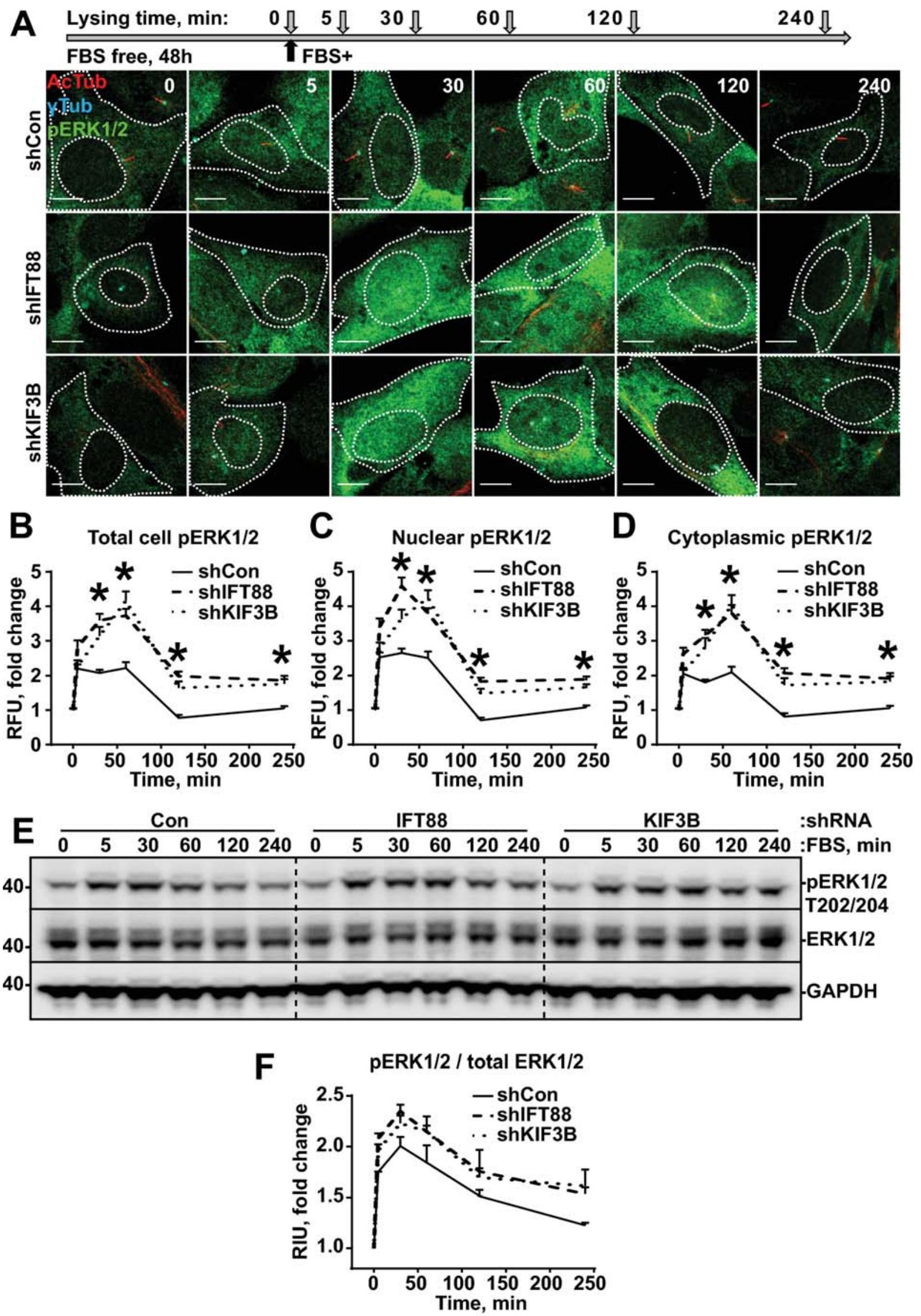
A Lysing time, min: $\quad 0 \rrbracket \quad 5 \rrbracket \quad 30 \rrbracket \quad 60 \rrbracket \quad 120 \rrbracket \quad 240 \rrbracket$
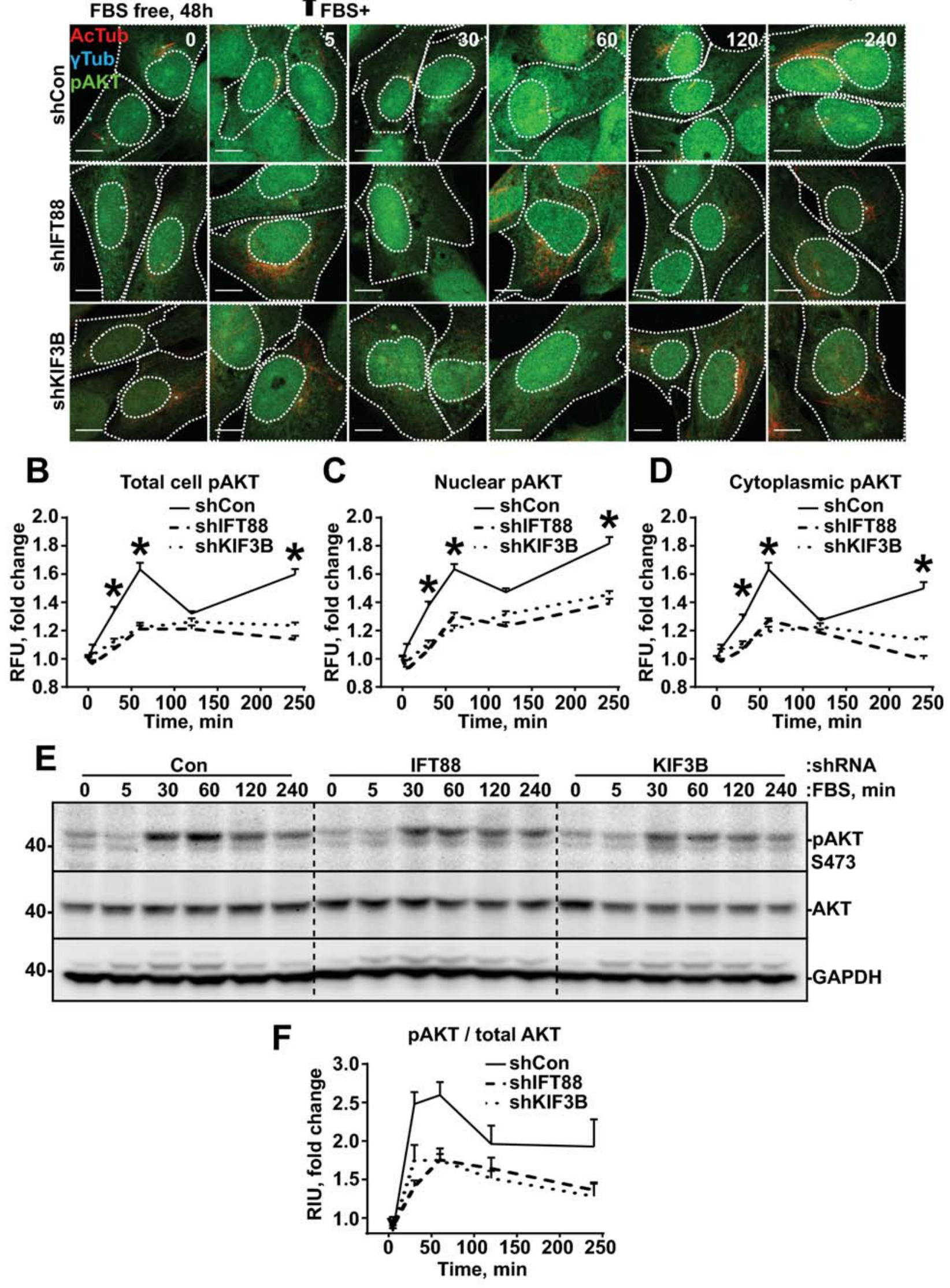

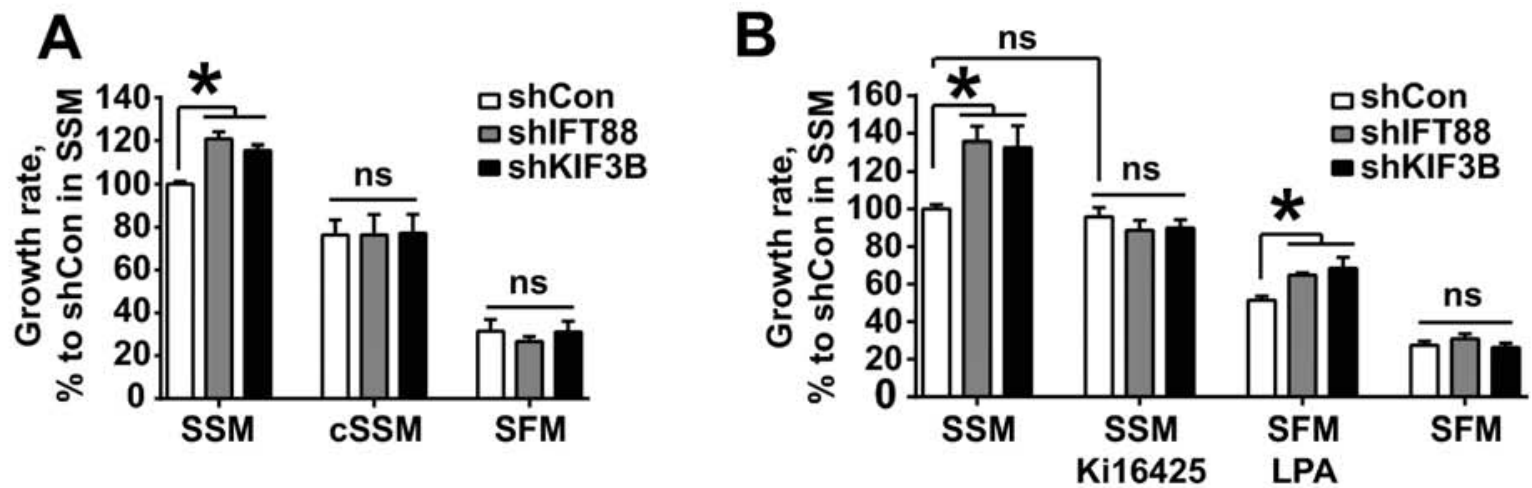
C Lysing time, min: $\quad 0 \rrbracket \quad 5 \rrbracket \quad 30 \rrbracket \quad 60 \rrbracket \quad 120 \rrbracket \quad 240 \rrbracket$ FBS free, 48h TLPA, $1 \mu \mathrm{h}$
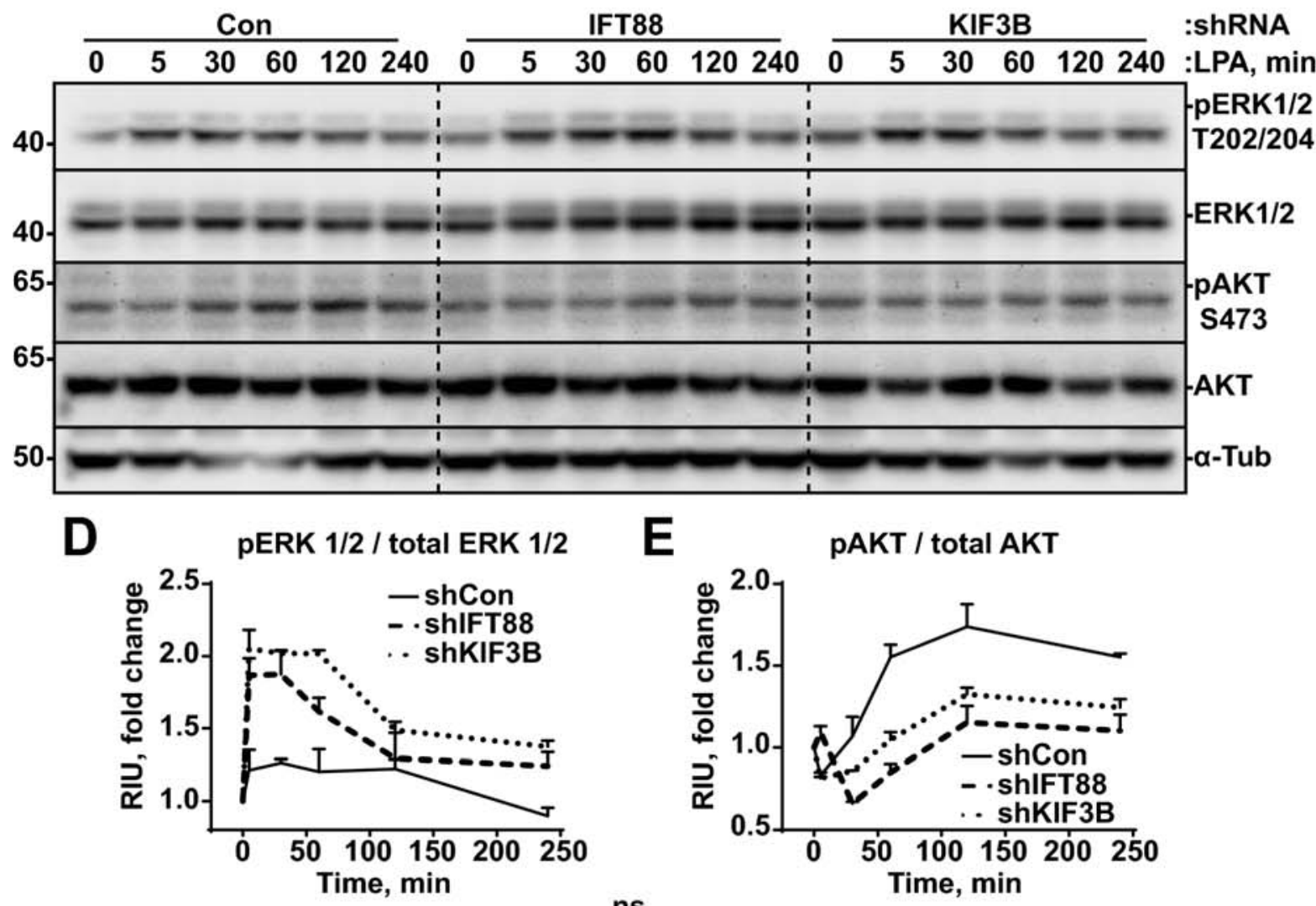

E
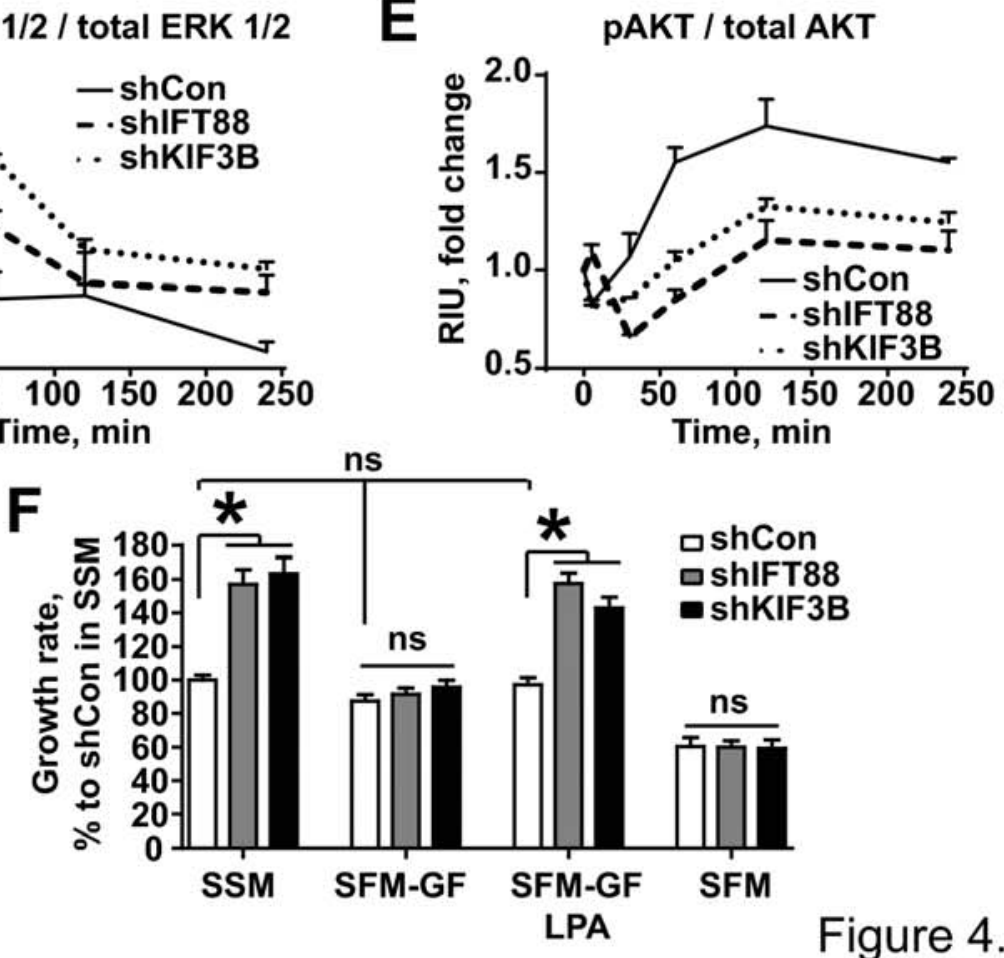

Figure 4. Loskutov 


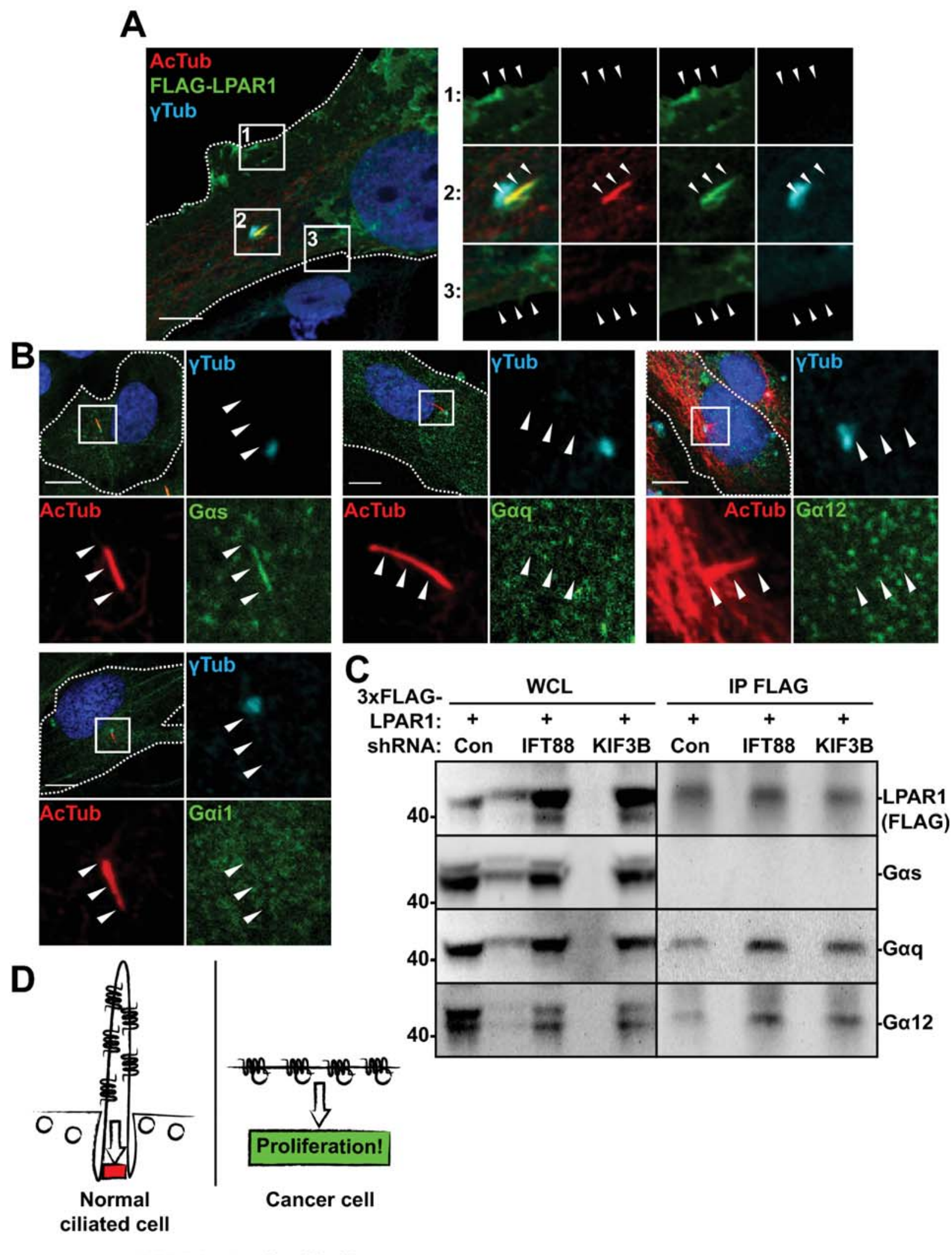

רm- LPAR1 O-Gaq/Ga12

Figure 5. Loskutov 
A
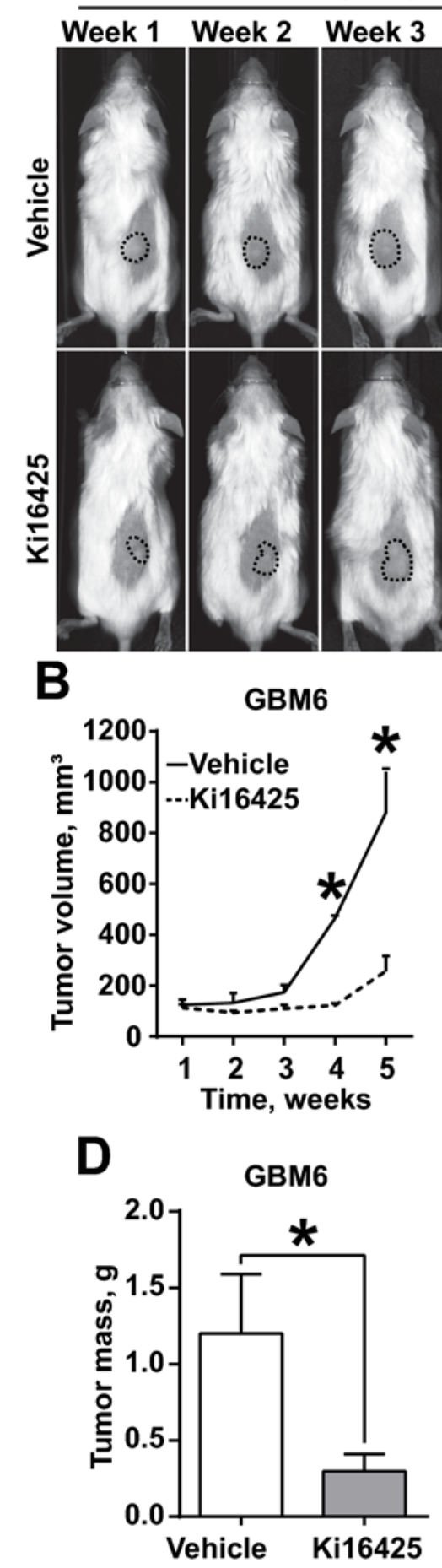

H

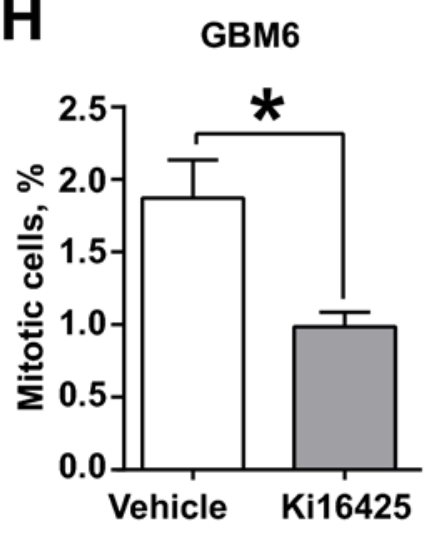

Week 4 Week 5

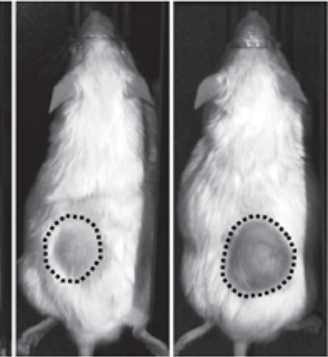

$\frac{\frac{0}{0}}{\frac{0}{5}}$

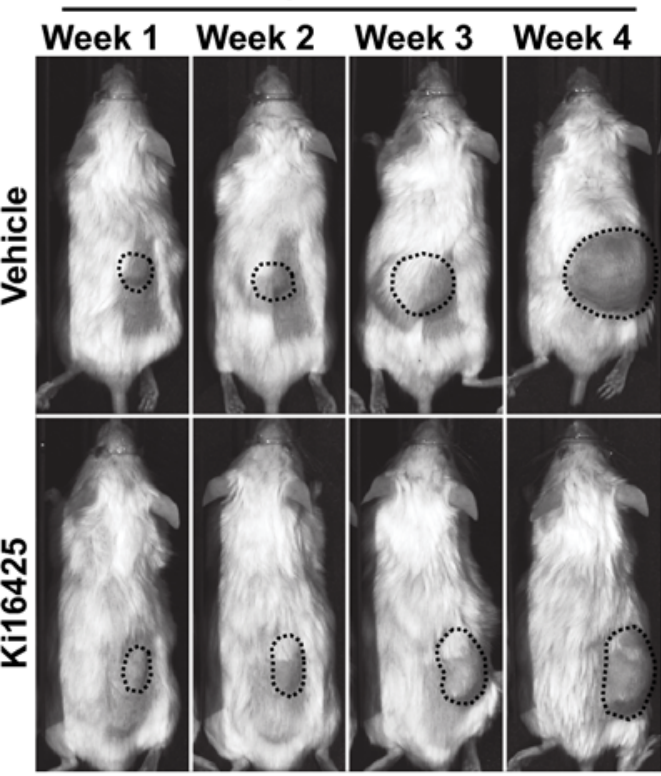

C

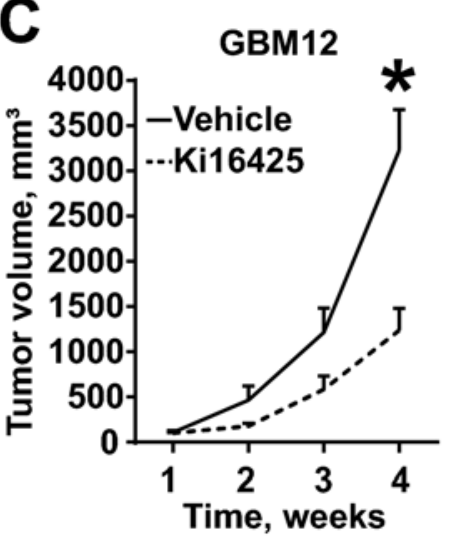

E
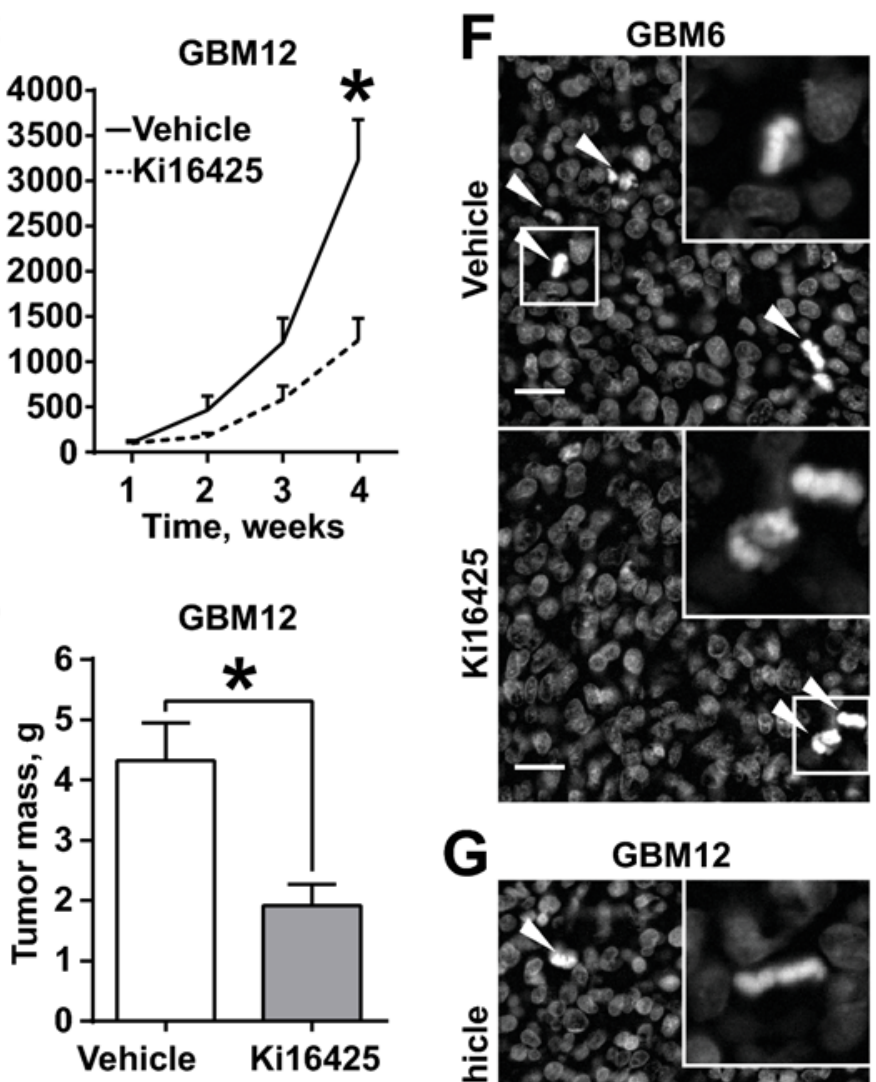

G GBM12
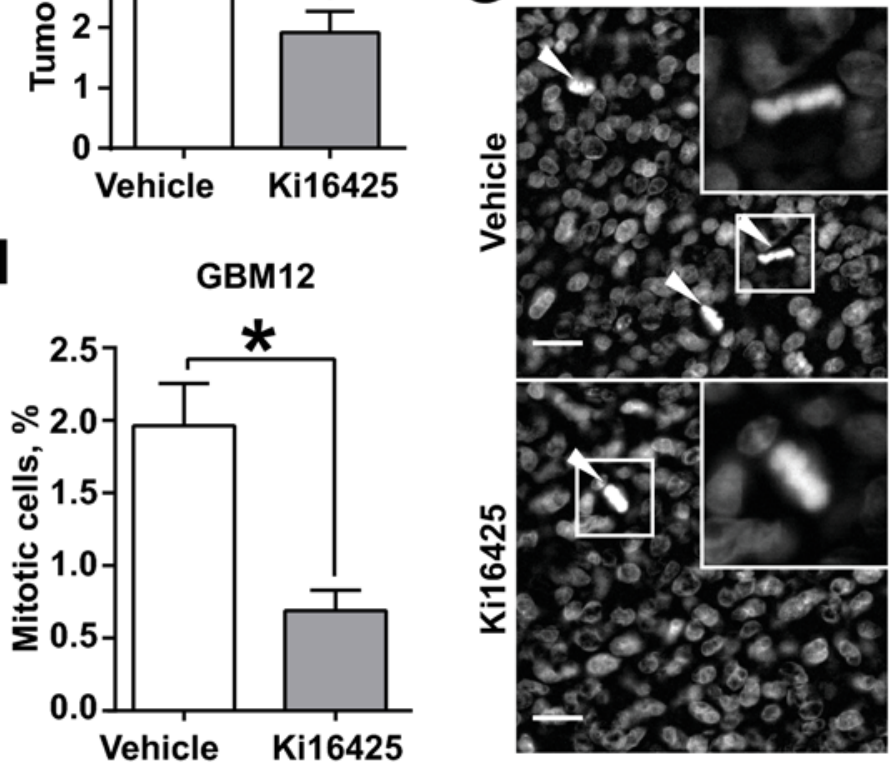

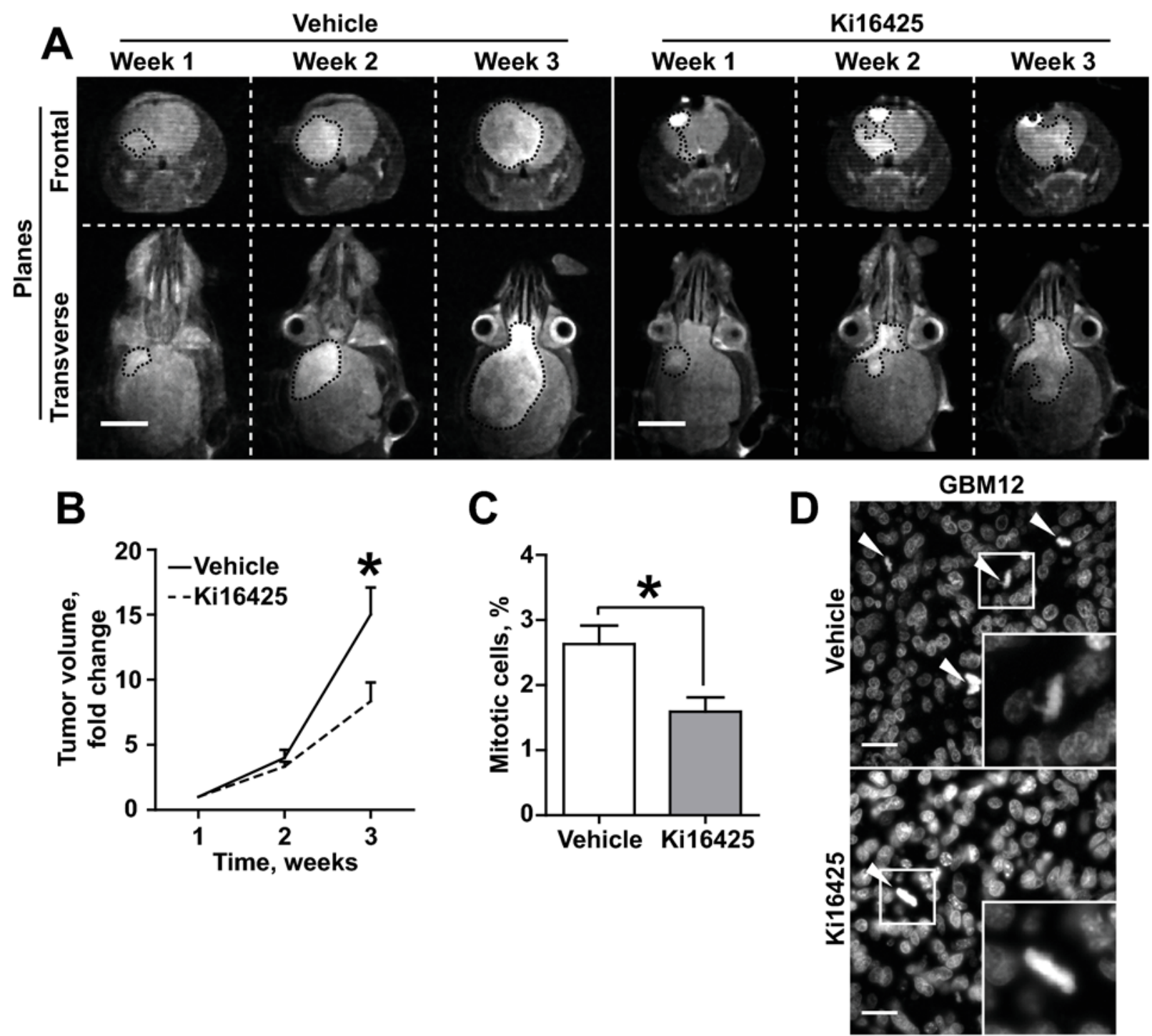

Figure 7. Loskutov 


\section{Supplementary Materials and Methods.}

\section{Generation of CRISPR-Cas9 driven LPAR1 knock out in astrocytes.}

sgRNA targeting LPAR1 were designed using Broad institute web tool: https://portals.broadinstitute.org/gpp/public/analysis-tools/sgrna-design; synthesized as separate oligo nucleotides and cloned into pLentiCRISPR v2 (1) (a gift from Feng Zhang (Addgene plasmid \# 52961)). Lentiviral particles were produced as previously described (2). Immortalized astrocytes were infected and selected on $1 \mu \mathrm{g} / \mathrm{ml}$ of puromycin until stable clones were formed. Individual cloned were established and tested for LPAR1 expression.

1. Sanjana NE, Shalem O, Zhang F. Improved vectors and genome-wide libraries for CRISPR screening. Nature methods. 2014;11(8):783-4.

2. Pugacheva EN, Jablonski SA, Hartman TR, Henske EP, Golemis EA. HEF1dependent Aurora A activation induces disassembly of the primary cilium. Cell. 2007;129(7):1351-63. 
A

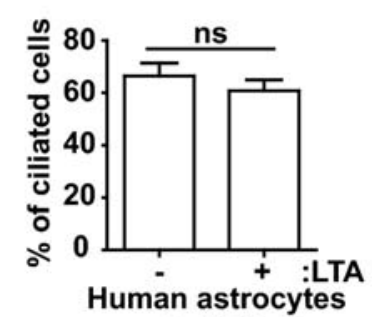

in SFM
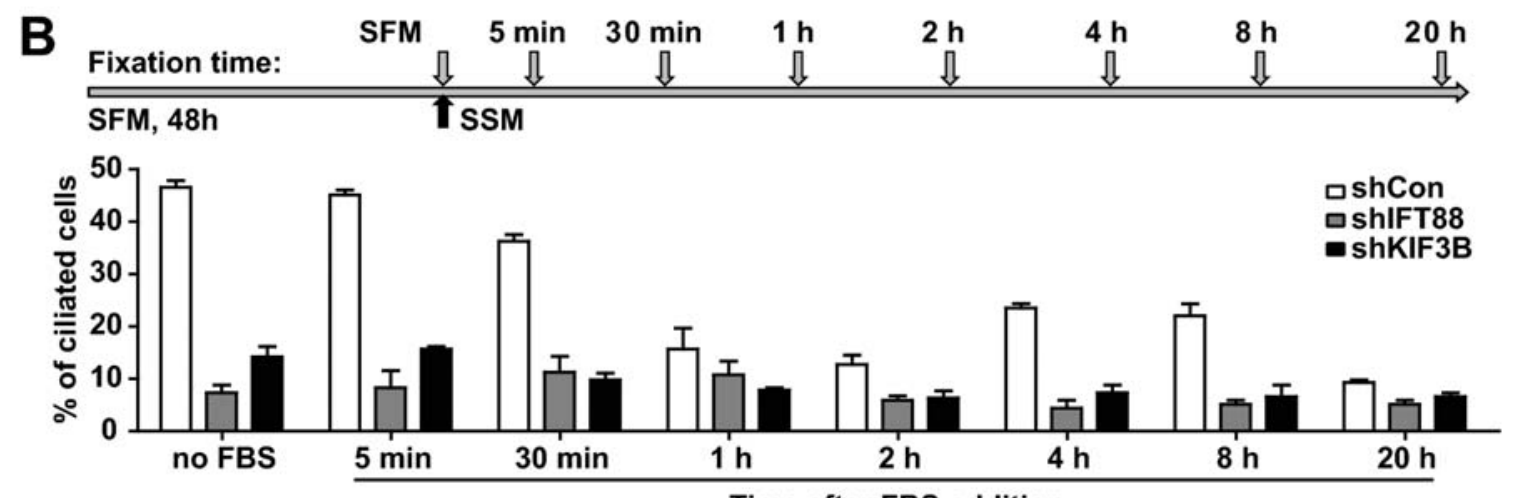

Time after FBS addition

Primary cilia formation in human astrocytes and astrocytes immortalized with large T antigen.

A. Quantification of primary cilia in human astrocytes and human astrocytes immortalized with large T antigen (LTA) in serum-free media (SFM) as in Fig.1 A-B; two-tailed Student's $t$-test, $n=3,100$ cells per experiment. B. Quantification of primary cilia over time in HA-LTA constitutively expressing shCon, shIFT88 or shKIF3B, pre-incubated for 48h with serum-free media (SFM) and stimulated with serum-supplemented media (SSM); experimental design on top, $\mathrm{n}=3$, per time point.

Supplementary Figure 1. Loskutov 


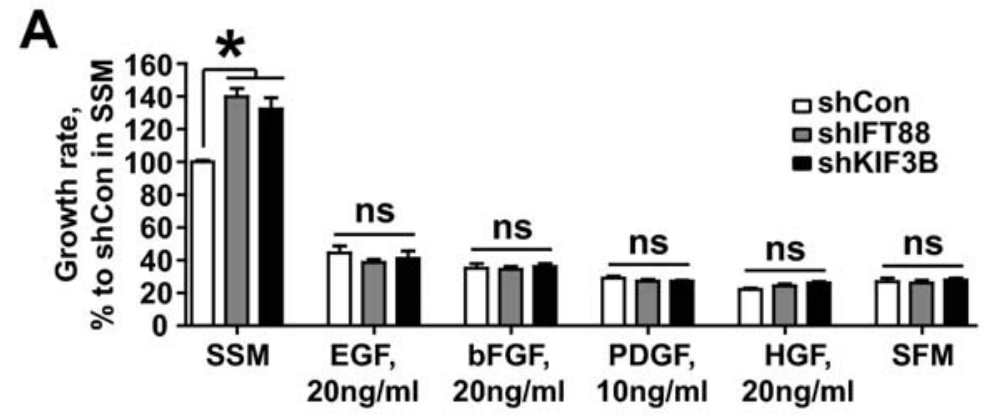

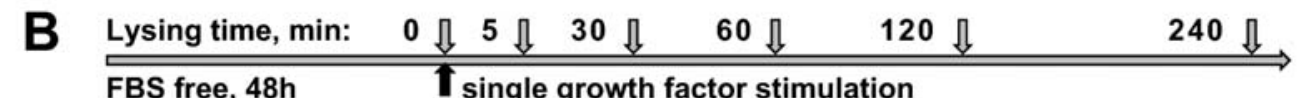

ShRNA: $\quad$ Con $\quad$ IFT88

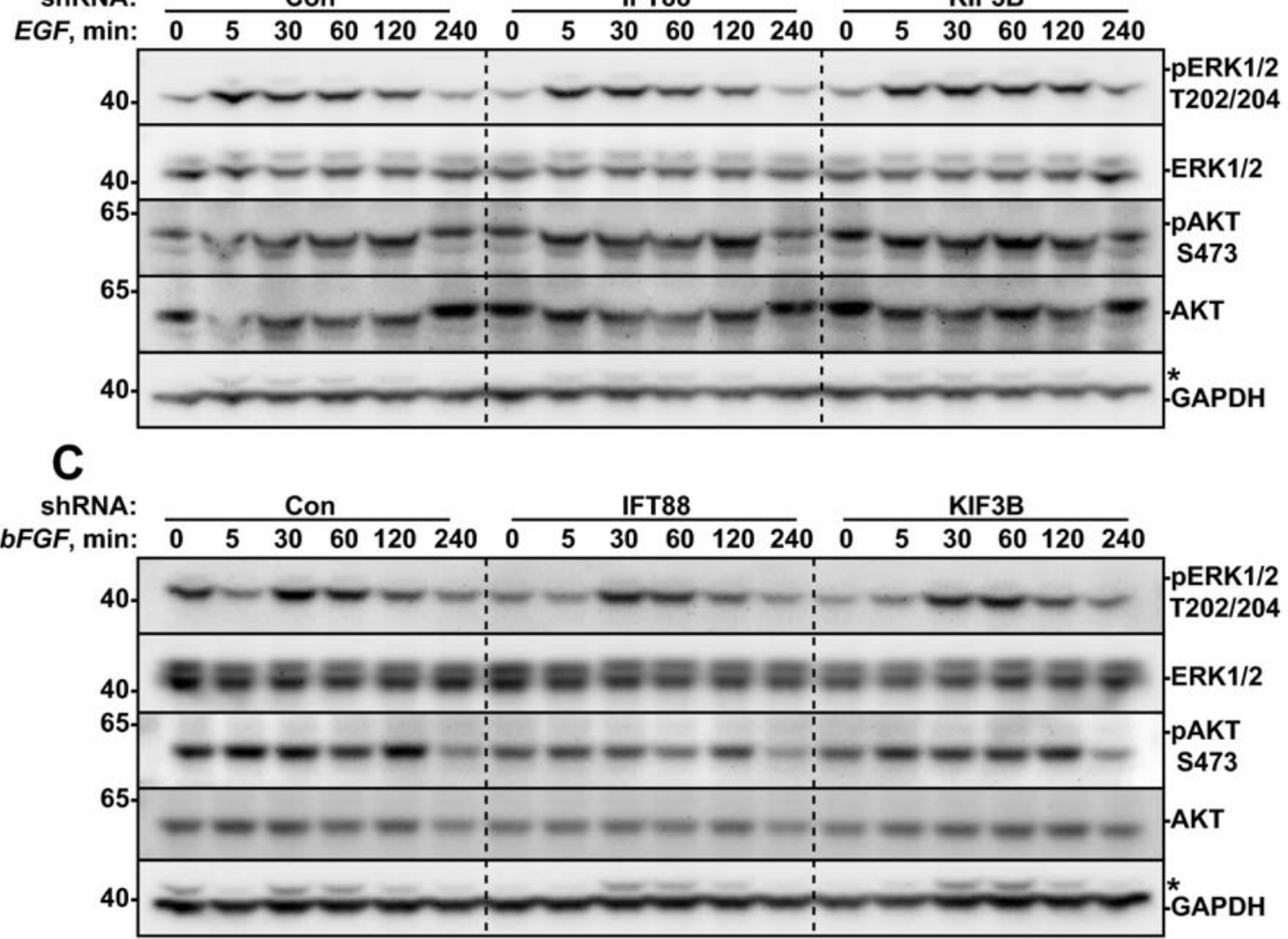

Proliferation and ERK1/2 and AKT phosphorylation in response to single growth factor stimulation of HA-LTA.

A. Growth rate of HA-LTA with intact (shCon) or impaired (shIFT88, shKIF3B) ciliogenesis in serum-supplemented media (SSM), serum-free media (SFM) or SFM supplemented with indicated single growth factors. One-way ANOVA with Dunnett's post hoc test, " $p<0.05 ; n=3$. B, C. Representative western blot of response to single growth factor stimulation for cells as in A. Experimental set up shown in top B: serum-starved cells were treated with $20 \mathrm{ng} / \mathrm{ml}$ of EGF (bottom B), 20ng/ml of bFGF (C), lysed in time-dependent manner; and stained with antibodies against Thr202/Tyr204 phosphorylated ERK1/2 (pERK1/2 T202/204), total ERK1/2, Ser473 phosphorylated AKT (pAKT S473), total AKT and GAPDH, as a loading control. * indicates bleed-through of pERK1/2 signal. 


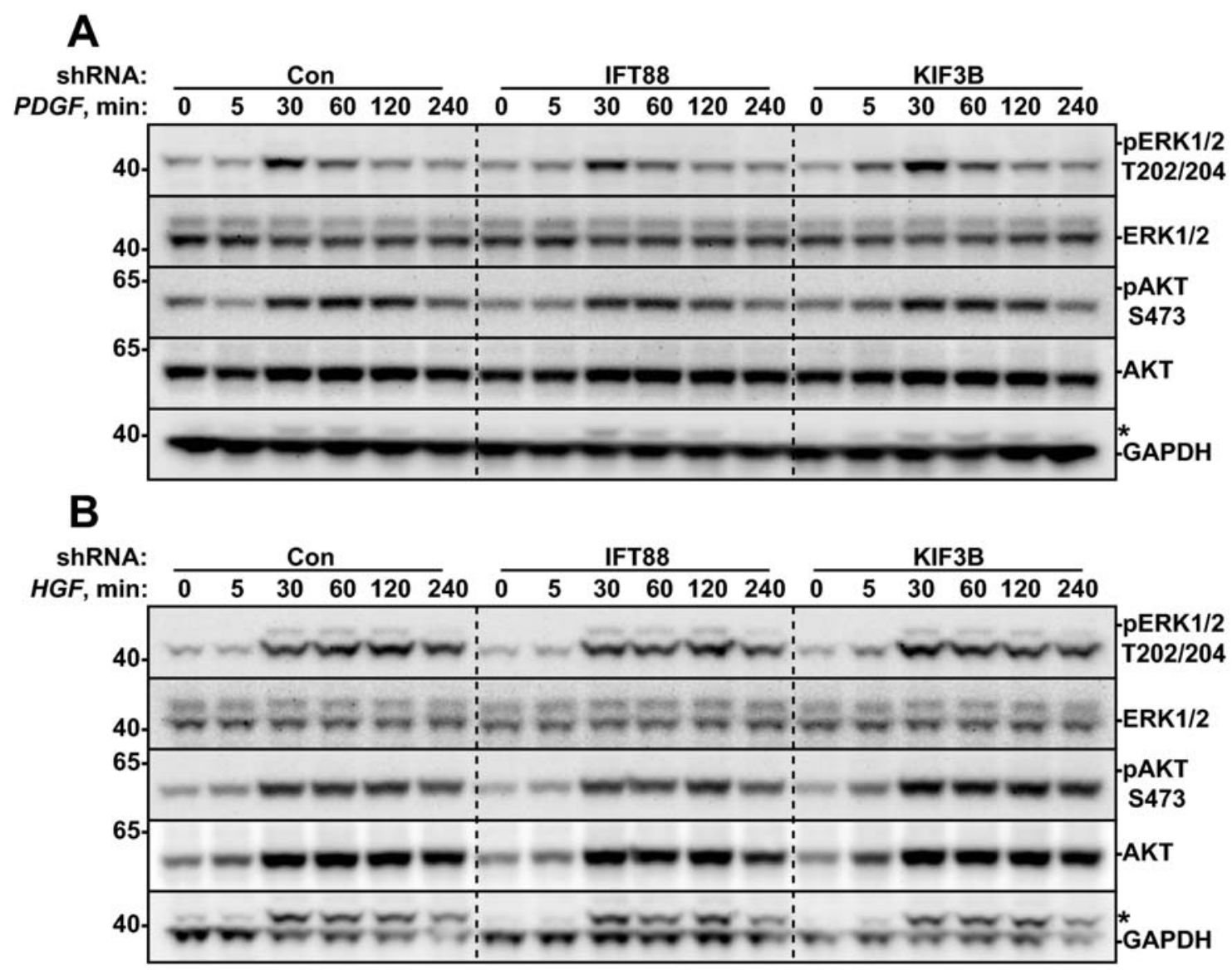

Proliferation and ERK1/2 and AKT phosphorylation in response to single growth factor stimulation of HA-LTA.

A, B. Representative western blot of response to single growth factor stimulation for cells as in Fig.S2A. Experimental set up shown in top Fig.S2B: serum-starved cells were treated with $10 \mathrm{ng} / \mathrm{ml}$ of PDGF-AB (A), or $20 \mathrm{ng} / \mathrm{ml}$ of HGF (B), lysed in time-dependent manner; and stained with antibodies against Thr202/Tyr204 phosphorylated ERK1/2 (pERK1/2 T202/204), total ERK1/2, Ser473 phosphorylated AKT (pAKT S473), total AKT and GAPDH, as a loading control. * indicates bleed-through of pERK1/2 signal. 

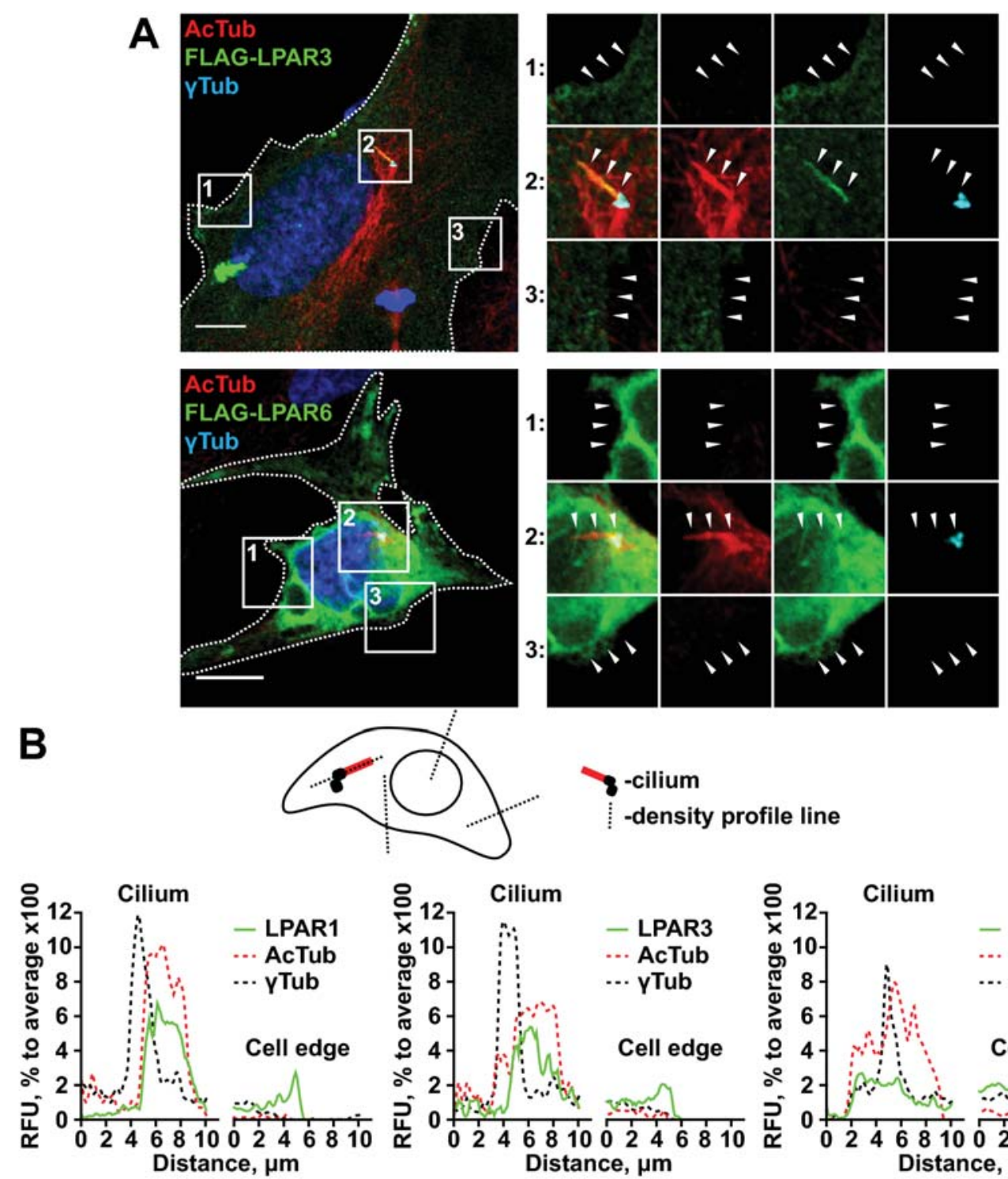

B

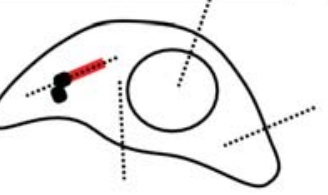

8 -cilium

-density profile line
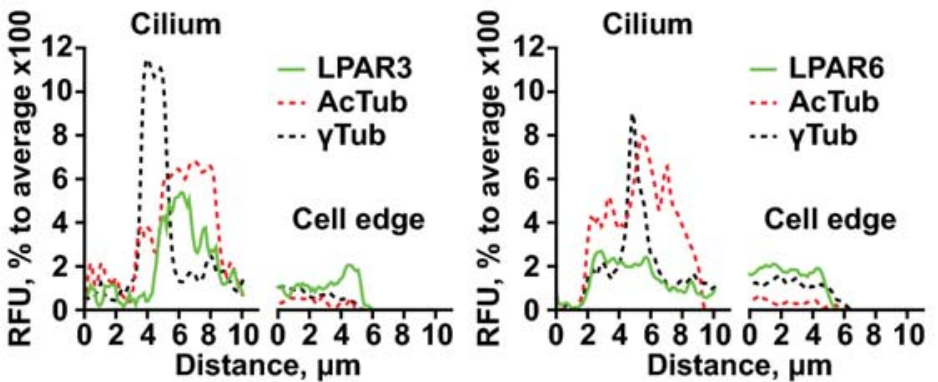

LPAR1, 3 and 6 subcellular localization in cells with assembled primary cilium.

A. Representative images of cells with primary cilia expressing 3xFLAG LPAR3 and LPAR6, stained for FLAG-tag, acetylated $\alpha$-tubulin (AcTub, cilia marker) and $\gamma$-tubulin ( $ү$ Tub, centriole/basal body marker). Scale bar - 10 $\mu$ m. B. Signal intensity profile of the primary cilium and cell edge regions of cell in A and Fig.5A, as shown in pictogram on top.

Supplementary Figure 4. Loskutov 

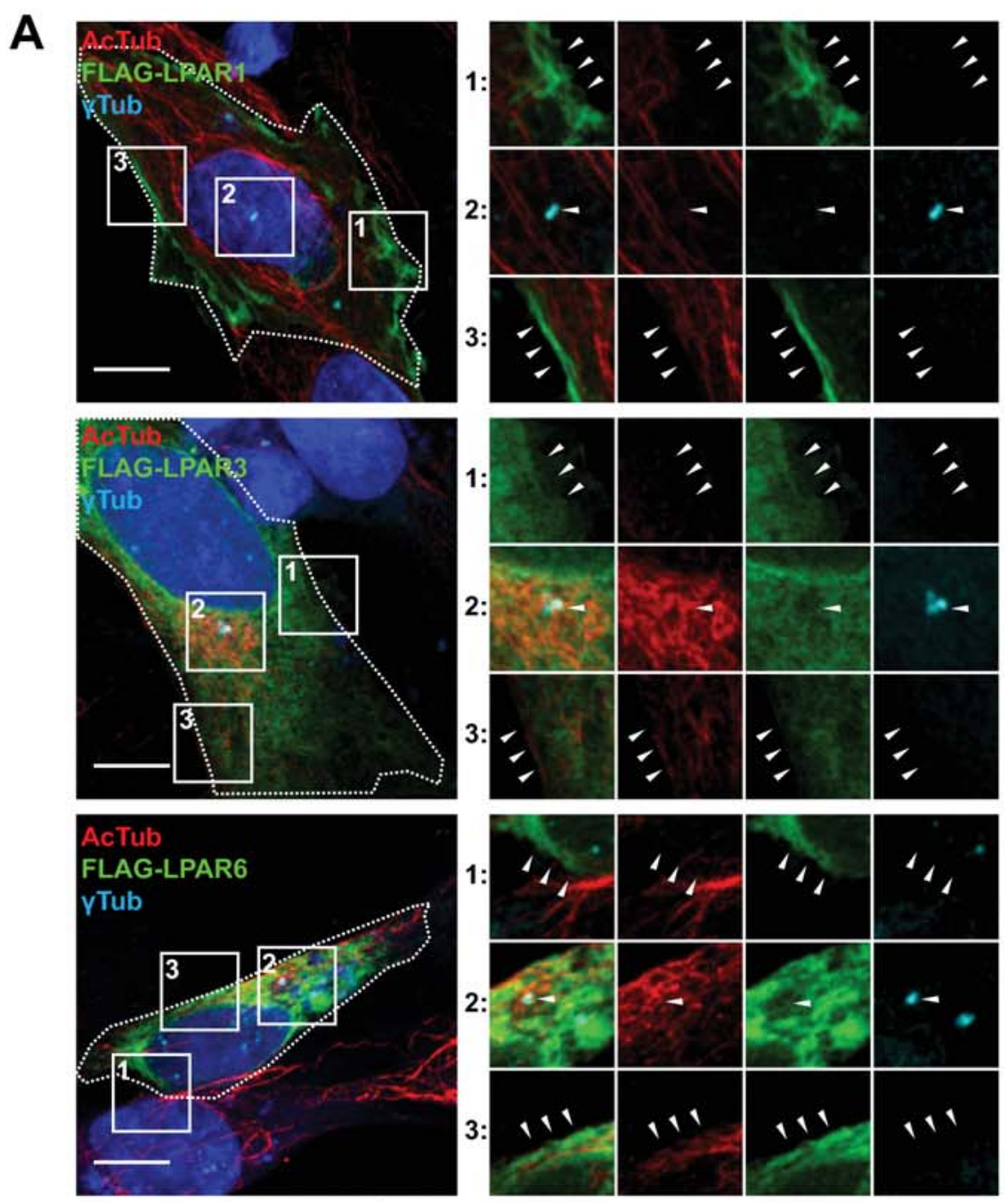

B

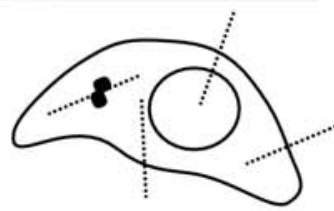

\section{8 -centriole}

-density profile line
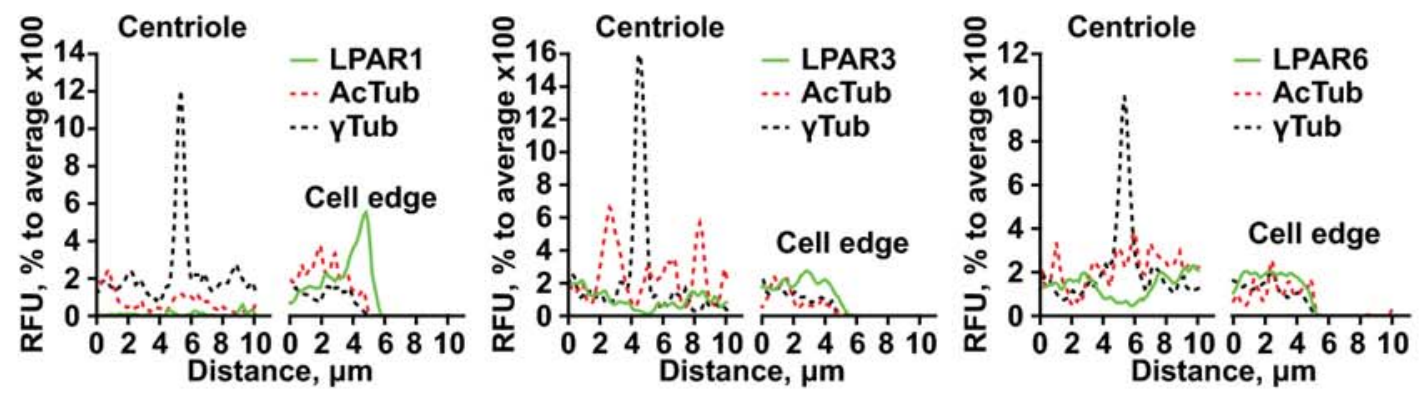

LPAR1, 3 and 6 subcellular localization in cells with disassembled primary cilium.

A. Representative images of cells w/o primary cilia expressing 3xFLAG tagged LPAR1, LPAR3 and LPAR6, stained for FLAG-tag, acetylated a-tubulin (AcTub, cilia marker) and $\gamma$-tubulin ( $\gamma$ Tub, centriole/basal body marker). Scale bar $-10 \mu \mathrm{m}$. B. Signal intensity profile of the centriole and cell edge regions of cell in A, as shown in pictogram on top. 


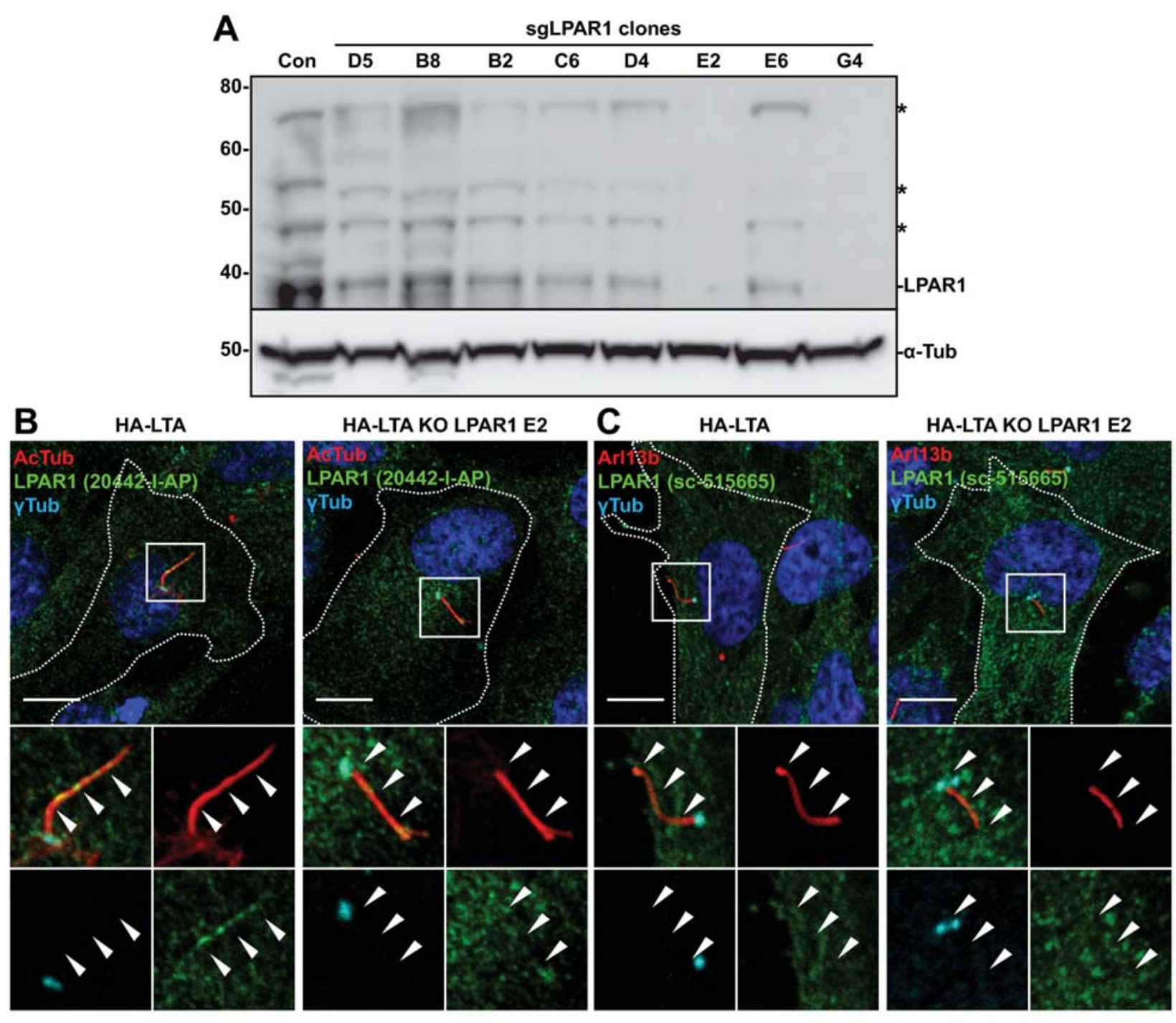

LPAR1 antibodies validation for immunofluorescent staining.

A. Western blot of CRISPR-Cas9 induced knockout of LPAR1 in immortalized astrocytes (HA-LTA) stably expressing sgRNA (Con) or sgRNA against LPAR1. * indicates glycosylated forms of LPAR1. B-C. Representative image of HA-LTA, stained for acetylated $\alpha$-tubulin (AcTub, cilium marker; B) or Arl13b (cilium marker; C), $y$-tubulin ( $y$ Tub, basal body marker) and LPAR1 (B - Proteintech 20442-I-AP, C - SantaCruz sc-515665); scale bar - 10 $\mu$ m.

Supplementary Figure 6. Loskutov 

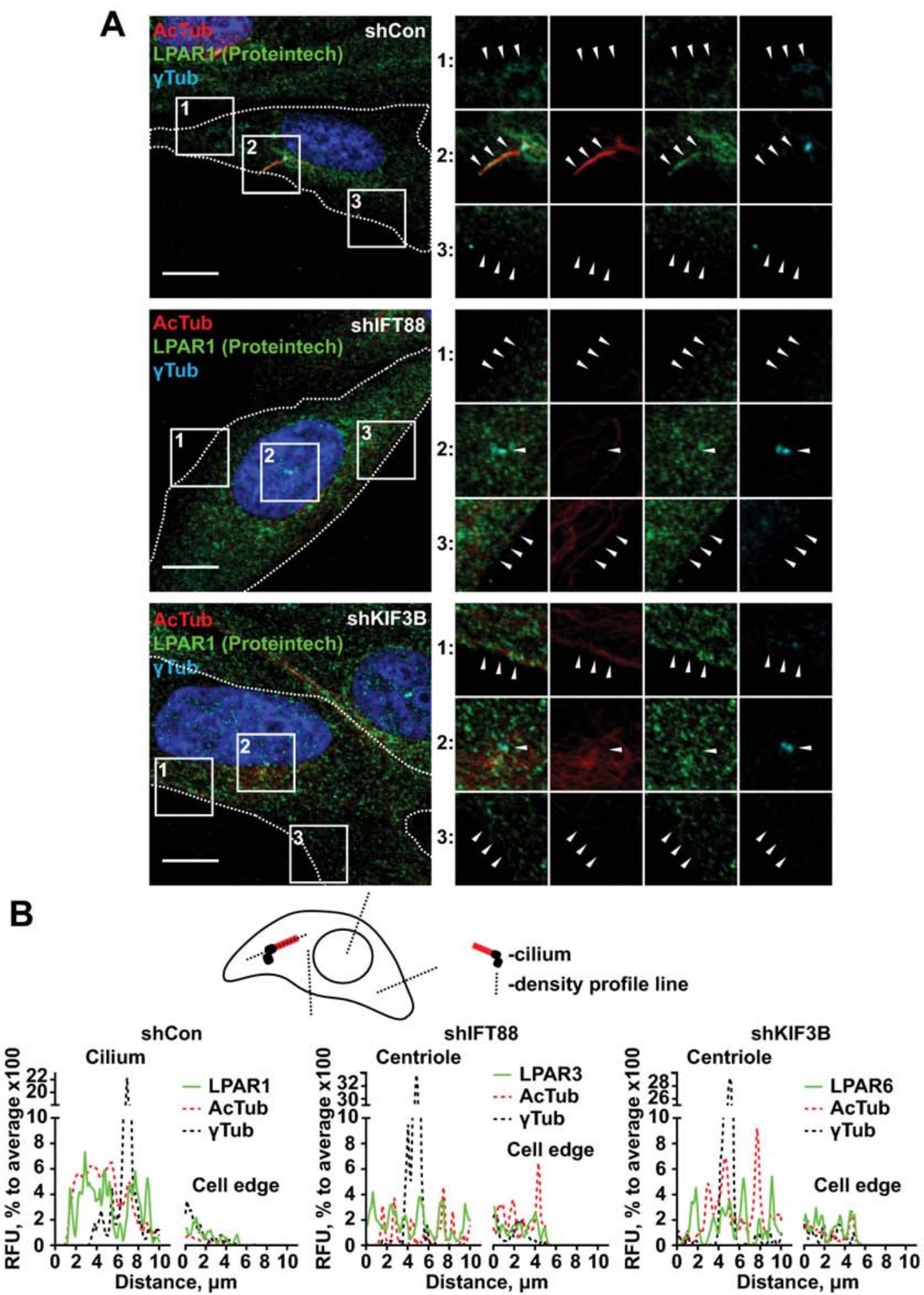

Endogenous LPAR1 localization in cells with and without primary cilium.

A. Representative images of HA-LTA with intact (shCon) or impaired (shIFT88, shKIF3B), stained for LPAR1, acetylated $\alpha$-tubulin (AcTub, cilia marker) and $\gamma$-tubulin ( $\gamma$ Tub, centriole/basal body marker). Scale bar - 10 $\mu$ m. B. Signal intensity profile of the cilium/centriole and cell edge regions of cells in $\mathbf{A}$, as shown in pictogram on top. 

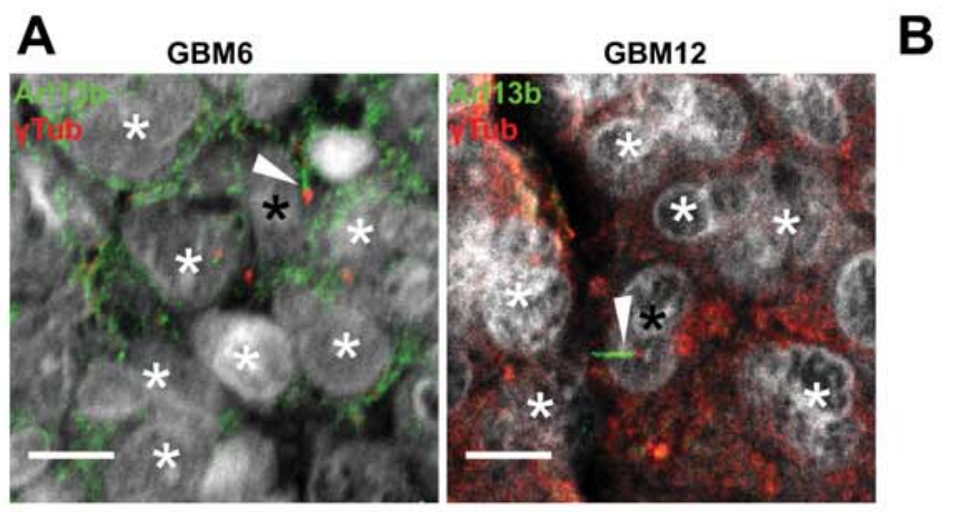

\section{Primary cilia in GBM PDXs}
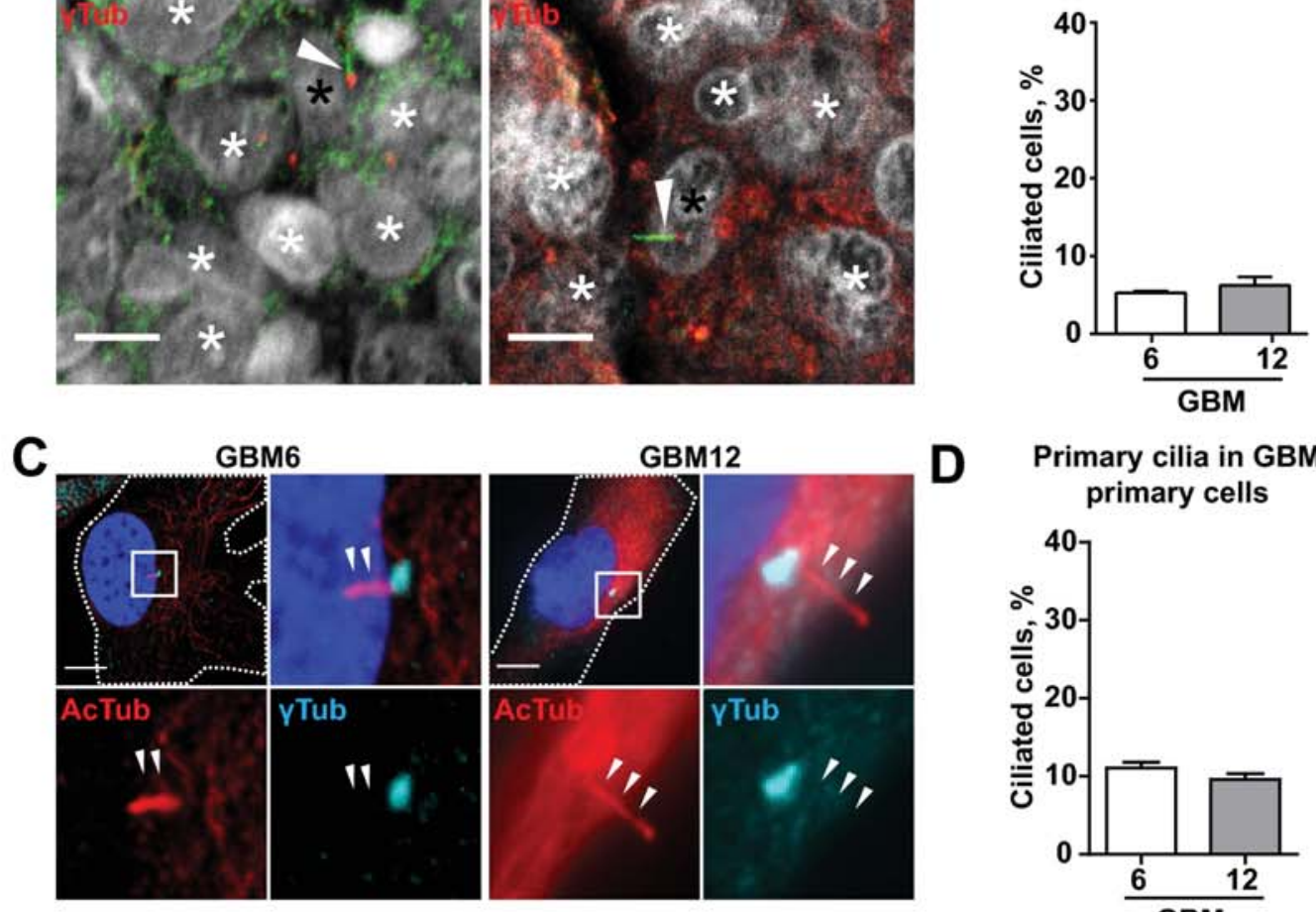

Primary cilia in GBM primary cells
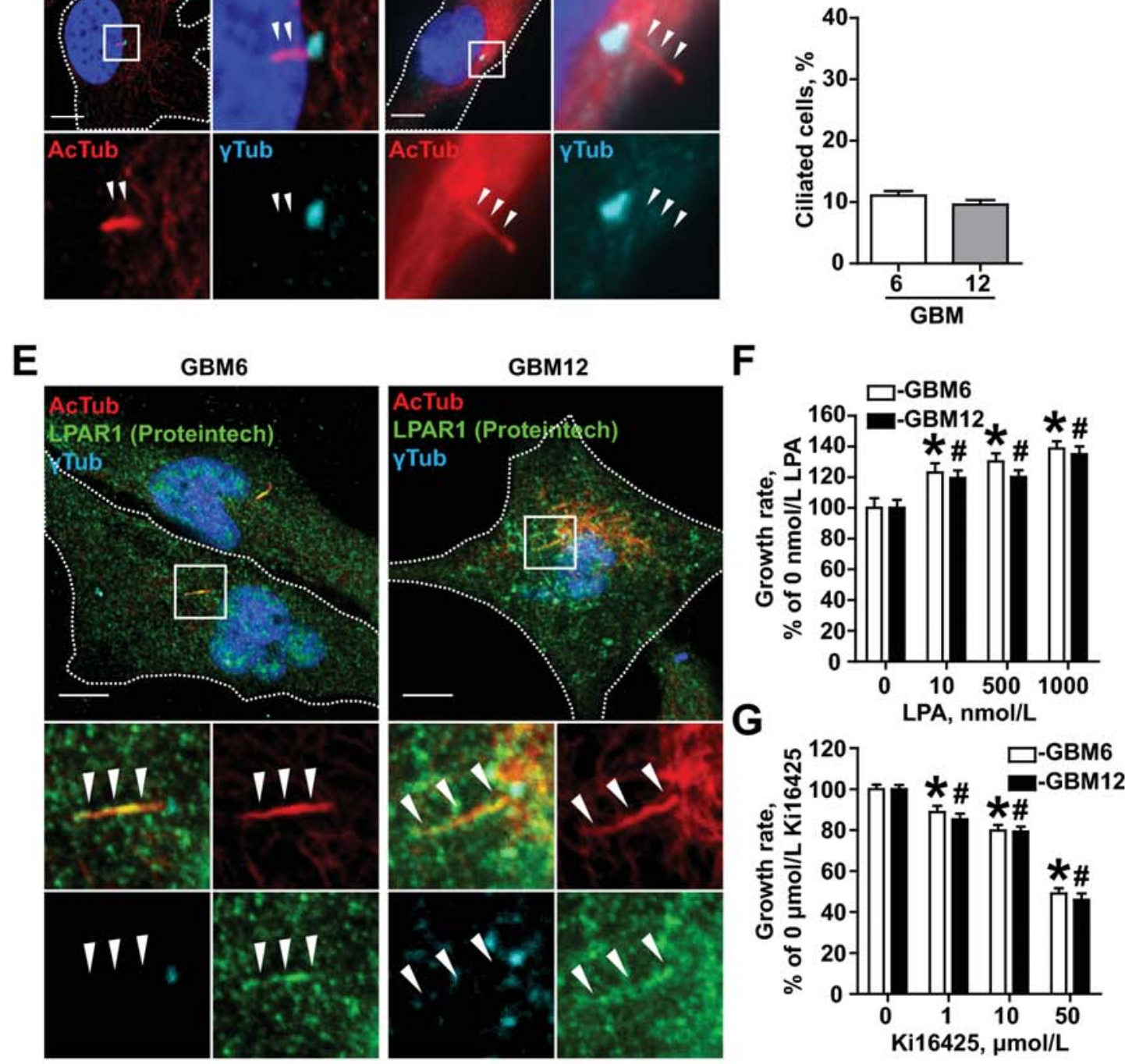

GBM6 and GBM12 have decreased ciliation and utilize LPA as a growth factor.

A. Representative images of GBM6 and GBM12 PDXs stained for Arl13b (marker of cilia) and $\gamma$-tubulin ( $\gamma$ Tub, marker of centriole/basal body). Arrows indicate primary cilia, black asterisks - ciliated cells, white asterisks - decili-

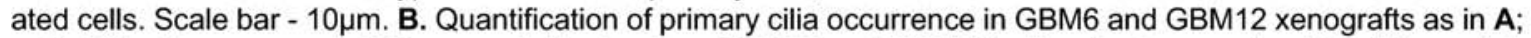
$n=3,100$ cells per group. C. Representative images of GBM6 and GBM12 cultured primary cells stained for acetylated $\alpha$-tubulin (AcTub, marker of cilia) and $\gamma$-tubulin ( $\gamma$ Tub, marker of centriole/basal body). Arrows indicate primary

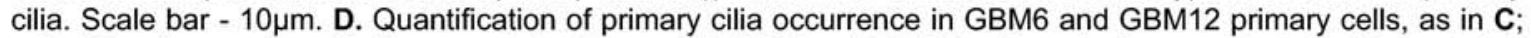
$n=3,100$ cells per group. E. Representative images of GBM6 and GBM12 cultured primary cells stained for acetylated a-tubulin (AcTub, marker of cilia), LPAR1 and $y$-tubulin ( $\gamma$ Tub, marker of centriole/basal body). Arrows indicate primary cilia. Scale bar - 10 $\mu \mathrm{m}$. F. Growth rate of GBM6 and GBM12 primary cells in serum-free media supplemented with $20 \mathrm{ng} / \mathrm{ml}$ of EGF, $20 \mathrm{ng} / \mathrm{ml}$ of bFGF, B27 supplement and indicated concentrations of LPA. One-way ANOVA with Dunnett's post hoc test; ${ }^{*}, " p<0.05$ for GBM6 and GBM12 respectively, compared to no LPA control; $n=3$. G. 


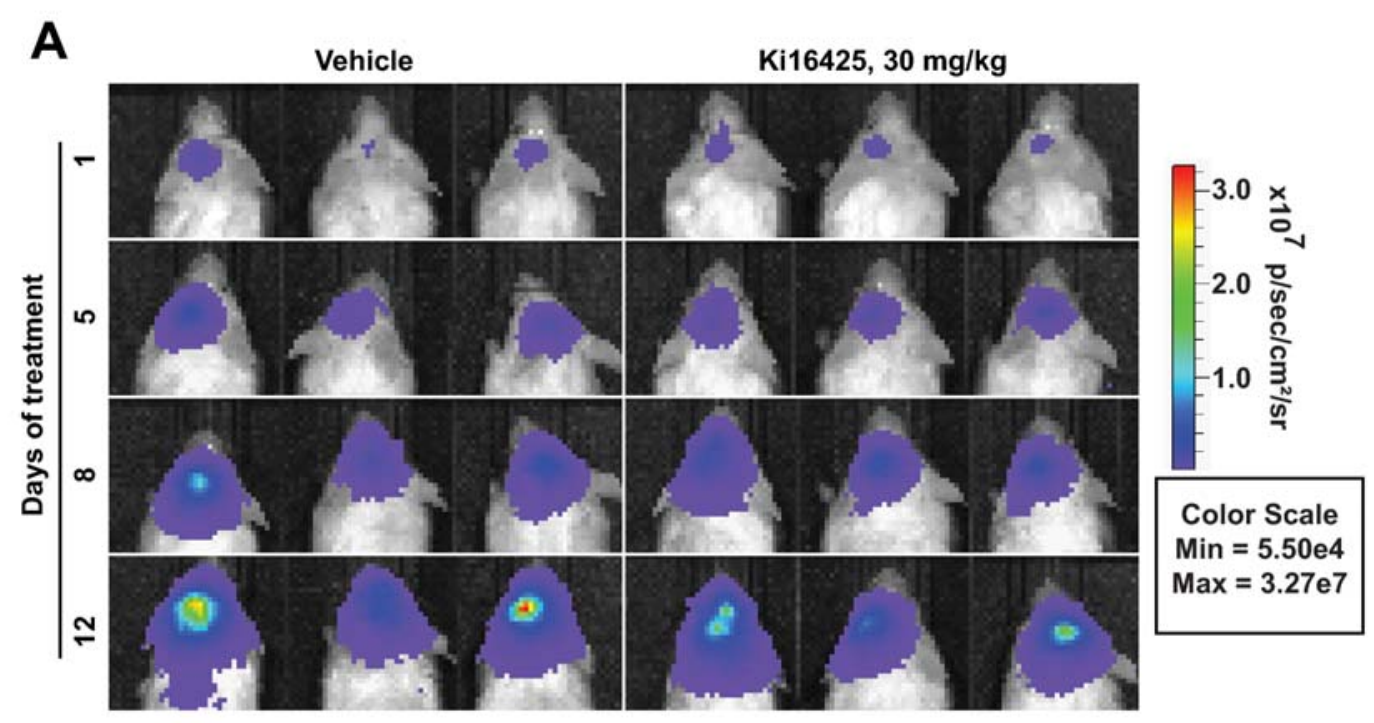

B

\begin{tabular}{llrr} 
C & \multicolumn{3}{r}{ Time post PEG-PLGA nanoparticle injection, $h$} \\
\cline { 2 - 4 } & 1 & 2 & 4
\end{tabular}
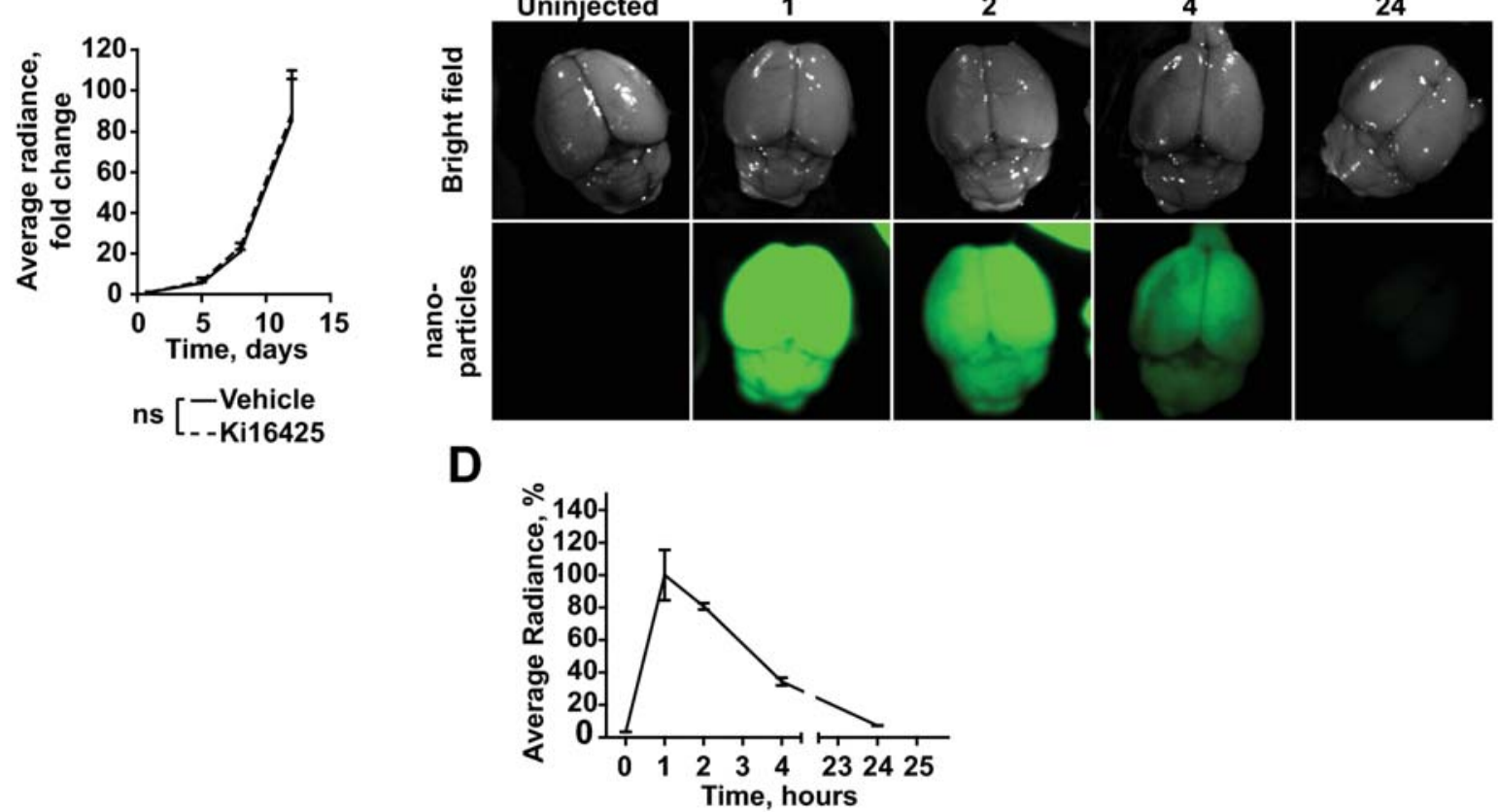

Administration of Ki16425 has no effect on intracranial tumor growth.

A. Representative images of GBM12 growing in brains of mice treated with Vehicle-control or Ki16425. B. Quantification of bioluminescence, as in A; two-way ANOVA, Tukey post hoc test; $n=5$. C. Representative images of mice brains injected with PEG-PLGA nanoparticles loaded with fluorescent dye. D. Quantification of fluorescence from brains as in $\mathrm{C} ; \mathrm{n}=2$. 


\begin{tabular}{|c|c|c|c|c|c|}
\hline target & cat.\# & $\begin{array}{c}\text { host } \\
\text { species }\end{array}$ & company & application & dilution \\
\hline $\begin{array}{c}\text { acetyated } \\
\text { alpha tubulin }\end{array}$ & T6793 & mouse & Sigma & $\mathrm{IF}, \mathrm{F}-\mathrm{IHC}$ & $1: 1000$ \\
\hline $\begin{array}{c}\text { acetyated } \\
\text { alpha tubulin }\end{array}$ & $5335 S$ & rabbit & Cell Signaling & IF & $1: 500$ \\
\hline gamma tubulin & sc-7396 & goat & Santa Cruz & $\mathrm{IF}, \mathrm{F}-\mathrm{IHC}$ & $1: 500$ \\
\hline IFT88 & $60227-1-\lg$ & mouse & Proteintech & WB & $1: 1000$ \\
\hline Kif3B & sc-50456 & rabbit & Santa Cruz & WB & $1: 500$ \\
\hline alpha tubulin & 16199 & mouse & Sigma & WB & $1: 40000$ \\
\hline $\begin{array}{l}\text { pERK1/2 } \\
\text { T202/204 }\end{array}$ & 9101 & rabbit & Cell Signaling & IF, WB & $1: 200,1: 1000$ \\
\hline ERK1/2 & 4695 & rabbit & Cell Signaling & WB & $1: 1000$ \\
\hline GAPDH & MAB374 & mouse & Millipore & WB & $1: 80000$ \\
\hline pAKT S473 & AF887 & rabbit & R\&D Systems & IF, WB & $1: 100,1: 500$ \\
\hline AKT & 2920 & mouse & Cell Signaling & WB & $1: 1000$ \\
\hline FLAG & F1804 & mouse & Sigma & IF, WB & $1: 500,1: 1000$ \\
\hline FLAG & PA1-984B & rabbit & $\begin{array}{c}\text { Thermo Fisher } \\
\text { Scientific }\end{array}$ & IF, WB & $1: 500,1: 1000$ \\
\hline G alpha s & sc-135914 & mouse & Santa Cruz & IF, WB & $1: 100,1: 500$ \\
\hline G alpha q & sc-393 & rabbit & Santa Cruz & IF, WB & $1: 200,1: 1000$ \\
\hline G alpha 12 & sc-409 & rabbit & Santa Cruz & $\mathrm{IF}, \mathrm{WB}$ & $1: 100,1: 200$ \\
\hline G alpha i1 & sc-391 & rabbit & Santa Cruz & IF, WB & $1: 100,1: 500$ \\
\hline Arl13b & 17711-1-AP & rabbit & Proteintech & IF, F-IHC & $1: 400,1: 200$ \\
\hline LPAR1 & 20442-1-AP & rabbit & Proteintech & IF & $1: 100$ \\
\hline LPAR1 & 10005280 & rabbit & Cyman chemicals & WB & $1: 250$ \\
\hline LPAR1 & sc-515665 & mouse & Santa Cruz & IF & $1: 100$ \\
\hline
\end{tabular}




\begin{tabular}{|c|c|c|c|c|}
\hline name & clone ID & targeting sequence & vector & company \\
\hline shIFT88\#1 & V3LHS_338157 & GGAATAACACTGACCACCT & pGIPZ & Dharmacon \\
\hline shIFT88\#2 & V3LHS_338155 & AGCATCTGAATACTGACCA & pGIPZ & Dharmacon \\
\hline shKif3B\#1 & V3LHS_644788 & TTGCTAGTCTCTTCTCTCA & pGIPZ & Dharmacon \\
\hline shKif3B\#2 & V3LHS_635533 & ATCTCATCTTCATCCTGCA & pGIPZ & Dharmacon \\
\hline
\end{tabular}

Supplementary table 2 


\begin{tabular}{|c|c|c|}
\hline name & sequence & company \\
\hline $\begin{array}{l}\text { BamHI- } \\
\text { LPAR1 }\end{array}$ & ATTGGATCCATGGCTGCCATCTCTACTTCC & IDT Technologies \\
\hline $\begin{array}{l}\text { LPAR1- } \\
\text { TGA-Xhol }\end{array}$ & ATTCTCGAGTCAAACCACAGAGTGGTCATTGC & Invitrogen \\
\hline $\begin{array}{l}\text { BamHI- } \\
\text { LPAR3 }\end{array}$ & ATTGGATCCATGAATGAGTGTCACTATGACAAGC & IDT Technologies \\
\hline $\begin{array}{l}\text { LPAR3- } \\
\text { TGA-Xhol }\end{array}$ & ATTCTCGAGTCAGGAAGTGCTTTTATTGCAGACTG & Invitrogen \\
\hline $\begin{array}{l}\text { BamHI- } \\
\text { LPAR6 }\end{array}$ & ATTGGATCCATGGTAAGCGTTAACAGCTCC & IDT Technologies \\
\hline $\begin{array}{c}\text { LPAR6- } \\
\text { TGA-Xhol }\end{array}$ & ATTCTCGAGTCAGGCAGCAGATTCATTGTCAAATATC & Invitrogen \\
\hline $\begin{array}{l}\text { ER-3xFlag- } \\
\text { MCS } \\
\text { (forward } \\
\text { strand) }\end{array}$ & $\begin{array}{c}\text { GATCCTAAGCTTACCGGTATGAAGACGATCATCGCCCTGAGCT } \\
\text { ACATCTTCTGCCTGGTATTCGCCATGGACTACAAAGACCATGA } \\
\text { CGGTGATTATAAAGATCATGACATCGATTACAAGGATGACGAT } \\
\text { GACAAGGGAGGTGGAGGCGGTGGAGGATCCTGTACAGCTAG } \\
\text { CGAATTCTGCAGATATCGGCGCGCCGTTTAAACACGCGTCTC } \\
\text { GAGTGATTAATTAAGGTCGACGATCCT }\end{array}$ & Invitrogen \\
\hline sgLPAR1_F & caccgTCTTTGGCTATGTTCGCCAG & Invitrogen \\
\hline $\begin{array}{c}\text { sgLPAR1_ } \\
\text { R }\end{array}$ & aaacCTGGCGAACATAGCCAAAGAc & Invitrogen \\
\hline
\end{tabular}

Supplementary table 3 
Study 2: The role of KIF2C/AURKA signaling in cilia loss and progression of glioblastoma.

Yuriy V. Loskutov, Joshua Arnold, Sila Yanardag, Werner J. Geldenhuys and Elena N. Pugacheva 


\begin{abstract}
The primary cilium is a ubiquitous organelle presented on most human cells. It serves as a crucial signaling hub for multiple pathways including growth factor and G-protein coupled receptors. Loss of primary cilia was observed in various cancers, however, the implications of this event are unclear. Our long-term goal is to delineate the molecular mechanism of primary cilia disassembly under normal and pathological conditions and determine if the loss of the cilium is required for cancer progression. Aurora kinase A, a common proto-oncogene often overexpressed in GBM, initiates rapid cilia disassembly, but the downstream effectors of this pathway still have not been found. One of the potential AURKA effectors is the motor protein KIF2C, known to directly destabilize microtubules. AURKA can phosphorylate KIF2C on multiple sites during mitosis, however, nothing is known about AURKA and KIF2C interaction in non-mitotic cells. We found that KIF2C overexpression is triggering cilia disassembly in AURKA dependent manner, and are focusing on elucidating the molecular mechanism of the KIF2C driven cilia disassembly. Phosphorylation of KIF2C on S715 by AURKA was reported to enchance spindle pole microtubule targeting. Both spindle pole and axonemal microtubules are highly post-translationally modified, thus our central hypothesisis that AURKA-dependent phosphorylation of KIF2C on S715 leads to increased affinity towards post-translationally modified microtubules (acetylated and/or detyrosinated), and cilia disassembly, resulting in increase in cell proliferation and tumor progression.
\end{abstract}




\section{Introduction}

Glioblastoma multiforme (GBM) is one of the most deadly cancers for which no effective treatment strategy currently exists. The primary cilium is a ubiquitous microtubule-based organelle that protrudes from the apical surface of most human cells serving as a cellular antenna for signal transduction and is an important regulator of mitosis. Cilia are lost in many types of cancer including GBM (1-6). The importance of cilia loss for cancer progression is largely unknown, although several attempts to rescue ciliation in cancer cells reveal the therapeutic benefit behind primary cilia restoration ( 7 , 8). The long-term goal of this study is to delineate the molecular mechanism of primary cilia disassembly under normal and pathological conditions and determine if the loss of cilium is required for cancer progression. This knowledge is critical for the development of new therapeutic strategies to prevent and eradicate tumor growth. Aurora kinase $A$ (AURKA or AurA), a common proto-oncogene that is often overexpressed in GBM (9-12), initiates rapid cilia disassembly $(7,13)$, but the downstream effectors of this pathway have still not been found. One potential AURKA effector is the motor protein KIF2C, known to directly destabilize microtubules. KIF2C and its family member KIF2A were shown to promote cilium disassembly upon overexpression (14). KIF2C is phosphorylated by AURKA, which promotes its localization to highly post-translationally-modified spindle pole microtubules (15). Axonemal microtubules bear similar post-translational modifications as spindle pole microtubules and are usually detyrosinated (16). Interestingly, KIF2C has decreased activity towards detyrosinated microtubules (17), thus, the central hypothesis of this study is that AURKA-dependent phosphorylation of KIF2C leads to a change in substrate preference and cilia disassembly, resulting in an increase in cell proliferation and tumor progression. Rescue of ciliation will inhibit proliferation, disease progression, and also potentially, recurrence. This hypothesis was tested through the execution of the following aims:

Aim \#1: Determine the mechanism/s of KIF2C-driven deciliation. The working hypothesis is that AURKA phosphorylation promotes KIF2C translocation from the cytoplasm to the primary cilium, where it orchestrates the disassembly of axonemal microtubules. 
Aim \#2: Determine the therapeutic benefits of combination therapy of KIF2C depletion and AURKA inhibition in the treatment of glioblastoma in patient-derived xenograft (PDX) models. The hypothesis is that the combination of KIF2C depletion and inhibition of AURKA will synergistically increase the incidence of primary cilia in cancer cells, as well as decrease tumor growth and potentially, recurrence. The rationale for the proposed work is that it will elucidate new mechanisms driving cilia disassembly, provide insight into the critical role of the primary cilia in cancer progression, and reveal new strategies for a targeted treatment of cancer. 


\section{Materials and methods}

\section{Cell lines and reagents}

Human astrocytes isolated from human cortex (1800) were obtained from ScienCell Research Labs and maintained in DMEM/F12 supplemented with $10 \%$ heat-inactivated FBS, Antibiotic-Antimycotic (ThermoFisher), and $10 \mu \mathrm{g} / \mathrm{ml}$ of gentamycin (MP Biomedicals). Cells were propagated and cryopreserved at passage 2; for all studies, cells were not passaged more than 10 times or 8 weeks, and no authentication or mycoplasma testing were performed. For immortalization, primary astrocytes at passage 5 or 6 were cultured until $50-75 \%$ confluency and transfected with SV40 large T-antigen

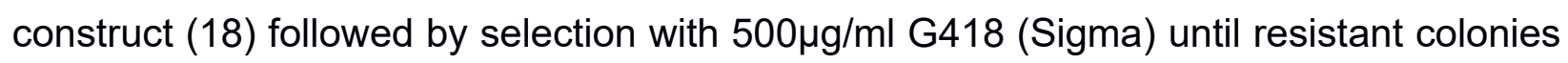
were formed. RPE1 hTert cells were obtained from ATCC and cultured according to ATCC recommendations. U87MG and U373MG were a kind gift from Dr. Daniel C. Flynn and were also maintained according to ATCC recommendations. GBM6 and 12 PDXs (19) were kindly provided by Dr. Jann Sarkaria (Mayo Clinic, Rochester, MN) through a shared MTA agreement, and no authentication or mycoplasma testing were performed. PDXs were used for cell culture isolation as previously described (20). A list of antibodies and their used applications is outlined in Table 1. shRNA constructs were obtained from Dharmacon and are outlined in Table 2. All primers were purchased from IDT Technologies, the sequences of which are reported in Table 3. MLN8237 (Selleckchem) and Tubastatin A (Selleckchem) were also used.

\section{Western blotting}

Western blotting was performed using standard procedures (21). Primary antibodies that were used are outlined in Table 1. Secondary anti-mouse and anti-rabbit HRPconjugated antibodies (Jackson ImmunoResearch Labs) were diluted 1:10,000 followed by chemiluminescence-based detection with HyGLO ${ }^{\mathrm{TM}}$ (Denville Scientific). Bands were quantified using the digital electrophoresis documentation and image analysis software GeneTools (Syngene Corp.) with signal intensity normalized to a-tubulin.

\section{Immunofluorescent cell analysis}


Cells were processed as previously described (13). Primary antibodies that were used are outlined in Table 1. Secondary antibodies included AlexaFluor 488, 555, and 647 (ThermoFisher). Images were captured using a standard setting by an LSM510 confocal microscope (Zeiss) (21). All images represent whole-cell 3D reconstructed projections with $0.4 \mu \mathrm{m}$ steps. All quantifications were done using ImageJ $(\mathrm{NIH})$.

\section{KIF2C cloning and cell lines generation}

KIF2C cDNA was purchased from PlasmID, PCR-amplified, and cloned into pEGFP (Clontech) vector between EcoRI and Xhol restriction sites. For inducible expression, EGFP-KIF2C fusion cDNA was cloned into pLUTZ lentivirus vector between Agel and Xhol restriction sites (22). All constructs were validated by sequencing.

Lentiviral particles were produced as previously described (13). Cells were infected and selected with correspondent antibiotics until stable clones were formed.

\section{Cell growth/proliferation analysis}

Cell growth rate was determined using semi-automated cell counting in ImageJ $(\mathrm{NIH})$. Cells were plated at $1 \times 10^{4}$ cells per well and grown in the specified conditions for five days, fixed with methanol, and stained with Hoechst33342. Four random 10x fields per well were analyzed with at least three replicates per independent experiment; each graph represents at least three independent experiments. 


\section{Results}

KIF2C overexpression drives cilia disassembly in an AURKA-dependent manner.

To test whether overexpression of KIF2C can cause loss of primary cilium, we generated RPE1-hTert and human immortalized astrocytes with inducible overexpression of GFP-tagged KIF2C. In both cell lines, overnight induction of KIF2C expression under ciliated, serum pre-starved conditions resulted in robust disassembly of primary cilia (Fig.1A, B). To test if cilium disassembly was KIF2C dose-dependent, time course experiments with limited KIF2C induction times were performed. The time course experiment revealed robust KIF2C dose-dependent disassembly of primary cilia (Fig.1CD).

To test if AURKA plays a role in KIF2C-driven cilia disassembly, a small molecule inhibitor highly specific for AURKA called MLN8237 was used. Inhibition of AURKA and simultaneous induction of KIF2C significantly attenuated KIF2C-driven cilia disassembly (Fig.1E), suggesting that AURKA activity is required. Interestingly, KIF2C was noted to be present inside the primary cilium in several cells, and its presence was associated with decreased acetylated tubulin staining in the same area (Fig.1F). These data argue that KIF2C enters primary cilium prior to disassembling it.

\section{Ciliated cells are likely to be more a differentiated cell population within GBM.}

GBM tumor cells have decreased ciliation, but nevertheless up to $10 \%$ of GBM tumor cells possess primary cilia in vivo (23). This was confirmed for two PDX-derived GBM primary cell lines GBM6 and GBM12 (Study 1); these cell lines represent classical and mesenchymal subtypes of GBM, respectively, and were chosen due to their high expression of AURKA and KIF2C and the worst prognosis. To test if the ciliated population of GBM cells had any associated phenotype, Sox2 and CD44 expression was analyzed. Sox2 is enriched in self-renewing neural progenitor cells (24), and its loss in GBM tumorinitiating cells causes abrogation of proliferation and tumorigenicity (25). CD44 is highly enriched in neural stem cells (26). The ciliated population of both GBM6 and 12 had only about $5 \%$ CD44-positive and $60 \%$ Sox2-positive cells, versus $40 \%$ and $80 \%$ in non- 
ciliated cells, respectively (Fig. $2 \mathrm{~A}-\mathrm{C}$ ), suggesting that this population is more differentiated and less proliferative.

\section{Depletion of KIF2C or inhibition of AURKA inhibit GBM cell proliferation and restore ciliation.}

To test if KIF2C has any effect on the proliferation of GBM cells, we generated U87MG cells with stable shRNA-driven depletion of KIF2C (Fig.3A). All cell sublines had at least an $80 \%$ depletion of KIF2C, and proliferated significantly slower compared to the control cell line (Fig.3B).Since AURKA activity is required for KIF2C-driven cilia disassembly, it was tested whether the inhibition of AURKA can restore ciliation. Inhibition of AURKA for $24 \mathrm{~h}$ with $50 \mathrm{nM}$ of MLN8237 was sufficient to cause a twofold increase in the ciliation of U87MG cells (Fig.3C) and also inhibit proliferation (Fig.3D). In PDX-derived GBM primary cells, incubation with MLN8237 for 24h was sufficient to increase ciliation of GBM6 cells up to $60 \%$, as compared to $10-20 \%$ in the DMSO control group (Fig.3E). Interestingly, there were no changes in the total number of mitotic figures, however, half of the mitotic figures in MLN8237-treated cells represented characteristic abnormalities such as monopolar spindles (Fig.3F-G). 


\section{Future directions}

\section{Validation of GFP-KIF2C data with untagged KIF2C.}

Data obtained from this study indicates that overexpression of GFP-KIF2C is sufficient to induce cilia disassembly (Fig.2), however, the level of overexpressed protein is much higher than the endogenous KIF2C level (Fig.2C). This can be explained by decreased depolymerization activity of EGFP-KIF2C (27) or the potential suppression of EGFPKIF2C cilia entry due to size exclusion (28). To address this issue, KIF2C cDNA was cloned into pLUTZ vector between EcoRI and Xhol restriction sites, allowing for the inducible expression of KIF2C without a tag. Utilization of this construct will allow the confirmation of previously obtained results, and clarify if KIF2C triggers cilia disassembly in a more physiological range. It is expected that lower levels of KIF2C trigger cilia disassembly, as well as more abundant KIF2C entry into the cilium.

\section{Evaluating the effects of $\mathbf{S} 715$ phosphorylation on KIF2C activity in vivo.}

To test whether phosphorylation status of KIF2C at the $\mathrm{S} 715$ site has an effect on cilia disassembly, we generated a series of KIF2C mutants: KIF2C-S715A (phosphor-dead), KIF2C-S715E (phosphor-mimicking) and KIF2C-KVD (microtubule disassembly-impaired (29)) in pLUTZ vector (Fig.4A). Utilization of these constructs will allow for evaluation if S715 phosphorylation effects the ability of KIF2C to disassemble primary cilia. It is expected that KIF2C-S715E will be more effective in cilium disassembly than KIF2C-wt, while KIF2C-S715A will be less effective in cilium disassembly than KIF2C-wt. KIF2CKVD will be utilized as negative control, since its overexpression is not expected to produce any effect on primary cilia. In addition, since KIF2C-KVD is supposed to be targeted to the cilium as well as KIF2C-wt, it is expected to see accumulation of KIF2C$\mathrm{KVD}$ at the tip/along the primary cilium upon overexpression.

\footnotetext{
Evaluating the effects of S715 phosphorylation on KIF2C depolymerization activity in vitro.

To test whether the phosphorylation status of KIF2C at the $\mathrm{S} 715$ site has an effect on in vitro microtubule depolymerization activity, cDNA for KIF2C wt, KIF2C S715A, S715E and KVD) was cloned in pcDNA3.1 6His-Flag vector (Fig.4B). This system allows to
} 
express KIF2C and the mutants in HEK293T cells (Fig.4C). Future plans call for purifying the indicated proteins and using them for in vitro microtubule depolymerization assays (30). It is not expected to see any difference in depolymerization activity between KIF2Cwt, KIF2C-S715A, and KIF2C-S715E, since tubulin available on the market consists of a mixture of tyrosinated and detyrosinated isoforms. To evaluate the substrate preference of KIF2C and its mutants, tyrosinated and detyrosinated tubulin dimers will be purified using previously described methodology (31). In experiments with tyrosinated tubulin, it is expected to see strong disassembly with KIF2C-wt, KIF2C-S715A, and KIF2C-S715E, while detyrosinated tubulin is predicted to be more resistant to KIF2C-wt and KIF2CS715A (17), but more sensitive to KIF2C-S715E (15).

\section{Evaluating the effects of KIF2C and AURKA depletion on the ciliation status of GBM PDXs in vivo and in vitro.}

To test whether depletion of KIF2C can restore ciliation in GBM PDXs, previously validated shRNA against KIF2C (Fig.3) will be subclonedfrom pGIPZ vectors into pTRIPZ vectors according to the manufacturer protocol to allow for inducible KIF2C depletion. Inducible shRNA against KIF2C will be introduced in GBM6 and GBM12 primary cultures and selected with puromycin. Selected cells will be injected into NSG mice for PDX amplification as described previously (20). Amplified PDXs will be validated for KIF2C depletion and used for in vivo and in vitro assessment of ciliation and proliferation. It is expected that primary cilia in GBM PDXs will be restored and severely suppress proliferation both in vitro and in vivo. Since the study data indicates that KIF2C-driven cilia disassembly is AURKA dependent (Fig.1E), inhibition of AURKA in conjunction with KIF2C depletion will be tested for their combined ability to restore ciliation and inhibit cancer cell proliferation. It is expected that better primary cilia restoration will occur with combination of AURKA inhibition and KIF2C depletion than with KIF2C depletion alone, since AURKA activation can initiate HDAC6-dependent cilia disassembly (13).

\section{Development of small molecule inhibitor for KIF2C.}

To develop an anti-KIF2C specific inhibitor, virtual screen of compounds was performed utilizing the publicly available crystal structure of the KIF2C motor domain 
(https://www.ncbi.nlm.nih.gov/Structure/pdb/2HEH). The 11 compounds (Table 4) with the highest fitting scores from this screen will be utilized in in vitro microtubule depolymerization assays. The compounds with the best ability to inhibit KIF2C-driven depolymerization will be tested further for their ability to inhibit KIF2C-driven cilia disassembly in cells, along with their effect on cell viability. Compounds showing the best results in these assays will be tested in their ability to restore primary cilium and suppress proliferation of PDX GBMs in vitro and in vivo. 


\section{Discussion}

Loss of the primary cilium seems to have a significant role in maintaining a highly proliferative phenotype in cancer $(7,8)$. At the same time, inhibition of primary cilia formation does not play a significant role in GBM tumor cell proliferation both in vitro and in vivo (27), and moreover, these findings argue that these cells are more differentiated (Fig.2). Targeting cancer cells in order to restore primary cilia is therefore expected to dampen proliferation and force re-differentiation of the cancer cells. Currently, the exact machinery participating in the disassembly of primary cilia has remained unknown, but this study establishes that KIF2C can enter primary cilium and promote disassembly in an AURKA-dependent manner. Targeting of either KIF2C or AURKA significantly affects proliferation of cancer cells. Elucidation of AURKA and KIF2C interactions that help promote primary cilia disassembly will allow for the development of new targeted therapies by preventing cilia loss of cancer cells. 


\section{References}

1. Basten SG, Willekers S, Vermaat JS, Slaats GG, Voest EE, van Diest PJ, et al. Reduced cilia frequencies in human renal cell carcinomas versus neighboring parenchymal tissue. Cilia. 2013;2(1):2.

2. Egeberg DL, Lethan M, Manguso R, Schneider L, Awan A, Jorgensen TS, et al. Primary cilia and aberrant cell signaling in epithelial ovarian cancer. Cilia. 2012;1(1):15.

3. Hassounah NB, Nagle R, Saboda K, Roe DJ, Dalkin BL, McDermott KM. Primary cilia are lost in preinvasive and invasive prostate cancer. PloS one. 2013;8(7):e68521.

4. Moser JJ, Fritzler MJ, Rattner JB. Primary ciliogenesis defects are associated with human astrocytoma/glioblastoma cells. BMC cancer. 2009;9:448.

5. Radford R, Slattery C, Jennings $\mathrm{P}$, Blacque $\mathrm{O}$, Pfaller W, Gmuender $\mathrm{H}$, et al. Carcinogens induce loss of the primary cilium in human renal proximal tubular epithelial cells independently of effects on the cell cycle. American journal of physiology Renal physiology. 2012;302(8):F905-16.

6. Seeley ES, Carriere C, Goetze T, Longnecker DS, Korc M. Pancreatic cancer and precursor pancreatic intraepithelial neoplasia lesions are devoid of primary cilia. Cancer research. 2009;69(2):422-30.

7. Gradilone SA, Radtke BN, Bogert PS, Huang BQ, Gajdos GB, LaRusso NF. HDAC6 inhibition restores ciliary expression and decreases tumor growth. Cancer research. 2013;73(7):2259-70.

8. Yang Y, Roine N, Makela TP. CCRK depletion inhibits glioblastoma cell proliferation in a cilium-dependent manner. EMBO reports. 2013;14(8):741-7.

9. Barton VN, Foreman NK, Donson AM, Birks DK, Handler MH, Vibhakar R. Aurora kinase $A$ as a rational target for therapy in glioblastoma. Journal of neurosurgery Pediatrics. 2010;6(1):98-105.

10. Hong X, O'Donnell JP, Salazar CR, Van Brocklyn JR, Barnett KD, Pearl DK, et al. The selective Aurora-A kinase inhibitor MLN8237 (alisertib) potently inhibits proliferation of glioblastoma neurosphere tumor stem-like cells and potentiates the effects of temozolomide and ionizing radiation. Cancer chemotherapy and pharmacology. 2014;73(5):983-90.

11. Lehman NL, O'Donnell JP, Whiteley LJ, Stapp RT, Lehman TD, Roszka KM, et al. Aurora A is differentially expressed in gliomas, is associated with patient survival in glioblastoma and is a potential chemotherapeutic target in gliomas. Cell cycle. 2012;11(3):489-502.

12. Samaras V, Stamatelli A, Samaras E, Arnaoutoglou C, Arnaoutoglou M, Stergiou I, et al. Comparative immunohistochemical analysis of aurora-A and aurora-B expression in human glioblastomas. Associations with proliferative activity and clinicopathological features. Pathology, research and practice. 2009;205(11):765-73.

13. Pugacheva EN, Jablonski SA, Hartman TR, Henske EP, Golemis EA. HEF1dependent Aurora A activation induces disassembly of the primary cilium. Cell. 2007;129(7):1351-63.

14. Miyamoto $T$, Hosoba K, Ochiai $H$, Royba E, Izumi $H$, Sakuma T, et al. The Microtubule-Depolymerizing Activity of a Mitotic Kinesin Protein KIF2A Drives Primary Cilia Disassembly Coupled with Cell Proliferation. Cell reports. 2015. 
15. Zhang X, Ems-McClung SC, Walczak CE. Aurora A phosphorylates MCAK to control ran-dependent spindle bipolarity. Molecular biology of the cell. 2008;19(7):275265.

16. Janke C, Bulinski JC. Post-translational regulation of the microtubule cytoskeleton: mechanisms and functions. Nature reviews Molecular cell biology. 2011;12(12):773-86.

17. Peris L, Wagenbach M, Lafanechere L, Brocard J, Moore AT, Kozielski F, et al. Motor-dependent microtubule disassembly driven by tubulin tyrosination. The Journal of cell biology. 2009;185(7):1159-66.

18. Schuermann M. An expression vector system for stable expression of oncogenes. Nucleic acids research. 1990;18(16):4945-6.

19. Carlson BL, Grogan PT, Mladek AC, Schroeder MA, Kitange GJ, Decker PA, et al. Radiosensitizing effects of temozolomide observed in vivo only in a subset of O6methylguanine-DNA methyltransferase methylated glioblastoma multiforme xenografts. International journal of radiation oncology, biology, physics. 2009;75(1):212-9.

20. Carlson BL, Pokorny JL, Schroeder MA, Sarkaria JN. Establishment, maintenance and in vitro and in vivo applications of primary human glioblastoma multiforme (GBM) xenograft models for translational biology studies and drug discovery. Current protocols in pharmacology. 2011; Chapter 14:Unit 146.

21. Kozyreva VK, Kiseleva AA, Ice RJ, Jones BC, Loskutov YV, Matalkah F, et al. Combination of Eribulin and Aurora A Inhibitor MLN8237 Prevents Metastatic Colonization and Induces Cytotoxic Autophagy in Breast Cancer. Molecular cancer therapeutics. 2016;15(8):1809-22.

22. Ice RJ, McLaughlin SL, Livengood RH, Culp MV, Eddy ER, Ivanov AV, et al. NEDD9 depletion destabilizes Aurora A kinase and heightens the efficacy of Aurora A inhibitors: implications for treatment of metastatic solid tumors. Cancer research. 2013;73(10):3168-80.

23. Sarkisian MR, Siebzehnrubl D, Hoang-Minh L, Deleyrolle L, Silver DJ, Siebzehnrubl FA, et al. Detection of primary cilia in human glioblastoma. Journal of neurooncology. 2014;117(1):15-24.

24. Hagey DW, Muhr J. Sox2 acts in a dose-dependent fashion to regulate proliferation of cortical progenitors. Cell reports. 2014;9(5):1908-20.

25. Gangemi RM, Griffero F, Marubbi D, Perera M, Capra MC, Malatesta P, et al. SOX2 silencing in glioblastoma tumor-initiating cells causes stop of proliferation and loss of tumorigenicity. Stem cells. 2009;27(1):40-8.

26. Pollard SM, Wallbank R, Tomlinson S, Grotewold L, Smith A. Fibroblast growth factor induces a neural stem cell phenotype in foetal forebrain progenitors and during embryonic stem cell differentiation. Molecular and cellular neurosciences. 2008;38(3):393-403.

27. Helenius J, Brouhard G, Kalaidzidis Y, Diez S, Howard J. The depolymerizing kinesin MCAK uses lattice diffusion to rapidly target microtubule ends. Nature. 2006;441(7089):115-9.

28. Lin YC, Niewiadomski P, Lin B, Nakamura H, Phua SC, Jiao J, et al. Chemically inducible diffusion trap at cilia reveals molecular sieve-like barrier. Nature chemical biology. 2013;9(7):437-43. 
29. Ogawa T, Nitta R, Okada Y, Hirokawa N. A common mechanism for microtubule destabilizers-M type kinesins stabilize curling of the protofilament using the class-specific neck and loops. Cell. 2004;116(4):591-602.

30. Mirigian M, Mukherjee K, Bane SL, Sackett DL. Measurement of in vitro microtubule polymerization by turbidity and fluorescence. Methods in cell biology. 2013;115:215-29.

31. Lafanechere L, Job D. Preparation of pure tyrosinated or detyrosinated tubulin isoforms. Methods in molecular biology. 2011;777:71-86.

32. Hoang-Minh LB, Deleyrolle LP, Siebzehnrubl D, Ugartemendia G, Futch H, Griffith $\mathrm{B}$, et al. Disruption of KIF3A in patient-derived glioblastoma cells: effects on ciliogenesis, hedgehog sensitivity, and tumorigenesis. Oncotarget. 2016;7(6):7029-43. 


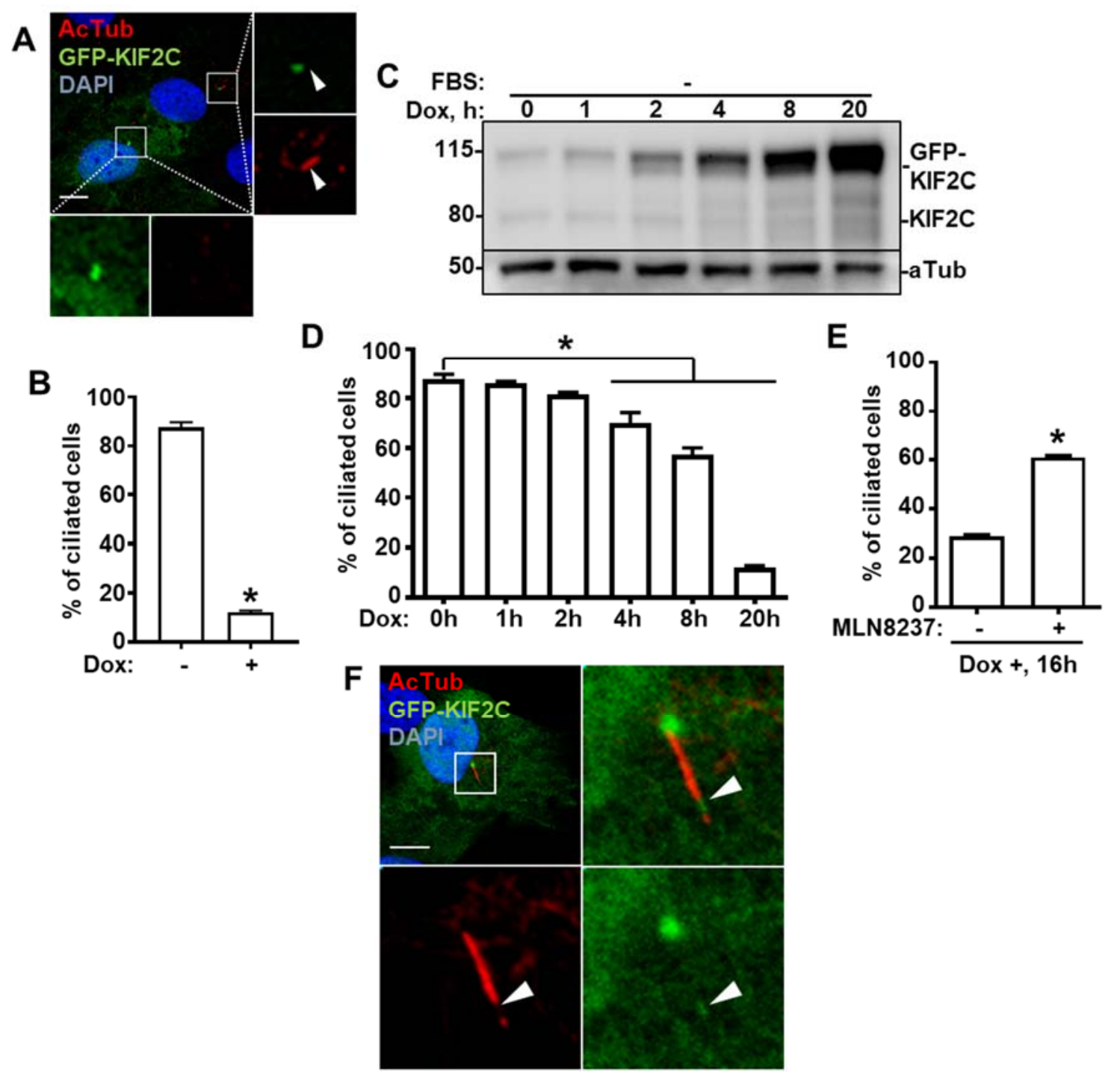

Fig. 1. KIF2C overexpression drives cilia disassembly in an AURKA-dependent manner.

(A) Representative image of RPE1-hTert cells with (left-bottom corner) and without overexpression of GFP-KIF2C, stained for acetylated $\alpha$-tubulin (AcTub, cilium marker)

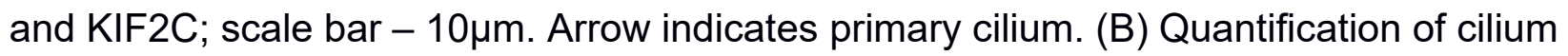
in cells with (Dox+) without (Dox-) induction of EGFP-KIF2C expression as in (A) upon $24 \mathrm{~h}$ of serum starvation; 300 cells total, 100 cells in each of 3 independent experiments; Student's $t$-test, $p<0.05$. (C) Western blot of KIF2C in RPE1-hTert cells after 24h of serum starvation and induction of EGFP-KIF2C expression for the indicated number of hours. (D) Quantification of cells forming primary cilium upon induction of GFP-KIF2C expression 
for the indicated number of hours as in (C); 300 cells total, 100 cells in each of 3 independent experiments; one-way ANOVA with Dunnett's post hoc test, $p<0.05$. (E) Quantification of cells forming primary cilium as in (B) upon induction of GFP-KIF2C expression for $16 \mathrm{~h}$ in the presence or absence of 50nM MLN8237; 300 cells total, 100 cells in each of 3 independent experiments; one-way ANOVA with Dunnett's post hoc test, $p<0.05$. (F) Representative image of the primary cilium in human astrocytes after $48 \mathrm{~h}$ of serum starvation, followed by $8 \mathrm{~h}$ induction of GFP-KIF2C expression, stained for acetylated $\alpha$-tubulin (AcTub, cilium marker) and KIF2C; scale bar $-10 \mu \mathrm{m}$. Arrow indicates KIF2C accumulation in primary cilium. 

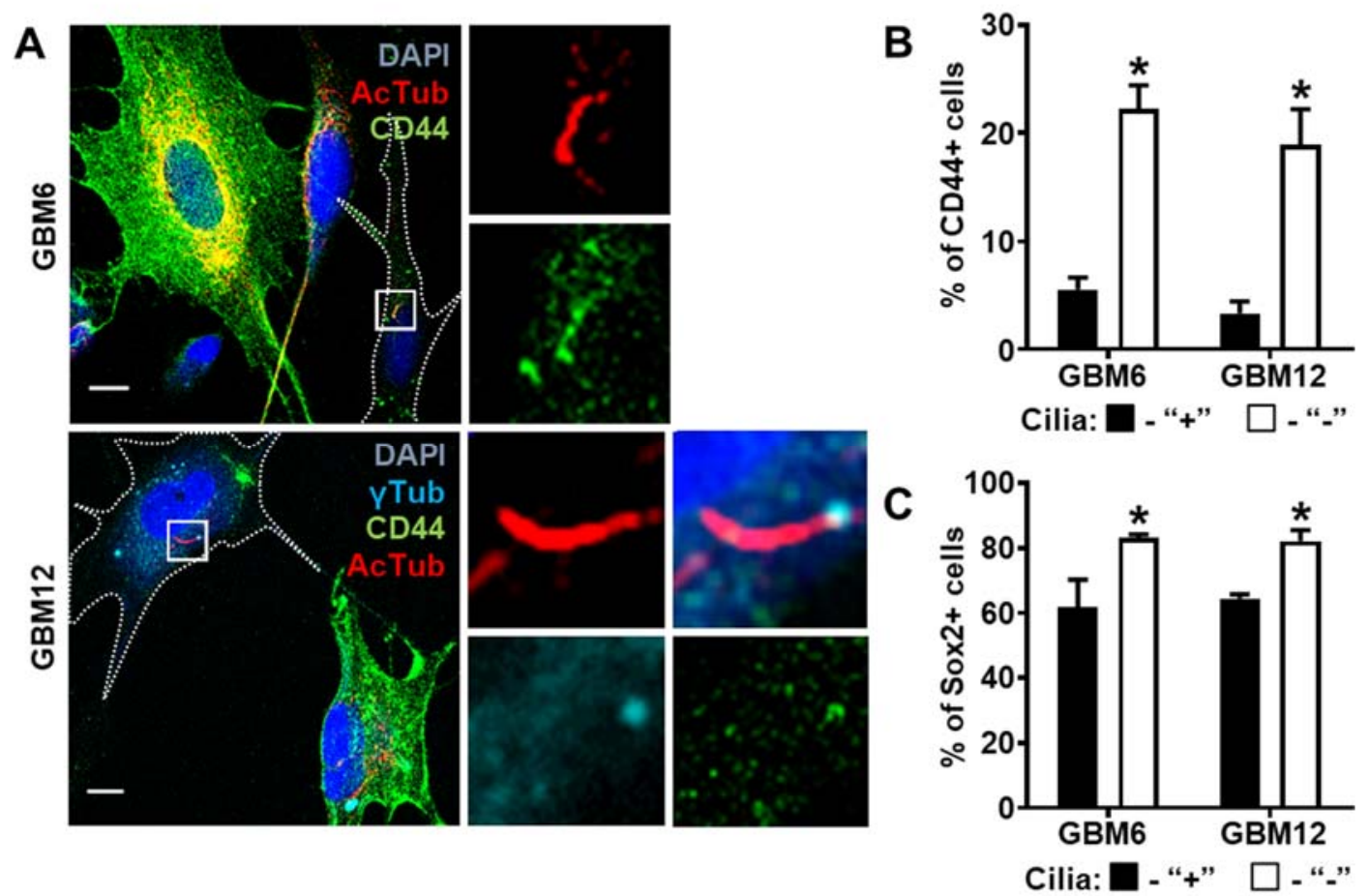

Fig. 2. Stem-cell/differentiation marker status of ciliated cells is different from cells without primary cilia.

(A) Representative image of GBM6 and GBM12 cells with and without primary cilia stained for acetylated $\alpha$-tubulin (AcTub, cilium marker), $\gamma$-tubulin ( $\mathrm{YTub}$, basal body

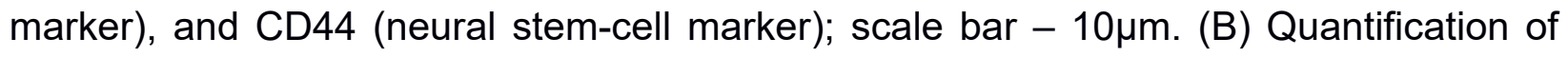
CD44+ cells as in (A); 200 cells total, 100 cells in each of 2 independent experiments; Student's $t$-test, $p<0.05$. (C) Quantification of Sox2+ cells; 200 cells total, 100 cells in each of 2 independent experiments; Student's $t$-test, $p<0.05$. 

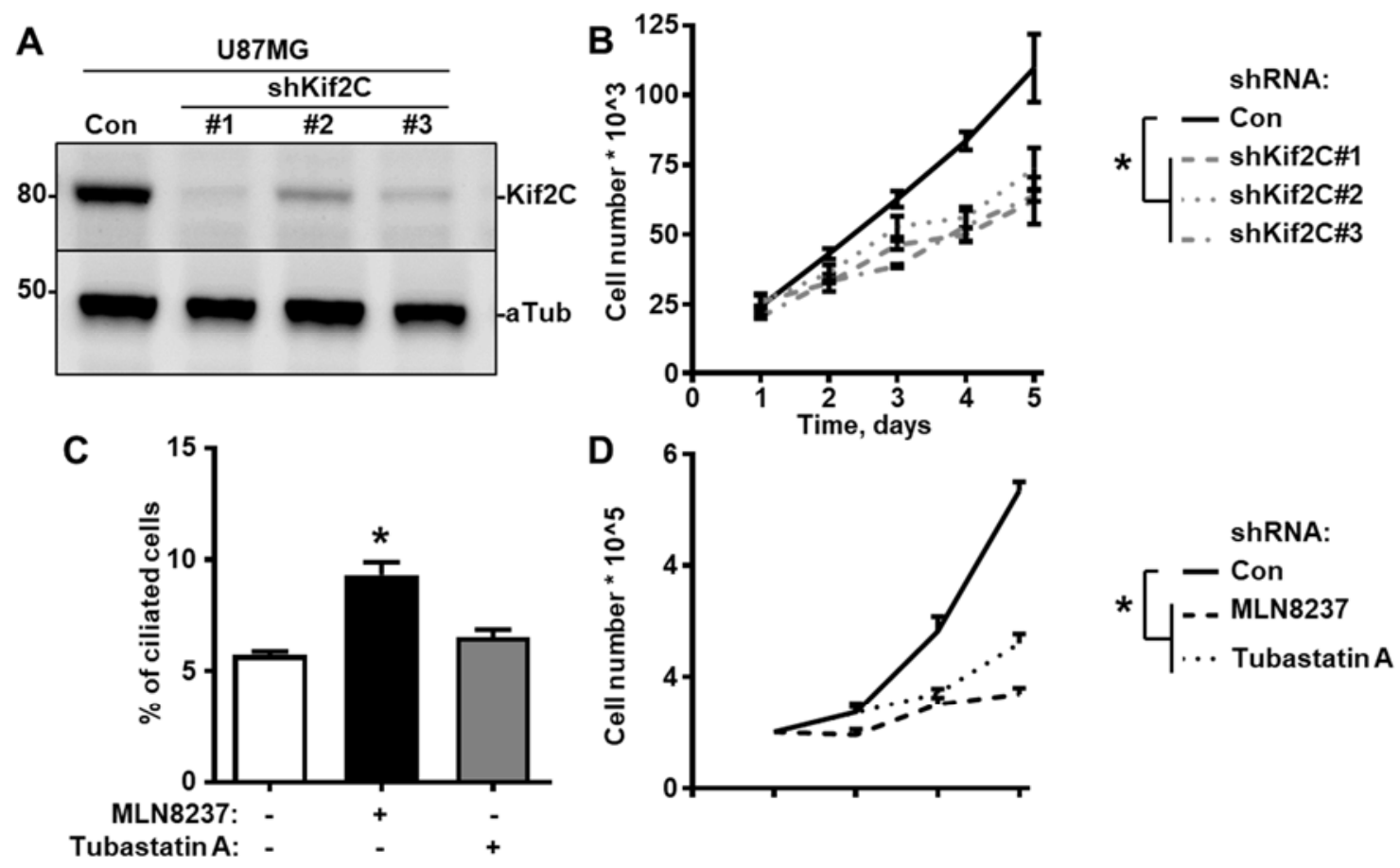

E
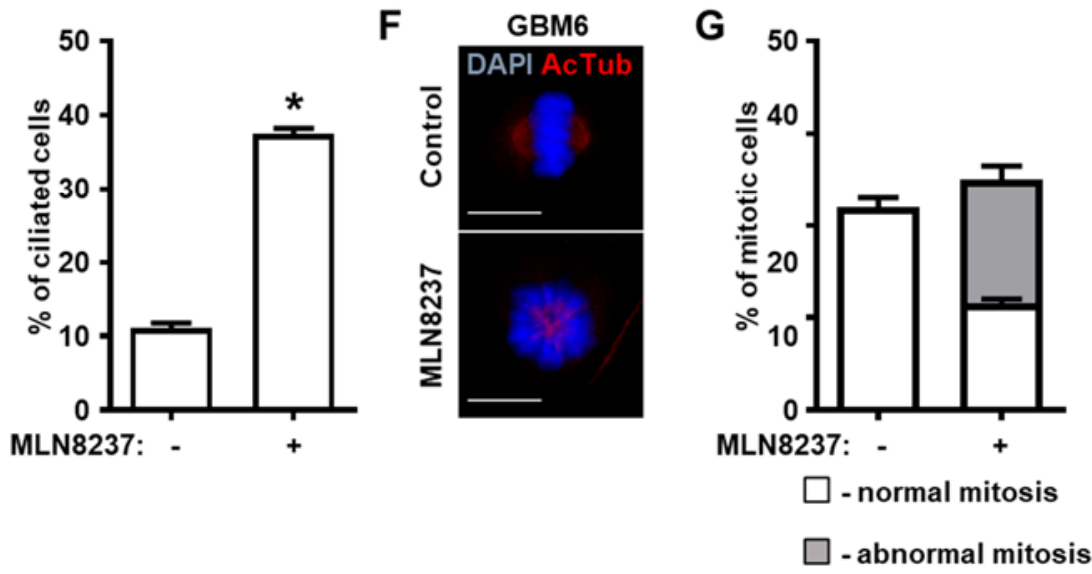

Fig. 3. Effects of KIF2C depletion and inhibition of AURKA on GBM cell proliferation and ciliation.

(A) Western blot of KIF2C in U87MG cells stably-expressing shRNA against KIF2C. (B) Growth curve of U87MG cells as in (A); slopes of the fitted lines significantly different in F-test, * $p<0.05$ (C) Quantification of cilium in U87MG cells treated with 50nM MLN8237 or $15 \mu \mathrm{M}$ Tubastatin A; 500 cells total, 250 cells in each of 2 independent experiments; one-way ANOVA with Dunnett's post hoc test, $p<0.05$. (D) Growth curve of U87MG cells as in $(C)$; slopes of the fitted lines significantly different in F-test, ${ }^{*} p<0.05$. (E) 
Quantification of GBM6 cells forming primary cilium in the presence of 50nM MLN8237; 300 cells total, 100 cells in each of 3 independent experiments; Student's $t$-test, $p<0.05$. (F) Representative image of the mitotic figures in GBM6 cells as in (E). Top image depicts normal mitotic figure, and bottom image depicts abnormal, monopolar mitotic figure; stained for acetylated $\alpha$-tubulin (AcTub, cilium marker) and DAPI; scale bar - 10 $\mu \mathrm{m}$. (G) Quantification of mitotic figures as in (E and F); 200 cells total, 100 cells in each of 2 independent experiments. 


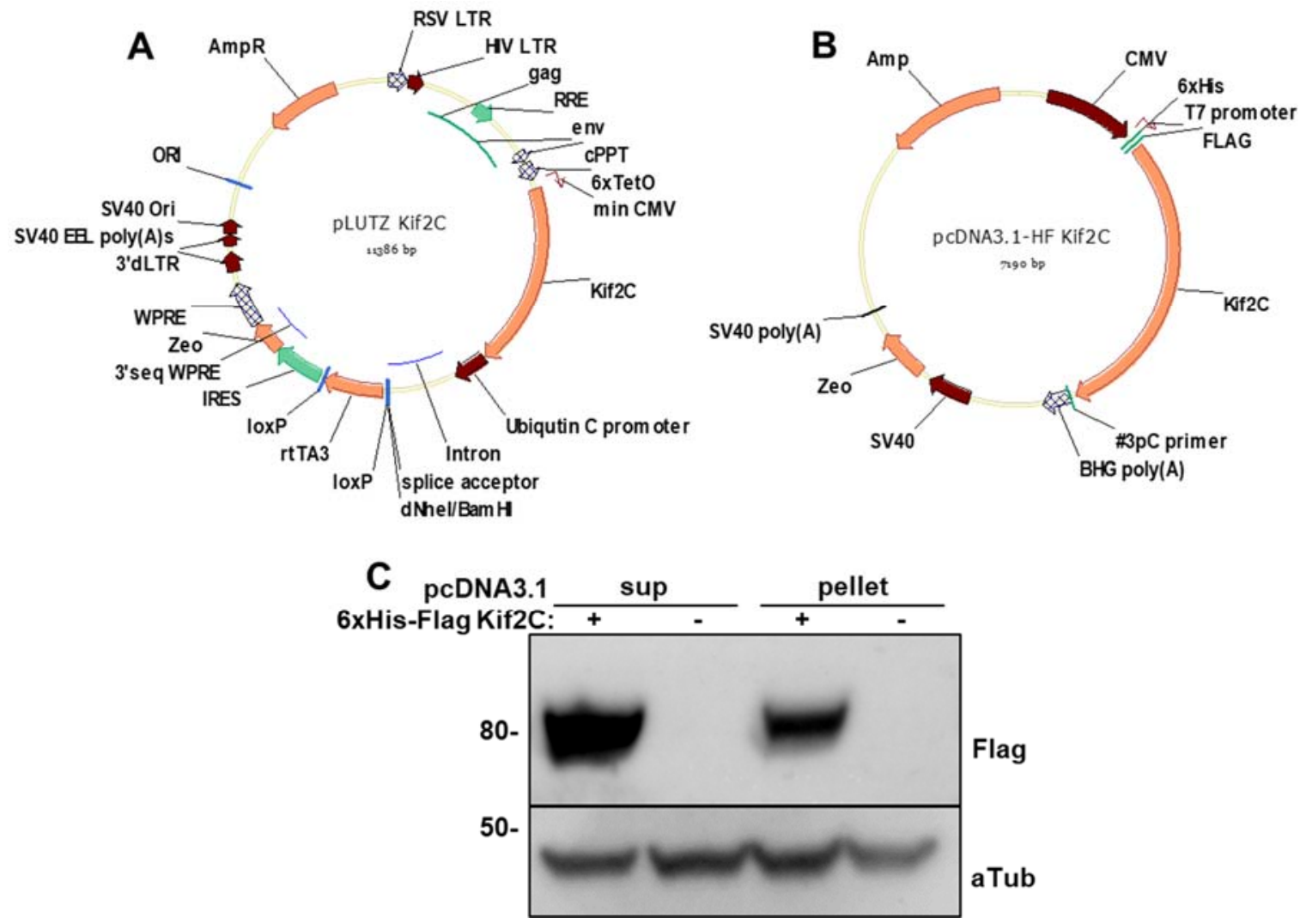

Fig. 4. KIF2C cloning and protein production.

(A) Map of pLUTZ KIF2C construct.(B) Map of pcDNA3.1 6xHis-Flag KIF2C construct. (C) Western blot of 6xHis-Flag-KIF2C expressed in HEK293T cells. Cells were lysed in phosphate-buffered saline with $15 \mathrm{mM}$ imidazole. 
Table 1.

\begin{tabular}{|c|c|c|c|c|c|}
\hline target & cat.\# & $\begin{array}{c}\text { host } \\
\text { species }\end{array}$ & company & application & dilution \\
\hline $\begin{array}{c}\text { acetyated } \\
\text { alpha } \\
\text { tubulin }\end{array}$ & T6793 & mouse & Sigma & IF & $1: 1000$ \\
\hline $\begin{array}{c}\text { gamma } \\
\text { tubulin }\end{array}$ & sc-7396 & goat & Santa Cruz & IF & $1: 500$ \\
\hline $\begin{array}{c}\text { alpha } \\
\text { tubulin }\end{array}$ & 16199 & mouse & Sigma & WB & $1: 40000$ \\
\hline CD44 & sc-9960 & mouse & Santa Cruz & IF & $1: 400$ \\
\hline Sox2 & 35795 & rabbit & $\begin{array}{c}\text { Signaling } \\
\text { Technology }\end{array}$ & IF & $1: 400$ \\
\hline KIF2C & sc-81305 & mouse & Santa Cruz & IF, WB & $1: 200$, \\
\end{tabular}

Table 2.

\begin{tabular}{|c|c|c|c|c|}
\hline name & clone ID & targeting sequence & vector & company \\
\hline shKIF2C\#1 & V3LHS_357508 & AAACTACTGTCATACTCCT & pGIPZ & Dharmacon \\
\hline shKIF2C\#2 & V3LHS_357509 & TGGAGTTGACGGATCTCCG & pGIPZ & Dharmacon \\
\hline shKIF2C\#3 & V2LHS_78032 & TTATTTGCAGTCGTCACTG & pGIPZ & Dharmacon \\
\hline
\end{tabular}

Table 3.

\begin{tabular}{|c|c|c|}
\hline name & sequence & company \\
\hline EcoRI-Kif2C & ATTGAATTCATGGCCATGGACTCG & IDT Technologies \\
\hline Kif2C-Xhol & ATTCTCGAGTCGTCACTGGGGC & IDT Technologies \\
\hline
\end{tabular}


Table 4.

\begin{tabular}{|c|c|c|}
\hline compound ID & compound name & company \\
\hline 7693705 & $\begin{array}{l}\text { 2-\{2-[(5-hydroxy-6-methyl-1,2,4-triazin-3- } \\
\text { yl)thio]ethyl\}-1H-isoindole-1,3(2H)-dione }\end{array}$ & ChemBridge \\
\hline 7657128 & $\begin{array}{l}\text { 4-(3-\{[4-(2-hydroxyethyl)-1-piperazinyl]sulfonyl }\}- \\
\text { 4-methylphenyl)-2-methyl-1(2H)-phthalazinone }\end{array}$ & ChemBridge \\
\hline 11300854 & $\begin{array}{c}\text { 6-(\{4-[(4-butyl-1H-1,2,3-triazol-1- } \\
\text { yl)methyl]piperidin-1-yl\}carbonyl)-1H-indole }\end{array}$ & ChemBridge \\
\hline 63713617 & $\begin{array}{l}\mathrm{N}-(2,1,3 \text {-benzothiadiazol-5-ylmethyl)-N-methyl- } \\
\text { 1H-pyrazole-3-carboxamide }\end{array}$ & ChemBridge \\
\hline 73545990 & $\begin{array}{c}\text { 3-\{2-[4-(2-fluorobenzyl)piperidin-1-yl]-2- } \\
\text { oxoethyl\}dihydropyrimidine-2,4(1H,3H)-dione }\end{array}$ & ChemBridge \\
\hline 61771203 & $\begin{array}{l}\text { 3-(2-fluorophenyl)-N-(imidazo[1,2-a]pyrimidin-2- } \\
\text { ylmethyl)-1H-pyrazole-5-carboxamide }\end{array}$ & ChemBridge \\
\hline 97609998 & $\begin{array}{c}\text { 2-amino-4-[5-(1H-pyrazol-3-yl)-2-thienyl]-6- }(1 \mathrm{H}- \\
\text { pyrrol-3-yl)nicotinonitrile }\end{array}$ & ChemBridge \\
\hline 82375256 & $\begin{array}{l}\mathrm{N} \text {-[2-(5-amino-1,3,4-thiadiazol-2-yl)ethyl]-5-(2- } \\
\text { fluorophenyl)pyrazolo[1,5-a]pyrimidin-7-amine }\end{array}$ & ChemBridge \\
\hline 80994660 & $\begin{array}{l}\text { 5-[(2-dibenzo[b,d]furan-4-yl-1H-imidazol-1- } \\
\text { yl)methyl]-1,2,4-oxadiazole-3-carboxamide }\end{array}$ & ChemBridge \\
\hline 22763338 & $\begin{array}{l}\text { 4-(2,6-dimethyl-3-pyridinyl)-N-methyl-N-\{[3-(3- } \\
\text { pyridinyl)-5-isoxazolyl]methyl\}-2-pyrimidinamine }\end{array}$ & ChemBridge \\
\hline 81086871 & $\begin{array}{l}\text { (1-methyl-1H-imidazol-2-yl)\{3-[6-(1H-pyrazol-1- } \\
\text { yl)pyrimidin-4-yl]phenyl\}methanone }\end{array}$ & ChemBridge \\
\hline
\end{tabular}




\section{General Discussion}

The primary cilium is a crucial organelle for the transduction of multiple signaling cascades (1-3). Loss of primary cilia is associated with an increase in cell proliferation in some cell types $(3,4)$, while suppressing cell proliferation in others $(5,6)$. In the majority of cancer types, including GBM, the length and number of primary cilia are significantly reduced or lost (7-10). Overall, the studies documented in this dissertation present multiple novel insights into the role of the primary cilium in the regulation of normal and cancer cell proliferation and in the mechanisms of cilia disassembly. In Study 1, it was demonstrated that the loss of primary cilia promotes proliferation of human astrocytes in a growth factor-dependent manner. For the first time, it was demonstrated that spatiotemporal characteristics of the cellular response to growth factors are drastically altered upon the loss of primary cilia. Previously, PDGF-AA signaling through PDGFRaa was reported to be lost in deciliated fibroblasts (11), and IGF1R signaling was significantly reduced (12), thus an increase in proliferation upon the loss of primary cilia is a somewhat unexpected phenomenon. Other RTKs such as EGFR, FGFR, and Tie1/2 were noticed to localize to primary cilia (13-17), but the significance of this is unknown. In addition, different GPCRs can accumulate in the primary cilium $(18,19)$ along with their downstream signaling components $(20,21)$. Therefore, loss of cilia can interfere with multiple signaling cascades of various modalities, and systematic studies of signaling alterations are very scarce. In Study 1, LPA was established to be the main non-peptide growth factor responsible for the increased proliferation of astrocytes with disrupted ciliogenesis. For the first time, scrutinous analysis of the hyperproliferative phenotype in cells with an engineered loss of cilia was able to establish the underlining mechanism for increased proliferation. It was found that LPA-LPAR1 signaling is regulated by primary cilia. Loss of primary cilia promotes redistribution of LPAR1, which is normally localized to the cilium, and streamlines signaling through $\mathrm{Ga}_{12} / \mathrm{Ga}_{\mathrm{q}}$, thus increasing proliferation. $\mathrm{Ga}_{12}$ and $\mathrm{Ga}_{\mathrm{q}}$ activation were previously reported to be implicated in cancer cell proliferation and cancer progression $(22,23)$. Furthermore, the LPAR1-Ga $\alpha_{12}$ module specifically was reported to drive ovarian cancer cell proliferation (24). These findings suggest that primary cilia restricts LPA-LPAR1-driven $\mathrm{Ga}_{12} / \mathrm{Ga}_{q}$ activation. Loss of cilia in GBM cells highjacks LPA signaling to maintain a highly proliferative phenotype, rendering 
them sensitive to inhibition of LPAR1. Utilization of a nanoparticle-based delivery of Ki16425, a small molecule inhibitor of LPAR1-3, as a monotherapy significantly decreased GBM growth in vivo. These results clearly indicate that inhibition of LPA signaling is a viable therapeutic option for GBM control in addition to standard care, especially in light of the implication of LPA in proliferation and migration/invasion $(25,26)$. Currently, the standard of care for GBM patients includes surgical resection of the tumor and a combination of radiation and chemotherapy (27). Unfortunately, the majority of patients experience recurrence of the disease within several months (28). Novel approaches in immunotherapy of GBM seem to be promising, but sustained responses are still rare (29). In part, this may be due to the prolonged lag period between the initiation of therapy and the tumor response (30), thus utilization of a tumor growth suppression agent in combination with an immunotherapeutic approach could be beneficial. Further studies are required to establish the possibility of combining LPAR inhibitors with conventional or immuno-based therapies. However, two LPAR inhibitors were recently used for clinical trials. BMS-986020, an LPAR1 inhibitor, is in Phase 2 clinical trials for idiopathic pulmonary fibrosis (NCT01766817); and SAR100842, an LPAR1 and 3 inhibitor, is in Phase 2 clinical trials for systemic sclerosis (NCT01651143). If the results of the current study can be replicated utilizing these compounds, GBM patient survival could be significantly improved, and disease control would become much easier. Based on Study 1's findings, it would be expected to see a substantial increase in recurrencefree survival upon inhibition of LPA signaling in addition to the current standard of care.

Since loss of primary cilia alters a great number of signaling pathways, restoration of primary cilia in cancer cells could potentially restore proper signaling and induce redifferentiation. So far, several attempts were made to restore cilia in cancer cells, and results have been very promising $(4,31)$. However, since the mechanisms of cilia disassembly are still not fully understood, it is difficult to pursue. Thus, it is crucial to delineate the pathways involved in cilium loss. Study 2 focused on the role of KIF2C in the disassembly of cilia. It was found that KIF2C can enter and disassemble primary cilia in an AURKA-dependent manner. The differentiation/stem marker status of ciliated GBM cells was evaluated, which confirmed that the cilium is likely to promote re-differentiation along with halting proliferation. Finally, it was established that targeting of KIF2C and 
AURKA drastically decreases proliferation of GBM cells, and moreover, AURKA inhibition can robustly restore primary cilia in these cells. AURKA is well known as a master regulator of cilia disassembly (32), as well as being an important mitotic regulator (33). Inhibition of AURKA, therefore, can suppress tumor growth in two ways: first, through direct inhibition of mitosis, and second, through restoration of the primary cilia. KIF2C is also involved in progression through mitosis, however depletion of KIF2C in nontransformed cells tends to generate a much milder phenotype than in cancer cells (34), indicating that KIF2C inhibition can potentially yield very little side effects. Further studies are required to elucidate the exact mechanism of AURKA-KIF2C cooperation in driving cilia disassembly. Unveiling the mechanisms of cilia disassembly in cancer cells will allow for the development of novel approaches for anti-cancer therapy. Restoration of primary cilia in cancer cells is expected to suppress proliferation and initiate re-differentiation, thus allowing for robust and prolonged disease control.

1. Christensen ST, Clement CA, Satir P, Pedersen LB. Primary cilia and coordination of receptor tyrosine kinase (RTK) signalling. The Journal of pathology. 2012;226(2):17284.

2. Robbins DJ, Fei DL, Riobo NA. The Hedgehog signal transduction network. Science signaling. 2012;5(246):re6.

3. Ezratty EJ, Stokes N, Chai S, Shah AS, Williams SE, Fuchs E. A role for the primary cilium in Notch signaling and epidermal differentiation during skin development. Cell. 2011;145(7):1129-41.

4. Gradilone SA, Radtke BN, Bogert PS, Huang BQ, Gajdos GB, LaRusso NF. HDAC6 inhibition restores ciliary expression and decreases tumor growth. Cancer research. 2013;73(7):2259-70.

5. Han YG, Spassky N, Romaguera-Ros M, Garcia-Verdugo JM, Aguilar A, Schneider-Maunoury S, et al. Hedgehog signaling and primary cilia are required for the formation of adult neural stem cells. Nature neuroscience. 2008;11(3):277-84.

6. Tong CK, Han YG, Shah JK, Obernier K, Guinto CD, Alvarez-Buylla A. Primary cilia are required in a unique subpopulation of neural progenitors. Proceedings of the National Academy of Sciences of the United States of America. 2014;111(34):12438-43. 7. Basten SG, Willekers S, Vermaat JS, Slaats GG, Voest EE, van Diest PJ, et al. Reduced cilia frequencies in human renal cell carcinomas versus neighboring parenchymal tissue. Cilia. 2013;2(1):2.

8. Hassounah NB, Nagle R, Saboda K, Roe DJ, Dalkin BL, McDermott KM. Primary cilia are lost in preinvasive and invasive prostate cancer. PloS one. 2013;8(7):e68521.

9. Moser JJ, Fritzler MJ, Rattner JB. Primary ciliogenesis defects are associated with human astrocytoma/glioblastoma cells. BMC cancer. 2009;9:448. 
10. Yuan K, Frolova N, Xie Y, Wang D, Cook L, Kwon YJ, et al. Primary cilia are decreased in breast cancer: analysis of a collection of human breast cancer cell lines and tissues. The journal of histochemistry and cytochemistry : official journal of the Histochemistry Society. 2010;58(10):857-70.

11. Schneider L, Clement CA, Teilmann SC, Pazour GJ, Hoffmann EK, Satir P, et al. PDGFRalphaalpha signaling is regulated through the primary cilium in fibroblasts. Current biology : CB. 2005;15(20):1861-6.

12. Zhu D, Shi S, Wang H, Liao K. Growth arrest induces primary-cilium formation and sensitizes IGF-1-receptor signaling during differentiation induction of 3T3-L1 preadipocytes. Journal of cell science. 2009;122(Pt 15):2760-8.

13. Danilov AI, Gomes-Leal W, Ahlenius H, Kokaia Z, Carlemalm E, Lindvall O. Ultrastructural and antigenic properties of neural stem cells and their progeny in adult rat subventricular zone. Glia. 2009;57(2):136-52.

14. Evans MJ, Fanucchi MV, Van Winkle LS, Baker GL, Murphy AE, Nishio SJ, et al. Fibroblast growth factor-2 during postnatal development of the tracheal basement membrane zone. American journal of physiology Lung cellular and molecular physiology. 2002;283(6):L1263-70.

15. Garcia-Gonzalez D, Murcia-Belmonte V, Esteban PF, Ortega F, Diaz D, SanchezVera I, et al. Anosmin-1 over-expression increases adult neurogenesis in the subventricular zone and neuroblast migration to the olfactory bulb. Brain structure \& function. 2016;221(1):239-60.

16. Ma R, Li WP, Rundle D, Kong J, Akbarali HI, Tsiokas L. PKD2 functions as an epidermal growth factor-activated plasma membrane channel. Molecular and cellular biology. 2005;25(18):8285-98.

17. Teilmann SC, Christensen ST. Localization of the angiopoietin receptors Tie-1 and Tie-2 on the primary cilia in the female reproductive organs. Cell biology international. 2005;29(5):340-6.

18. Mykytyn K, Askwith C. G-Protein-Coupled Receptor Signaling in Cilia. Cold Spring Harbor perspectives in biology. 2017;9(9).

19. Omori Y, Chaya T, Yoshida S, Irie S, Tsuji T, Furukawa T. Identification of G Protein-Coupled Receptors (GPCRs) in Primary Cilia and Their Possible Involvement in Body Weight Control. PloS one. 2015;10(6):e0128422.

20. Choi YH, Suzuki A, Hajarnis S, Ma Z, Chapin HC, Caplan MJ, et al. Polycystin-2 and phosphodiesterase $4 \mathrm{C}$ are components of a ciliary A-kinase anchoring protein complex that is disrupted in cystic kidney diseases. Proceedings of the National Academy of Sciences of the United States of America. 2011;108(26):10679-84.

21. He X, Zhang L, Chen Y, Remke M, Shih D, Lu F, et al. The G protein alpha subunit Galphas is a tumor suppressor in Sonic hedgehog-driven medulloblastoma. Nature medicine. 2014;20(9):1035-42.

22. Gan CP, Patel V, Mikelis CM, Zain RB, Molinolo AA, Abraham MT, et al. Heterotrimeric G-protein alpha-12 (Galpha12) subunit promotes oral cancer metastasis. Oncotarget. 2014;5(20):9626-40.

23. Kalinec G, Nazarali AJ, Hermouet S, Xu N, Gutkind JS. Mutated alpha subunit of the $\mathrm{Gq}$ protein induces malignant transformation in NIH 3T3 cells. Molecular and cellular biology. 1992;12(10):4687-93. 
24. Goldsmith ZG, Ha JH, Jayaraman M, Dhanasekaran DN. Lysophosphatidic Acid Stimulates the Proliferation of Ovarian Cancer Cells via the gep Proto-Oncogene Galpha(12). Genes \& cancer. 2011;2(5):563-75.

25. Gschwind A, Prenzel N, Ullrich A. Lysophosphatidic acid-induced squamous cell carcinoma cell proliferation and motility involves epidermal growth factor receptor signal transactivation. Cancer research. 2002;62(21):6329-36.

26. Manning TJ, Jr., Parker JC, Sontheimer H. Role of lysophosphatidic acid and rho in glioma cell motility. Cell motility and the cytoskeleton. 2000;45(3):185-99.

27. Adult Central Nervous System Tumors Treatment (PDQ $(R))$ : Health Professional Version. PDQ Cancer Information Summaries. Bethesda (MD)2002.

28. Birk HS, Han SJ, Butowski NA. Treatment options for recurrent high-grade gliomas. CNS oncology. 2017;6(1):61-70.

29. Huang B, Zhang H, Gu L, Ye B, Jian Z, Stary C, et al. Advances in Immunotherapy for Glioblastoma Multiforme. Journal of immunology research. 2017;2017:3597613.

30. Chiou VL, Burotto M. Pseudoprogression and Immune-Related Response in Solid Tumors. Journal of clinical oncology : official journal of the American Society of Clinical Oncology. 2015;33(31):3541-3.

31. Yang Y, Roine N, Makela TP. CCRK depletion inhibits glioblastoma cell proliferation in a cilium-dependent manner. EMBO reports. 2013;14(8):741-7.

32. Pugacheva EN, Jablonski SA, Hartman TR, Henske EP, Golemis EA. HEF1dependent Aurora A activation induces disassembly of the primary cilium. Cell. 2007;129(7):1351-63.

33. Horn V, Thelu J, Garcia A, Albiges-Rizo C, Block MR, Viallet J. Functional interaction of Aurora-A and PP2A during mitosis. Molecular biology of the cell. 2007;18(4):1233-41.

34. Hedrick DG, Stout JR, Walczak CE. Effects of anti-microtubule agents on microtubule organization in cells lacking the kinesin-13 MCAK. Cell cycle. 2008;7(14):2146-56. 


\section{Appendix 1. Financial support}

This research was supported by grants R21CA208875 (Elena N. Pugacheva), R01CA148671 (Elena N. Pugacheva) from the NIH/NCI, U54GM104942 (Werner J. Geldenhuys) from the NIGMS/NIH, WVU Cancer Institute Undergraduate Research Fellowship (Caryn L. Griffin), and "Let the Journey Begin" fund established by Erin Dunmire, WVU Cancer Institute. Andrey Bobko is supported by startup funding from WVCTSI. Naira V. Margaryan is supported by U54GM104942 from WVCTSI.

Imaging experiments were performed in the West Virginia University Microscope Imaging Facility, which has been supported by the WVU Cancer Institute and NIH grants P20RR016477/P20GM103434. 


\section{Appendix 2. Curriculum Vitae}

Name: $\quad$ Yuriy Loskutov

Address: $\quad 2813$ MBRCC, 1 Medical Center Drive

Morgantown, WV 26506

USA.

E-mail: ortoogon@gmail.com

Tel. (304)2930500

\section{EDUCATION}

\begin{tabular}{|c|c|c|}
\hline Degree & Institution & Date \\
\hline BSc & $\begin{array}{l}\text { Saint Petersburg State University, } \\
\text { Faculty of Biology and Soil Science, } \\
\text { Universitetskaya Naberezhnaia., St. Petersburg, } \\
\text { Russia, 199034 } \\
\text { Tel: 7(812)328-2000 }\end{array}$ & $6 / 24 / 2008$ \\
\hline MSc & $\begin{array}{l}\text { Saint Petersburg State University, } \\
\text { Faculty of Biology and Soil Science, } \\
\text { Universitetskaya Naberezhnaia., St. Petersburg, } \\
\text { Russia, 199034 } \\
\text { Tel: 7(812)328-2000 }\end{array}$ & 6/23/2010 \\
\hline PhD & $\begin{array}{l}\text { West Virginia University, } \\
\text { Department of Biochemistry, } \\
1 \text { Waterfront PI, Morgantown, WV } 26501 . \\
\text { Tel: (304) 293-2121 }\end{array}$ & 11/13/2017 \\
\hline
\end{tabular}




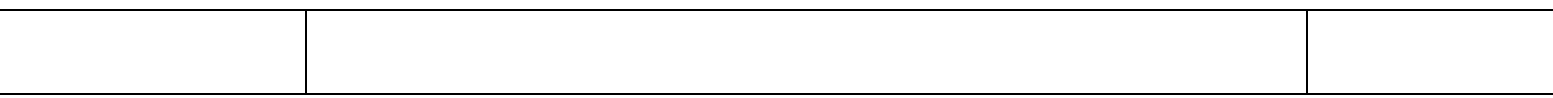

\section{RESEARCH EXPERIENCE}

\begin{tabular}{|c|c|}
\hline Graduate studen & $10 / 12 / 2012-11 / 13 / 2017$ \\
\hline $\begin{array}{l}\text { West Virginia University, } \\
\text { Department of Biochemistry } \\
1 \quad \text { Medical Center Drive, HSC-S, } \\
\text { MBRCC-2813, Morgantown, WV, 26506 } \\
\text { Tel: 304-293-0500 } \\
\text { Supervisor: Elena N Pugacheva, Ph.D } \\
\text { Associate Professor, Biochemistry and } \\
\text { WVU Cancer Institute, } \\
\text { Adjunct Assoc.Professor Radiation } \\
\text { Oncology } \\
\text { Co-leader of Breast Cancer Research } \\
\text { Program } \\
\text { PDX Core Facility Director HSC, } \\
\text { West Virginia University School of } \\
\text { Medicine } \\
\text { Health Sciences Center } \\
1 \text { Medical Center Drive, Rm.2832, } \\
\text { Morgantown, WV, 26506-9300. } \\
\text { Tel: (304)293-5295 }\end{array}$ & $\begin{array}{l}\text { Research subject: } \\
\text { Investigating the role of primary cilia and } \\
\text { associated signaling cascades in } \\
\text { maintaining highly proliferative } \\
\text { phenotype of glioblastoma, using } \\
\text { primary cells and patient derived } \\
\text { platforms. Devising novel therapeutic } \\
\text { strategies to treat glioblastoma, based } \\
\text { on inhibition of the abnormal growth } \\
\text { factor signaling initiated by loss of } \\
\text { primary cilia. }\end{array}$ \\
\hline
\end{tabular}

\begin{tabular}{|c|c|}
\hline Research Scholar & 09/28/2010-10/12/2012 \\
\hline $\begin{array}{l}\text { West Virginia University, } \\
\text { Department of Biochemistry } \\
1 \quad \text { Medical Center Drive, HSC-S, } \\
\text { MBRCC-2813, Morgantown, WV, } 26506 \\
\text { Tel: } 304-293-0500\end{array}$ & $\begin{array}{l}\text { Research subject: } \\
\text { Identification of novel targets of AURKA, } \\
\text { involved in primary cilia disassembly } \\
\text { during cell cycle. } \\
\text { Determine the role of NEDD9 adhesion }\end{array}$ \\
\hline Supervisor: Elena N Pugacheva, Ph.D & $\begin{array}{l}\text { adaptor protein in invasion of breast } \\
\text { cancer cells in vitro and in vivo using cell } \\
\text { lines and mouse model, investigating the }\end{array}$ \\
\hline
\end{tabular}




\begin{tabular}{|l|l|}
\hline Associate Professor, Biochemistry and & $\begin{array}{l}\text { role of NEDD9 in supporting MMP14 } \\
\text { WVCycling and activity. }\end{array}$ \\
Adjunct Assoc.Professor Radiation & \\
Oncology & \\
Co-leader of Breast Cancer Research & \\
Program & \\
PDX Core Facility Director HSC, & \\
West Virginia University School of & \\
Medicine & \\
Health Sciences Center & \\
1 Medical Center Drive, Rm.2832, & \\
Morgantown, WV, 26506-9300. & \\
Tel: (304)293-5295 & \\
\hline
\end{tabular}

\begin{tabular}{|c|c|}
\hline Junior scientist & $2009-06 / 01 / 2010$ \\
\hline $\begin{array}{l}\text { Pavlov Institute of Physiology, } \\
6 \text { Nab. Makarova, } 199034 \\
\text { St.Petersburg. Russia } \\
\text { Tel.: } 7(812) 3280701\end{array}$ & \multirow{2}{*}{$\begin{array}{l}\text { Research subject: } \\
\text { Investigating the interaction between } \\
\text { nervous and immune systems; TLR4 } \\
\text { expression in enteric neurons following } \\
\text { LPS challenge. }\end{array}$} \\
\hline $\begin{array}{l}\text { Supervisor: Soukhova Galia, PhD } \\
\text { Senior Scientist, } \\
\text { Pavlov Institute of Physiology, } \\
6 \text { Nab. Makarova, } 199034 \\
\text { St.Petersburg. Russia } \\
\text { Tel:7(812)783-1030 } \\
\text { gksouk@mail.ru }\end{array}$ & \\
\hline
\end{tabular}

\begin{tabular}{|c|c|}
\hline Undergradute student-researcher & 2006-2009 \\
\hline $\begin{array}{l}\text { Institute of Experimental Medicine, } \\
12 \text { Academic Pavlov str, } \\
\text { St.Petersburg, Russia, } 197376 \\
\text { Tel.: } 7(812) 2346868\end{array}$ & \multirow{2}{*}{$\begin{array}{l}\text { Research subject: } \\
\text { Interaction between nervous and } \\
\text { immune systems; studies dedicated to } \\
\text { preproorexin gene expression in the } \\
\text { hypothalamic cells of rats after LPS } \\
\text { challenge. }\end{array}$} \\
\hline $\begin{array}{l}\text { Supervisor: Novikova Natalia, Ph.D. } \\
\text { Senior Staff Scientist, } \\
\text { Institute of Experimental Medicine, }\end{array}$ & \\
\hline
\end{tabular}


12 Akademic Pavlov str,

St. Petersburg, Russia, 199034

Tel: 7(812)234-0764

novikiem@gmail.com

AWARDS AND HONORS

\begin{tabular}{|c|c|}
\hline Award & Years \\
\hline BSc diploma with honors & 2008 \\
\hline MSc diploma with honors & 2010 \\
\hline $\begin{array}{c}\text { Van Liere Memorial Convocation and HSC Research Day, } \\
\text { First Place Basic Science Year 5 Poster Presentation }\end{array}$ & 2017 \\
\hline
\end{tabular}

PROFESSIONAL SOCIETIES

\begin{tabular}{|c|c|c|}
\hline Role & Society & Years \\
\hline $\begin{array}{c}\text { Associate } \\
\text { Member }\end{array}$ & $\begin{array}{c}\text { American Association for Cancer } \\
\text { Research (AACR) }\end{array}$ & 2013-current \\
\hline
\end{tabular}

\section{TECHNICAL SKILLS}

\section{Bacterial cell culture:}

Preparation and propagation of cultured bacteria, transformation of bacteria cells. Preparation of chemically competent cells suitable for molecular cloning (DH5a) and protein production (BL21).

\section{Mammalian cell culture:}

Mammalian cells (including normal epithelial, fibroblast, astrocytes and cancer cell lines), generation of stable transgene expressing cell lines, cell lines with shRNA or CRISPR/Cas9-based depletion/knockout. Viral stock preparation and infection. Cell proliferation, adhesion and invasion assays in $2 \mathrm{D}$ and $3 \mathrm{D}$ matrix cultures.

\section{Molecular biology:}

PCR techniques, gel electrophoresis, genomic/plasmid DNA and RNA purification, site directed mutagenesis, DNA ligation/molecular cloning, expression and purification of proteins from bacterial and mammalian cells, in vitro kinase assay, protein labeling, immunoprecipitation, Western blotting, enzyme linked immunosorbent assay (ELISA), fluorescence-activated cell sorting (FACS). Design of custom lentivirus-based vectors.

\section{Imaging:}

Live cell imaging systems: confocal and bright field microscopy, confocal data analysis software and 3D deconvolution, imaging of primary cilia and vesicular transport. Focal 
adhesion and actin dynamics using fluorescently labels proteins. Fluorescence recovery after photobleaching (FRAP) and subsequent data analysis.

In vivo imaging techniques: ultrasound imaging using VeVo system, luciferase based xenograft imaging using IVIS system, contrast enhanced MRI using ICON system; and subsequent data analysis.

\section{Animal models:}

Solid knowledge of rodent physiology, animal handling, particularly laboratory rats and mice; maintenance of mouse colony, including managing transgenic mice strains; breast and glioblastoma xenograft tumor implantation, tumor bearing animal care and tumor burden evaluation. Rodent surgeries: estrogen pellets implantation/removal, tumors implantation/resection (subcutaneous and orthotopic), stereotactic guided intracranial injections. Behavioral evaluation in mice, including Morris water maze and open field test. Experienced in animal studies protocol development, management and review.

\section{Patient derived tumor models:}

Handling patient samples, cataloging and processing new samples; surgical implantation of the patient tumors, maintenance and support of patient-derived xenograft colony maintenance. Designing and running of the therapeutic compound screens in patientderived xenograft transplanted mice.

\section{Large data analysis:}

Experienced with TCGA data mining and analysis, as well as RNAseq data analysis and interpretation (as part of the bioinformatics workshop class by Dr. Peter Stoilov)

\section{Miscellaneous:}

Proficient in supplies ordering, lab maintenance, teaching of new students. Project development experience, grants and manuscripts writing and preparation for publication. Other Skills:

Proficient with Microsoft Office package, Vector NTI, ImageJ, Adobe Photoshop/GIMP and Illustrator/InkScape, GraphPad Prism, basic knowledge of R.

\section{RECOMMENDATIONS}

For further recommendations, please, contact:

Elena Pugacheva, PhD

Associate Professor, Biochemistry and WVU Cancer Institute,

Adjunct Assoc.Professor Radiation Oncology

Co-leader of Breast Cancer Research Program

PDX Core Facility Director HSC,

MBRCC 2813, 1 Medical Center Dr.,

Morgantown, 26506, WV, USA

Tel: 304-293-5295, epugacheva@hsc.wvu.edu 
Michael D. Schaller, PhD

Chairman, Department of Biochemistry, WVU

HSCN 3124, 1 Medical Center Dr.,

Morgantown, 26506, WV, USA

Tel: 304-293-9514, mschaller@hsc.wvu.edu

Michael Ruppert, MD/PhD

Professor, Department of Biochemistry, WVU,

Jo and Ben Statler Eminent Scholar \& Chair in Breast Cancer

Research

Co-Director, Program in Breast Cancer Research, MBRCC

BMRC-Erma Byrd 212, 1 Medical Center Dr.,

Morgantown, 26506, WV, USA

Tel: 304-293-5246, mruppert@hsc.wvu.edu

Peter Stoilov, $\mathrm{PhD}$

Associate Professor, Department of Biochemistry, WVU,

HSCN 3131 C, 1 Medical Center Dr.,

Morgantown, 26506, WV, USA

Tel: 304-293-6334, pstoilov@hsc.wvu.edu

Karen Martin, PhD

Research Assistant Professor, Department of Microbiology, Immunology \& Cell Biology, WVU,

Research Associate Professor, Department of Neurobiology and

Anatomy, WVU

Scientific and Technical Director, Microscope Imaging Facility,

WVU

Scientific and Technical Director, Animal Models \& Imaging

Facility, WVU 
BMRC-Erma Byrd 210, 1 Medical Center Dr.,

Morgantown, 26506, WV, USA

Tel: 304-293-6965, kamartin@hsc.wvu.edu

\section{PUBLICATIONS}

1. Loskutov YV, Griffin CL, Marinak KM, Bobko A, Margaryan NV, Geldenhuys WJ, et al. LPA signaling is regulated through the primary cilium: a novel target in glioblastoma. Oncogene.2017; in press.

2. Jones BC, Kelley LC, Loskutov YV, Marinak KM, Kozyreva VK, Smolkin MB, et al. Dual Targeting of Mesenchymal and Amoeboid Motility Hinders Metastatic Behavior. Molecular cancer research : MCR. 2017;15:670-82.

3. Kozyreva VK, Kiseleva AA, Ice RJ, Jones BC, Loskutov YV, Matalkah F, et al. Combination of Eribulin and Aurora A Inhibitor MLN8237 Prevents Metastatic Colonization and Induces Cytotoxic Autophagy in Breast Cancer. Molecular cancer therapeutics. 2016;15:1809-22.

4. Kozyulina PY, Loskutov YV, Kozyreva VK, Rajulapati A, Ice RJ, Jones BC, et al. Prometastatic NEDD9 Regulates Individual Cell Migration via Caveolin-1-Dependent Trafficking of Integrins. Molecular cancer research : MCR. 2015;13:423-38.

5. Lin CC, Sharma SB, Farrugia MK, McLaughlin SL, Ice RJ, Loskutov YV, et al. Kruppel-like factor 4 signals through microRNA-206 to promote tumor initiation and cell survival. Oncogenesis. 2015;4:e155.

6. Loskutov YV, Kozyulina PY, Kozyreva VK, Ice RJ, Jones BC, Roston TJ, et al. NEDD9/Arf6-dependent endocytic trafficking of matrix metalloproteinase 14: a novel mechanism for blocking mesenchymal cell invasion and metastasis of breast cancer. Oncogene. 2015;34:3662-75.

7. McLaughlin SL, Ice RJ, Rajulapati A, Kozyulina PY, Livengood RH, Kozyreva VK, et al. NEDD9 depletion leads to MMP14 inactivation by TIMP2 and prevents invasion and metastasis. Molecular cancer research : MCR. 2014;12:69-81.

8. Plotnikova OV, Nikonova AS, Loskutov YV, Kozyulina PY, Pugacheva EN, Golemis EA. Calmodulin activation of Aurora-A kinase (AURKA) is required during ciliary disassembly and in mitosis. Molecular biology of the cell. 2012;23:2658-70.

9. Perekrest SV, Abramova TV, Novikova NS, Loskutov YV, Rogers VJ, Korneva EA. Changes in immunoreactivity of orexin-A-positive neurons after intravenous lipopolysaccharide injection. Medical science monitor : international medical journal of experimental and clinical research. 2008;14:BR127-33. 